\title{
SHEAR DESIGN OF REINFORCED CONCRETE BEAMS WITH FRP LONGITUDINAL AND TRANSVERSE REINFORCEMENT
}

\author{
Eva Oller*, Antonio Marí*, Jesús Miguel Bairán*, Antoni Cladera**
}

*Universitat Politècnica de Catalunya, Barcelona, Spain

**Universitat de les Illes Balears, Palma de Mallorca, Spain

Corresponding author:

Eva Oller, e-mail: eva.oller@upc.edu, Phone (+34) 934016512

\begin{abstract}
A mechanical model for the prediction of the shear strength of reinforced concrete (RC) beams with longitudinal and transverse FRP reinforcement is presented. The model assumes that in FRP RC beams, the shear force is taken by the un-cracked concrete chord, by the residual tensile stresses along the crack length and by the FRP stirrups. Failure is considered to occur when the principal tensile stress at the concrete chord reaches the concrete tensile strength, assuming that the contribution of the FRP stirrups is limited by a possible brittle failure in the bent zone. The accuracy of the proposed method has been verified by comparing the model predictions with the results of 112 tests. The application of the model provides better statistical results (mean value $V_{\text {test }} / V_{\text {pred }}$ equal to 1.08 and COV of 19.5\%) than those obtained using the design equations of other current models or guidelines. Due to the simplicity, accuracy and mechanical derivation of the model it results suitable for design and verification in engineering practice.
\end{abstract}

Keywords: B. strength, B. stress transfer, C. analytical modelling, FRP stirrups.

\section{INTRODUCTION}

Fibre reinforced polymer (FRP) bars can be considered an advantageous alternative to steel bars for internal reinforcement of concrete structures, especially in environments exposed to corrosion. In these type of environments, the employment of FRP stirrups has even more sense than the use of longitudinal reinforcement because they are normally located as an outer reinforcement with respect to the flexural rebars [1]. In relation to the mechanical properties of the FRP reinforcement, the main 
differences in comparison with steel, are a lower modulus of elasticity and a linear elastic behaviour up to rupture, which implies a lack of plasticity.

It is commonly accepted that the shear strength in a $\mathrm{RC}$ beam is composed by the contribution of several mechanisms, as reported by [2], which can be summarized in: a) the shear resisted by the concrete compressed chord; b) the friction forces developed along the crack length, which are contrary to the relative displacement of both crack faces (aggregate interlock); c) the residual tensile strength existing between inclined cracks; d) the shear strength provided by the longitudinal reinforcement (dowel action); e) the shear strength provided by the transverse reinforcement (if it exists).

As described by Fico et al. [3], in the case of FRP reinforced concrete beams, the mechanical properties of the FRP longitudinal and/or transverse reinforcement affect the shear resisting mechanisms described for conventionally steel reinforced beams. According to [3], the contribution of the uncracked concrete chord for FRP RC beams differs from conventional RC beams. The main difference is related to the neutral axis depth, which is lower than in the steel case before it yields. However, since the FRP reinforcement does not yield, the compression area does not decrease further with increasing the load up to failure.

Due to the FRP lower shear stiffness, crack widths are bigger, reducing the aggregate interlock, the residual tensile strength between inclined cracks and the dowel action mechanisms. In the experimental program of Tottori and Wakui [4], it was observed that the dowel capacity of elements reinforced with FRP is lower (about 70\%) than when using reinforcing steel. According to [3], the shear strength provided by the dowel action of the FRP longitudinal reinforcement can be neglected for usual bar diameters, since it is smaller than other shear strength contributions even for steel reinforcement.

The FRP transverse reinforcement contribution depends on the level of stresses attained by the reinforcement. Since the FRP is linear elastic up to failure, the stirrups do not yield, and their level of stresses should be evaluated. In addition, it should be considered that the FRP stirrups tend to fail prematurely, in particular if they are intercepted by the shear crack in the proximity of the bent portion [5] due to stress concentration at this area. The tensile strength of the bent part of the bar is less than that of the straight part as observed in [1], [6]. After failure of the most stressed stirrup, its force is transferred to the rest of the stirrups crossing the critical crack leading to a progressive failure of them. According to this, and as will be shown later on, the FRP design guidelines limit the strain allowed in the FRP stirrups to lower values at ultimate state. 
Therefore, in beams with longitudinal and transverse FRP reinforcement, it can be considered that the shear forces are resisted by the same mechanisms as for conventionally RC beams with steel stirrups. However, due to the lower modulus of elasticity of the FRP compared to steel, wider and deeper cracks develop, and all the shear resisting components are lower in comparison to conventionally steel RC beams. Consequently, the overall shear capacity of concrete members reinforced with FRP bars is lower than that of elements reinforced with steel bars [7].

Shear design equations of FRP reinforced concrete beams with stirrups have been developed and some of them have been included in design guidelines (ACI-440.1R-06 [8], CNR-DT200/2003 [9], CSA S6-09 addendum [10], CSA-S806-12 [11], JSCE [12], ISIS-M03-01 [13]). According to all of them the shear strength of FRP RC structures with FRP stirrups is the sum of the concrete and the transverse FRP reinforcement contribution.

Appendix 1 summarizes some of the most relevant or recent existing shear design equations for FRP reinforced elements with FRP stirrups including some of the formulations and guidelines analysed by [3], [14], [15].

A considerable number of studies have been focused on the concrete shear strength contribution, but the research quantifying the stirrups contribution is relatively limited [15].

Fico et al. [3] performed a review of the current design provisions and presented an assessment of the Eurocode-like design equations for predicting the shear strength of FRP RC members with and without stirrups, considering the CNR-DT200/2003 [9], CSA S806-02 [16], JSCE [12], ACI-440.1R-06 [8]. By comparing the experimental and the theoretical ultimate shear forces of a database of 85 tests with FRP stirrups, Fico et al. [3] concluded that the least average value for $V_{\text {exp }} / V_{\text {pred }}$ was given by the CNRDT200/2003 [9] with the least coefficient of variation (32\%) and the most conservative model was the JSCE [12]. In consistency with the experimental results of Nagasaka et al. [17] where the average stress of FRP stirrups was only half of the breaking strength of bent portions, Fico et al. [3] suggested a limit strain value for the stirrups contribution depending on the fibre type: 0.0035 for CFRP, 0.0070 for AFRP, and 0.0085 for GFRP bars. By applying this limit strain value when calculating the stirrups contribution to the shear strength, and calculating the remaining contributions according to [9] for his database of 85 tests, the average value of $V_{\text {exp }} / V_{\text {pred }}$ without safety factors was 1.03 , and the coefficient of variation was $30 \%$. In addition, a limit of the transverse stirrups ratio of $1 \%$ was recommended for more reliable predictions. 
Machial et al. [14] compared, through a database of 46 tests with stirrups, the performance of the same guidelines as [3] and some other models, such as the CSA S6-09 addendum [10], the ISIS-M03-01 [13], the Modified Compression Field Theory [18], the Cracked Section Analysis model [4] and the modified Zsutty equations [19]. From the statistical analysis, the ISIS-M03-01 [13] produced the best results with a mean value $V_{\text {exp }} / V_{\text {pred }}$ (MV) of 1.09 and a COV of $20.5 \%$, followed by the Nehdi et al model [19] $(\mathrm{MV}=1.34, \mathrm{COV}=25.3 \%)$ and CSA-S6-09 (MV=1.48, COV=25.9\%). However, Machial et al. [14] concluded that the Addendum CSA S6-09 [10] gave the best balance of accuracy, scatter and efficiency because the ISIS-M03-01 [13] model produced unreliable results in calculating the concrete shear strength contribution.

Hegger et al. [20] developed a shear design equation where the concrete shear strength contribution has a Eurocode-like format, affected by some parameters related to the presence of FRP longitudinal reinforcement. The FRP shear reinforcement contribution depends on a limit stirrup strain based on the results of existing experimental work. Hegger et al. [20] verified their formulation through a database of 88 tests with FRP stirrups, with a mean value $V_{\text {tes }} / V_{\text {pred }}$ of 1.02 and a COV of $18 \%$.

Recently, Razaqpur and Spadea [15] presented the background of the CSA Standard S806-12 [11] for FRP and compared their predictions with those of some other methods (JSCE [12], CSA S6-06 ; ACI 440.1R-06 [21], CNR-DT203/2006 [9], Hoult et al. [22]) through a database of 119 tests. According to the variable angle truss model presented in [15], the two main parameters that affected the shear strength of FRP RC beams with transverse reinforcement were the angle of inclination of the diagonal concrete struts, $\theta$, and their compressive strength, $f_{\text {cd. }}$. Their conclusion from the comparative analysis was that the CSA S806-12 gave more accurate results than the remaining methods, with a mean value $V_{\text {exp }} / V_{\text {pred }}$ of 1.15 and a coefficient of variation of $20 \%$.

Marí et al. [23] recently developed a conceptual model, fully based on structural mechanics principles, for the prediction of the shear-flexural strength of RC beams with and without transverse steel reinforcement. The model assumes that, after the development of the first branch of the critical shear crack, failure is considered to occur when the stresses at any point of the concrete compression chord reach the assumed biaxial stress failure envelope. Simple and direct equations for shear strength verification and for design of the transverse reinforcement were provided. In [23], the method was validated by comparing its predictions with the results of 1131 shear tests, obtaining very good results in terms of mean value and coefficient of variation. A simpler version of this method for FRP RC beams 
without stirrups had been previously presented and experimentally verified in [24]. The model predictions were compared with the results of 144 tests on FRP reinforced concrete beams, providing better results than those obtained using the design equations of current codes of practice. The mean value of the experimental to theoretical ultimate shear force ratio $V_{\text {exp }} / V_{\text {pred }}$ was 1.09 and the COV was $14.8 \%$.

In the present paper, this model has been extended to evaluate the shear strength of FRP RC structures with FRP stirrups, considering the stirrups and the concrete contribution according to the observed behaviour in the existing experimental tests. To study the performance of the proposed shear formulation for FRP RC beams with FRP stirrups in comparison to the existing models, the authors have assembled an experimental database of 112 tests on rectangular FRP RC beams with FRP stirrups, which is summarized in Appendix 2.

\section{EXPERIMENTAL DATABASE}

\subsection{Description of the database}

A database of 122 tests of FRP reinforced concrete structures with FRP stirrups tested under one or two point load that failed in shear has been compiled based on the database of Fico et al. [3], Shehata et al. [1] and Razaqpur and Spadea [15] and some additional existing experimental programs. From this database, only 112 specimens had a rectangular section and the remaining 10 specimens had a T-section. The T-section specimens were not considered in the statistical analysis since the sample was not representative. The range of the variables of the 112 tests with rectangular section is presented in Table 1. Appendix 2 summarizes the details of the specimens analyzed.

Table 1. Range of variables in the compiled database of 112 tests of FRP RC beams with FRP stirrups.

\begin{tabular}{lcc}
\hline & Min & Max \\
\hline$b(\mathrm{~mm})$ & 150 & 457 \\
\hline$d(\mathrm{~mm})$ & 170 & 937 \\
\hline$a / d$ & 1.2 & 4.3 \\
\hline$f_{c}(\mathrm{MPa})$ & 20.0 & 84.2 \\
\hline$\rho(\%)$ & 0.51 & 3.65 \\
\hline$E_{r}(\mathrm{GPa})$ & 29 & 140 \\
\hline$\rho E_{r}(\mathrm{MPa})$ & 34 & 3171 \\
\hline$\rho_{t}(\%)$ & 0.04 & 1.50 \\
\hline$E_{t}(\mathrm{GPa})$ & 30 & 144 \\
\hline$\rho_{t} E_{t}(\mathrm{MPa})$ & 38 & 1695 \\
\hline$V_{u}(\mathrm{kN})$ & 49 & 590 \\
\hline
\end{tabular}




\subsection{Failure modes of the existing experimental programs}

In conventionally steel RC beams, there are different failure modes depending on the longitudinal and transverse reinforcement ratios and on the shear span to depth ratio. Changes in these failure modes are observed in the case of FRP RC beams with FRP stirrups due to the linear elastic behaviour of the FRP reinforcement. In conventionally RC beams, if the longitudinal reinforcement ratio is low, failure may be often due to a flexural-shear mechanism. Then, as described in [23], first of all flexural cracks initiate, and subsequently develop inclined through the web. As the load increases, damage concentrates around the so-called shear critical crack. After increasing the applied load, a second branch of the crack develops inside the concrete chord, eventually connecting the first crack and the point where the load is applied, producing failure. For this type of failure, the increment of tensile force in the longitudinal reinforcement due to the inclined crack, which depends on the shear force, will produce yielding of the longitudinal reinforcement. This is not the case for FRP longitudinal reinforcement, which is linear elastic up to failure, and which has an ultimate tensile strength higher than the steel yielding stress. In addition, designers are often required to use FRP longitudinal reinforcement ratios higher than the balanced reinforcement ratios to meet the serviceability criteria.

If the longitudinal reinforcement ratio is high, the transversal steel stirrups of conventionally RC beams might yield, and concrete chord crushing can be observed (brittle flexural failure). This type of failure can also develop in FRP RC beams with FRP stirrups. However, in this case, concrete crushing will occur if the FRP stirrups do not have previously failed locally in the bent zone.

Finally, in thin-walled beams, the web of the beam will crush if the inclined compressive stresses exceed the concrete strength.

The failure modes of some of the existing experimental programs have been analysed to evaluate the shear behaviour of FRP RC beams with FRP stirrups. As experimentally observed, the main difference of the shear behaviour of beams with FRP stirrups compared to conventional beams with steel stirrups is that stirrups do not yield, and they usually fail in their bottom bent zone. According to [25], [26], [27], and [6], this type of failure can be explained by the fact that bending of the FRP bars into the stirrups configuration, significantly reduces its strength at the bent portions, due to their unidirectional characteristics. A summary of the failure modes of some of the existing experimental programs is presented in the following. 
Nagasaka et al. [17], in 1993, tested 35 half scale rectangular beams with different type (CFRP, GFRP, AFRP, Hybrid, steel) and ratio (0, 0.5, 1.0 and 1.5\%) of transverse reinforcement, different concrete strengths and clear span. Half of the specimens with FRP stirrups (12 out of 24 tests) failed due to breaking of the stirrups at the bent zone and the rest of the specimens failed due to the crushing of concrete struts formed between two adjacent diagonal cracks or by crushing from flexural-compression.

In the experimental program of Zhao et al. [28], including 19 specimens with different types and ratios of longitudinal and transverse reinforcement, a shear compression failure was observed in almost all tests, without the rupture of any stirrup, except for beam \#2. In this case, the manufacture process of the stirrups, monolithically in the form of a closed loop, might have influenced the type of failure.

Ahmed et al. [10] tested three T-beams with CFRP stirrups $9.5 \mathrm{~mm}$ diameter with different spacing. The tensile strength of the stirrups was around $f_{\mathrm{tu}}=1538 \mathrm{~N} / \mathrm{mm}^{2}$ and their bend strength was 712 $\mathrm{N} / \mathrm{mm}^{2}\left(46 \% \cdot f_{t u}\right)$. Two of the three beams failed by diagonal tension failure due to the rupture of the stirrups initiated at the bent part, and the remaining one failed by flexure.

Bentz et al. [29] developed an experimental program of 11 shear tests of FRP RC beams, 5 of them with and 6 without GFRP stirrups. The beams showed different longitudinal GFRP reinforcement ratios and different transverse GFRP reinforcement ratios $\left(\rho_{t}=A_{t} / s / b_{w}\right)$. In relation to the failure mode of the tests with stirrups, Bentz et al. [29] reported that beam L05-1 failed in shear by stirrup rupture at the bottom bent zone with a maximum measured strain at mid-height of the beam of $55 \%$ the bare-bar rupture strain. Beam L05-2 failed at flexure, even though shear failure was imminent. Beam L20-1 failed by sliding along a large diagonal crack, showing the rupture of the stirrups at failure. Beam L20-2 failed in flexure by concrete crushing with the rupture of some stirrups. Bentz et al. [29] concluded that, with multiple layers of longitudinal bars, the stirrups rupture did not occur at the bent location (as in beam L05-1) but near the end of the lap-splice (L20-2).

Shehata et al. [1], [27] tested 10 T-beams in shear: 4 with CFRP stirrups, 4 with GFRP stirrups, 1 with steel stirrups and 1 without shear reinforcement. Test variables were the material and spacing of stirrups, and the type of flexural reinforcement (8 with steel strands, 2 with CFRP strands). All beams failed in shear before yielding or rupture of the longitudinal reinforcement. In the 8 beams with FRP stirrups, shear failure was initiated by rupture of the FRP stirrups at the bent zone ( 6 beams) or by crushing of the concrete in the shear span ( 2 beams). According to the experimental results, the effective stress in the stirrups at failure was as low as $50 \%$ of the strength parallel to the fibres provided that shear 
failure occurs due to the rupture of the stirrups. For closely spaced stirrups, a lower contribution of the stirrups was obtained. It might be because the chance for the diagonal crack to intersect the bent zone of the stirrups is higher [1], [27].

Niewels [20], [30] carried out an experimental program with 4 concrete beams with FRP flexural and shear reinforcement tested in shear in two phases. The variables of the tests were the type longitudinal bar and stirrups, and the amount of transverse reinforcement. The beams with stirrups failed in the shear compression zone due to overstress in shear and compression. Stirrups strains above 10\%o were measured. However, the stirrups did not fail due to concentration of stresses at the bent zone.

Spadea [31] performed an experimental program of 40 beams ( 8 series of 5 identical specimens) with GFRP or CFRP longitudinal and transverse reinforcement tested in a 4 point-bending configuration. Shear failure was observed in almost all tests. In series I and III, the diagonal shear crack opened near the load application point with an inclination angle over $70^{\circ}$. In the remaining beams, the shear crack opens at mid shear span with $\theta$ angles ranging between $41^{\circ}$ and $65^{\circ}$. A shear failure with the critical crack closer to the load application point or at mid shear span was observed in Series I, III, V and VII. Series II, IV, VI and VIII failed due to concrete crushing at the compression chord produced by the combined shearflexural effect. According to [31], the stirrups were not broken at failure.

As a conclusion, from the existing experimental tests with FRP stirrups compiled in the database where failure was clearly reported (42 tests), $43 \%$ of tests failed due to rupture of the FRP stirrups in the bent zone and the remaining $57 \%$ tests failed due to concrete crushing of the struts between inclined shear cracks or due to crushing at the concrete chord. However, it is not clear enough if in the latter group, the stirrups crossing the critical diagonal crack had already failed or not.

Finally, it is important to highlight that the observed experimental failures should be considered in the formulation of any theoretical model to evaluate the shear strength of FRP RC beams with FRP stirrups.

\section{PROPOSED SHEAR-FLEXURAL MECHANICAL MODEL FOR FRP RC BEAMS WITH FRP STIRRUPS}

\subsection{Behaviour of FRP RC beams with FRP stirrups}

The shear transfer action of a beam without stirrups can be represented, in a simplified manner, by a truss model (see Fig. 1), with a compression concrete chord; a tensile chord, which is the longitudinal 
reinforcement; inclined concrete struts between cracks and inclined concrete ties which may cross the cracks up to a certain load level (Fig. 1a). These ties represent the resultant of the residual tensile stresses and the frictional stresses along the crack. The inclination of the ties depends on the crack opening. As the load increases, the crack width also increases, and the angle of concrete tie with respect to the horizontal (Fig. 1b) tends to increase. Then, the contribution of the shear resisted along the crack $\left(V_{w}\right)$ is reduced and compensated by an increment of inclination of the compression chord (strut BD in Fig. 1), which increases the shear taken by the compression chord, $V_{c}$. In summary, according to the above described evolution of the shear transfer mechanisms, it is expected that, for large crack widths, the web contribution to the shear strength is relatively small when compared to that of the compression concrete chord. When the cracks are very wide, the capacity of the concrete tie results very weakened and its force is reduced. Thus, due to equilibrium conditions in the bottom node, the diagonal strut must unload and the increment of force $\Delta T$ at the tensile reinforcement also decreases. At a certain load level, the equilibrium of this region is no longer possible as a truss, and failure occurs.

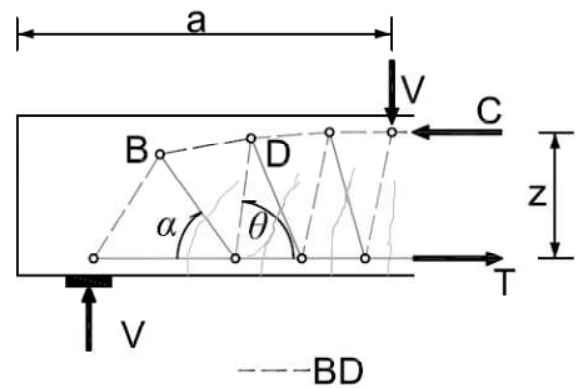

a) Slightly cracked

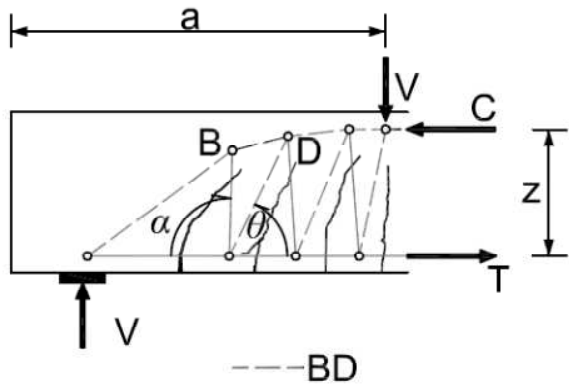

b) Heavily cracked

Fig. 1. Strut and tie models for moderate and large crack widths.

In order to obtain the failure load, the shear stress distribution must be determined at any load level. For this purpose, consider a slice of a diagonally cracked beam without stirrups, as shown in Fig. $2 \mathrm{a}$, where the neutral axis depth is assumed to be placed at the crack tip. Fig. $2 \mathrm{~b}$ shows the distribution of normal and shear stresses in sections 1 and 2. Since the normal stresses in the compression chord due to flexure are higher in section 2 (where the moment is higher), there is a point inside the un-cracked chord where the difference $\Delta \sigma(z)=0$ and, consequently, the shear stresses have a maximum upwards the neutral axis. This fact is more noticeable as the crack width increases, especially for FRP RC beams. 


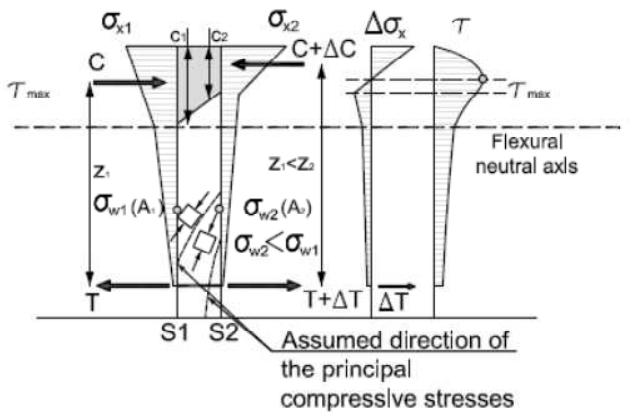

b) With inclined cracks.

Beam actlon and arch actlon

Fig. 2. Stresses distributions in diagonally cracked reinforced concrete members.

The presence of FRP stirrups modifies the resisting mechanism at failure. The stirrups provide the necessary tensile forces to satisfy the equilibrium of the truss, without the need of the concrete ties. However, in addition to the direct contribution of the stirrups to the shear strength, the stirrups provide a) a constraint to the diagonal crack opening, increasing the friction and the residual stresses; b) vertical confinement stresses on the compressed concrete chord, increasing its strength; and c) a support to the longitudinal bars, constraining their vertical displacement and enhancing their capacity for shear transfer. However, the friction and residual stresses as well as the dowel action effect are less important for FRP than for conventionally steel RC beams.

The contribution of each shear transfer mechanism to the shear strength depends on the load level and especially on the crack opening. The higher the crack width, the lesser is the shear transferred along the cracks, and the higher is the shear taken by the un-cracked concrete chord, which has its shear transfer capacity enhanced thanks to the presence of normal stresses.

\subsection{Basic assumptions of the method}

(1) At the ultimate load level, shear and bending are resisted by the joint contributions of the uncracked concrete zone $\left(V_{c}\right)$, the transverse reinforcement crossing the diagonal critical shear crack $\left(V_{t}\right)$, the tensile stresses transferred along the crack, $\left(V_{w}\right)$, depending on its width, and the shear transferred by the longitudinal reinforcement $\left(V_{l}\right)$, see Fig. 3 . 

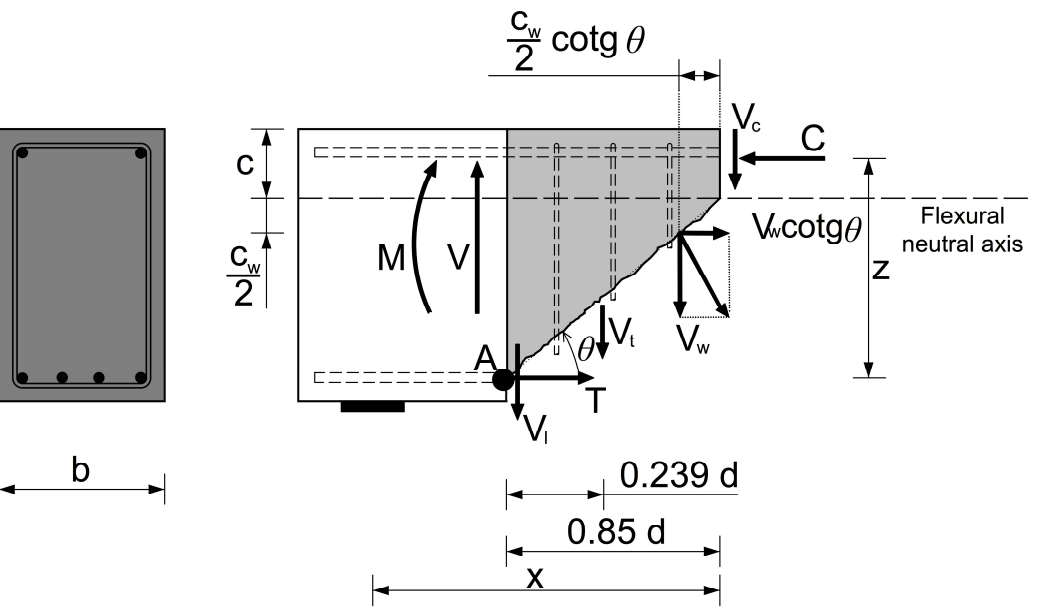

Fig. 3. Shear transfer mechanisms considered.

(2) The following distributions of stresses along the concrete chord depth have been assumed: a) linear distribution of $\sigma_{x}$, which is consistent with the moderate level of normal stresses that exist in the critical section, as will be shown later; b) a parabolic distribution of the shear stresses, with $\tau=0$ at the top fiber and at the neutral axis and with its maximum at $y=c / 2$ (see Fig. 4), being $c$, the neutral axis depth. Such assumption barely affects in practice the shear stress resultant $\left(V_{c}\right)$.

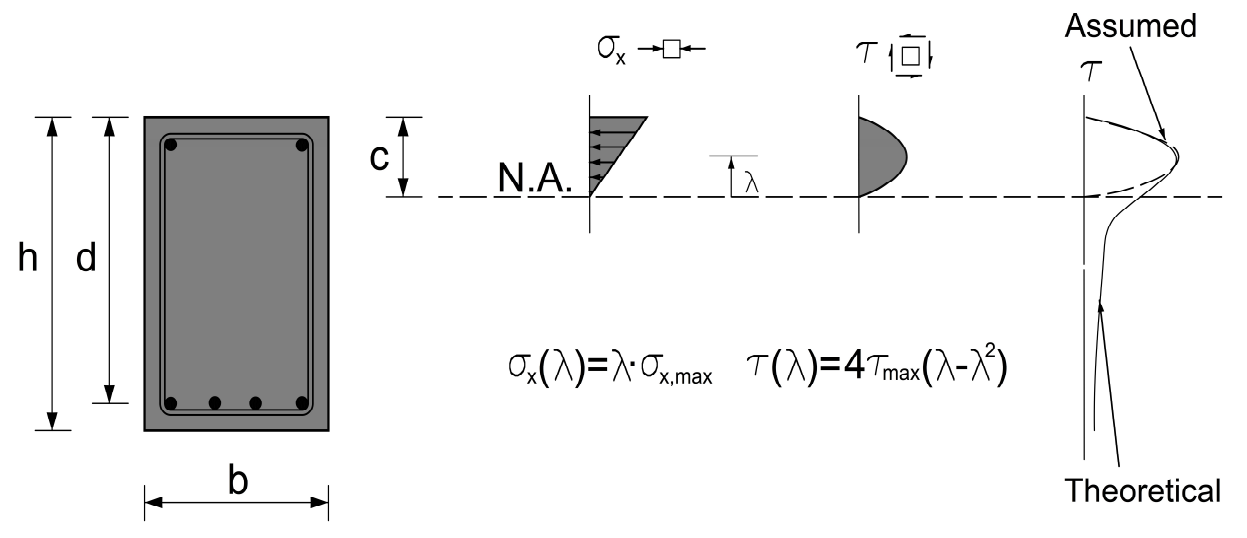

Fig. 4. Considered distributions of stresses at the un-cracked concrete chord.

(3) The depth of the un-cracked concrete zone is equal to the neutral axis depth in pure bending.

(4) Failure occurs when the tensile principal stresses $\left(\sigma_{1}\right)$ reach the concrete tensile strength. 
(5) The projection of the critical shear crack is considered to be equal to $0.85 \cdot d$ (see Fig. 3). This value is in accordance with experimental observations made by the authors for RC beams [24] [32]-[34].

(6) For beams with constant geometry and reinforcement amount along their length, the weakest section in front of a combined shear-bending failure is not placed at a fixed distance from the support. On the contrary, it is considered to be placed at the tip of the first branch of the critical diagonal crack [23] (see Fig. 5).

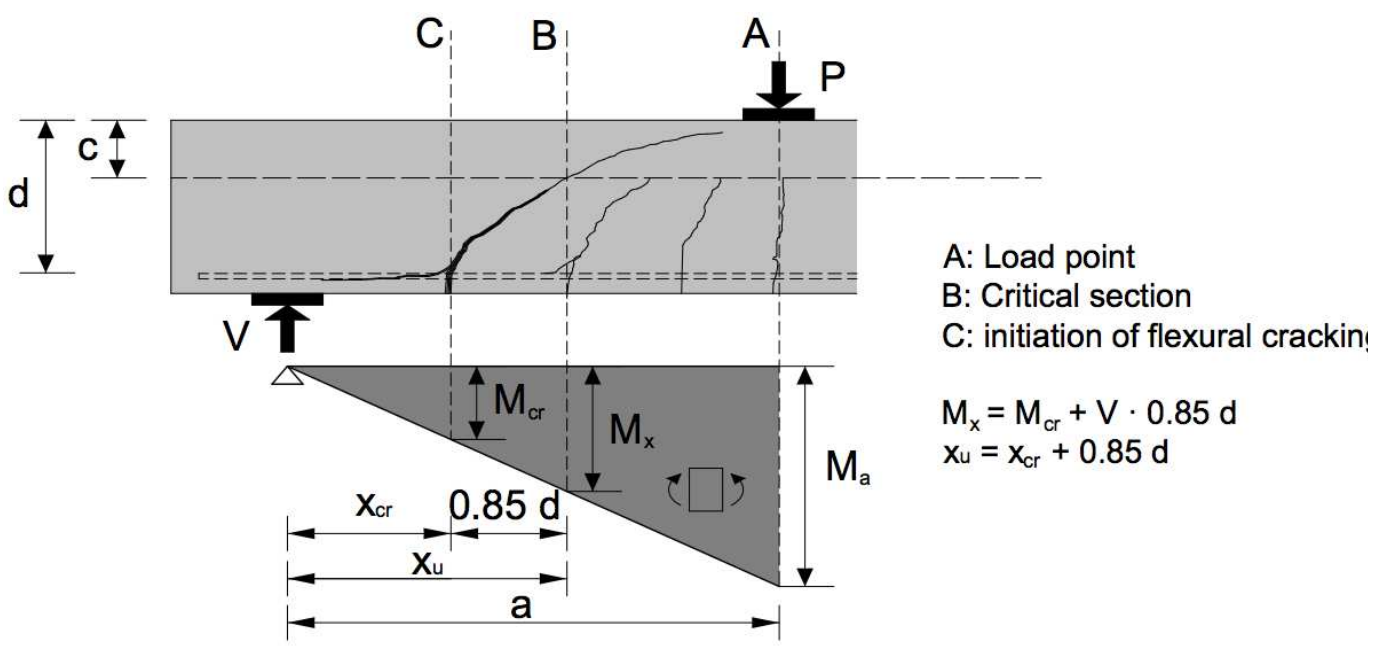

Fig. 5. Position of the critical section in the beam.

(7) The critical point inside the compression chord, where failure will initiate, will be that with the principal stress at failure equal to the tensile concrete strength, and will depend on the distributions of normal and shear stresses along the concrete un-cracked chord. Studies carried out by the authors [24] showed that for the linear and parabolic distributions assumed for the normal and shear stresses, respectively, the critical point is placed at a distance from the neutral axis $c$ around $y=0.425 \cdot c$, for ratios $x / d=M /(V \cdot d)<3.0$, which are values where usually the critical crack develops. In addition, the assumption made for the distribution of shear stresses in the concrete chord does not affect the value of the shear stress at the critical point.

(8) The FRP stirrups have a linear elastic response up to failure. According to that, and assuming that the strain at each stirrup is proportional to the crack opening, the distribution of stirrups forces along the inclined crack is linear, being maximum near the crack mouth, where the crack crosses the longitudinal reinforcement (see Fig. 6). 
(9) It is assumed that the longitudinal reinforcing bars are effectively anchored, so that all reinforcement is effective at the shear critical section.

\subsection{Shear strength of beams longitudinally reinforced with FRP bars and with transverse FRP stirrups}

\subsubsection{Contribution of the FRP stirrups}

The contribution of the FRP stirrups can be calculated as the sum of the tensile stresses at the stirrups crossing the critical shear crack, whose horizontal projection is equal to $0.85 \cdot d$, as shown in Eq. (1) in a dimensionless form:

$v_{t}=\frac{V_{t}}{f_{c t} \cdot b \cdot d}=\frac{\rho_{t} \cdot 0.85 \cdot \sigma_{t}}{f_{c t}}=\frac{\rho_{t} \cdot 0.85 \cdot E_{t} \cdot \varepsilon_{t}}{f_{c t}}$

where $\rho_{t}$ is the transverse reinforcement ratio; $f_{c t}$ is the concrete the tensile strength; $E_{t}$ is the modulus of elasticity of the transverse reinforcement; and $\varepsilon_{t}$ is the mean strain in the FRP stirrups, considering that the FRP stirrup at the crack tip fails due to rupture at the bent zone. As stated in [1], [6] and [10], the tensile strength of the bent part of the FRP stirrups is significantly lower than that of the straight part. According to the JSCE [12] the maximum stress at the stirrup reduced by the bent at its corner can be expressed as:

$$
\sigma_{t}=\left(0.05 \cdot \frac{r_{b}}{d_{b}}+0.3\right) \cdot f_{t u} \leq f_{t u}
$$

According to [7], the ACI 440 Committee modified this equation to make it more conservative as follows:

$$
\sigma_{t}=\left(0.05 \cdot \frac{r_{b}}{d_{b}}+0.11\right) \cdot f_{t u} \quad 0.25 \cdot f_{t u} \leq \sigma_{t} \leq f_{t u}
$$

According to the JSCE [12] formulation, the mean value of the tensile stress at the stirrups for failure at the bent zone is $45 \%$ of the ultimate stress of the stirrup. This value is similar to that recommended by other authors, such as Guadagnini et al. [35]. The mean value of the ACI-440 Committee is more conservative, $26 \%$ of the ultimate stress of the stirrup. According to the experimental background summarized in section 2, the value given by the JSCE is more similar to the maximum strain measured at the stirrups just before failure. Therefore, Eq. (2) will be used in the following development. 
According to assumption 7, the stirrup closest to the crack mouth carries higher stresses than the stirrup at the crack tip, whose stresses are almost zero. Thus, it is assumed that the most loaded stirrup fails locally in the bent zone and the stresses in the remaining stirrups crossing the critical shear crack follow a linear distribution.

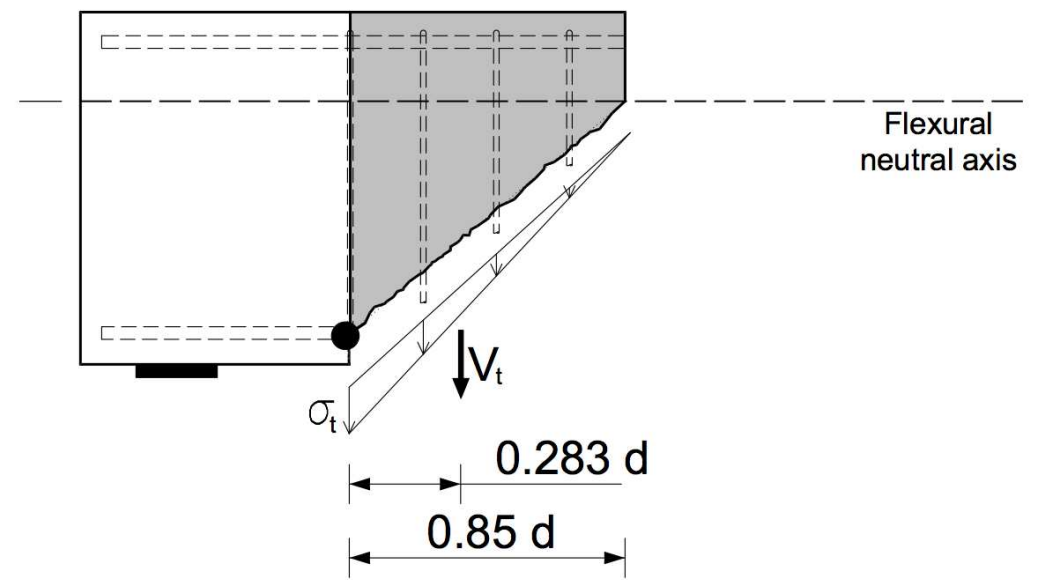

Fig. 6. Linear distribution of stresses in the FRP stirrups crossing the critical shear crack.

The mean value of the strain of all the stirrups crossing the shear crack can be obtained as a function of the number of stirrups or in a simplified manner, a mean value of 0.50 times the strain in the most loaded stirrup can be considered. Therefore, the mean strain at the stirrups crossing the crack can be obtained as half of the stirrup strain at failure of the FRP bent zone.

$\varepsilon_{t}=0.50 \cdot \varepsilon_{t, \lim }=0.50 \cdot 0.45 \cdot \varepsilon_{t u}=0.225 \cdot \varepsilon_{t u}$

where $\varepsilon_{t u}$ is the ultimate strain of the transverse FRP stirrups.

In [15], the stress in the shear reinforcement, $\sigma_{t}$, is not only the value associated to the maximum stress at failure in the bent zone, but also the permissible value to limit the diagonal crack width under service load. In addition, at ultimate limit state, $\sigma_{t}$ should not diminish the aggregate interlock component. In the existing guidelines, the value of the stirrups strain that limits the diagonal crack width ranges between 0.0025 and 0.005 [15].

In the present paper, the diagonal crack width has not been limited, so the stress in the shear reinforcement is assumed as the value associated to stirrup failure at the bent zone. This assumption can be explained by the fact that the aggregate interlock effect is formulated as a function of the crack opening in section 3.3.2.

3.3.2 Shear transferred along the crack 
The shear transferred along the critical shear crack is considered due to the residual tensile stresses and the frictional stresses, both related to the three dimensional irregularities of the crack surface. The residual stresses are the tensile stresses that can be transferred across a concrete crack in tension, up to a maximum crack width. Frictional stresses are those, which oppose to the slip between both surfaces of the crack, and decrease as the crack width increases. Both types of stresses are interrelated as crack opening and crack slip are too, but it is difficult to obtain them separately. For this reason, in this work only the residual stresses are considered and it will be assumed that the resulting principal stresses are normal to the average crack surface.

To evaluate the residual tensile stresses, a tensile stress-strain relationship with a post-peak linear softening branch will be considered, in which the ultimate tensile strain $\varepsilon_{c, t u}$ depends on the fracture energy.

Even though the tensile stresses along the crack will have an approximately triangular distribution, an energetically equivalent constant distribution of tensile stresses of value $f_{c t} / 2$ will be adopted in this work for simplicity (see Fig. 7). The length along the crack where the tensile stresses are extended will be called $l_{w}$, and its vertical projection (depth of the tensile zone) will be called $c_{w}$. Then, the expression of the shear force resisted along the crack, $V_{w}$, is:

$$
V_{w}=\int_{0}^{l_{w}} \sigma_{w} \cdot b \cdot d l \approx \frac{c_{w}}{\sin \theta} \cdot \sigma_{w} \cdot b \cdot \cos \theta=c_{w} \cdot \sigma_{w} \cdot b \cdot \cot \theta
$$

The value of $c_{w}$ can be obtained by setting the compatibility of deformations in a direction normal to the crack as explained in Marí et al. [23]:

$$
c_{w}=(d-c) \cdot \frac{\varepsilon_{c t, u}}{\varepsilon_{s}} \cdot \sin ^{2} \theta
$$

Substituting Eq. (6) in Eq. (5), $V_{w}$ can be expressed as:

$$
V_{w}=0.425 \cdot f_{c t} \cdot b \cdot d \cdot \frac{\varepsilon_{c t, u}}{\varepsilon_{s}} \cdot \sin ^{2} \theta
$$



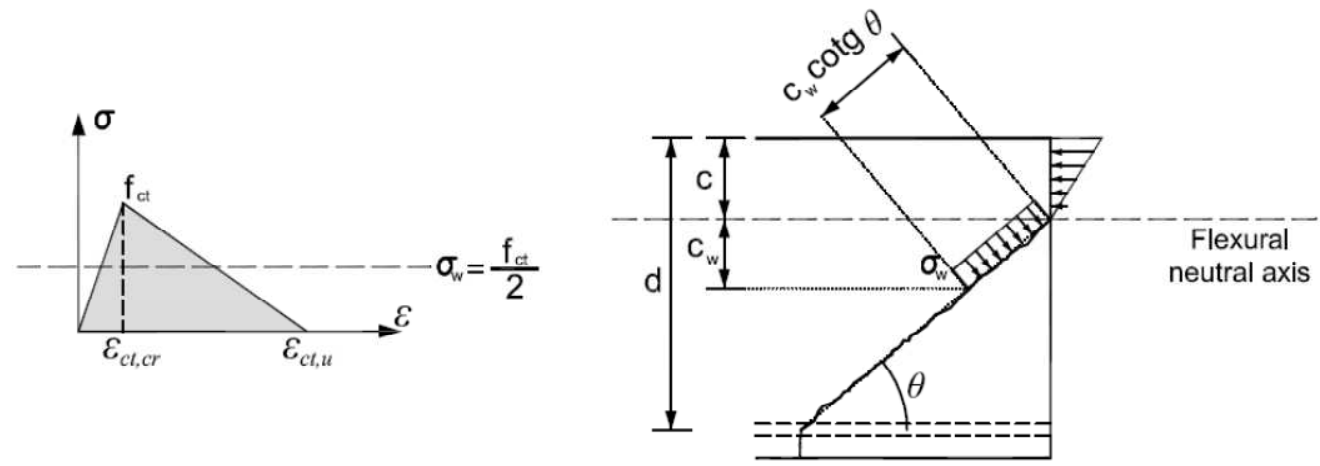

Fig. 7. Tensile stress-strain curve for concrete and tensile residual stresses at the crack.

As explained in [23], the ultimate concrete tensile strain, $\varepsilon_{c t, u}$, can be related to the fracture energy $G_{f}$, which can be expressed as a function of the concrete strains at the beginning of the macrocracking $\left(\mathcal{E}_{c t, c r}=f_{c l} / E_{c}\right)$, the ultimate tensile strain $\left(\varepsilon_{c t, u}\right)$, and $s_{m \theta}$, the average spacing of the inclined cracks.

$$
\mathcal{E}_{c t, u}=\varepsilon_{c t, c r}+\frac{2 \cdot G_{f}}{f_{c t} \cdot s_{m \theta}}=\frac{f_{c t}}{E_{c}}+\frac{2 \cdot G_{f}}{f_{c t} \cdot s_{m \theta}}=\frac{f_{c t}}{E_{c}} \cdot\left(1+\frac{2 \cdot G_{f} \cdot E_{c}}{f_{c t}^{2} \cdot s_{m \theta}}\right)
$$

The shear transferred along the crack, can be, then, expressed in dimensionless terms, as:

$$
v_{w}=\frac{V_{w}}{f_{c t} \cdot b \cdot d}=\frac{0.425 \cdot \sin ^{2} \theta \cdot f_{c t}}{E_{c} \cdot \varepsilon_{r}}\left(1+\frac{2 \cdot G_{f} \cdot E_{c}}{f_{c t}^{2} \cdot s_{m \theta}}\right)
$$

The mean spacing between inclined cracks, $s_{m}$, varies from one point to the other of the crack and is affected by bond with the longitudinal and transverse reinforcements. In this work, it is assumed that the crack close to the critical shear crack is formed in the vertical of the mid-height of the shear critical crack (see Fig. 8). This is in accordance with the observed experimental crack patterns of some existing tests, such as [10]. Therefore, the average crack spacing, $s_{m \theta}$, is considered equal to:

$$
s_{m \theta}=\frac{(d-c)}{2} \cos \theta
$$


Fig. 8. Diagonal crack spacing.

The strain, $\varepsilon_{r}$, at the longitudinal reinforcement, can be expressed as a function of the maximum strain at the transverse stirrups:

$\varepsilon_{r}=\varepsilon_{t} \cdot \cot \theta$

In addition, a conservative value for the mean angle of the crack can be assumed, $\left(\theta=41.4^{\circ}\right.$ which corresponds to $c / d=0.25$ ). Then, the diagonal crack spacing, $s_{m \theta}$, from Eq. (10) is similar to the effective depth divided by $4, d / 4$, and the following simplified equation for the shear transferred by the crack can be obtained:

$$
v_{w}=\frac{V_{w}}{f_{c t} \cdot b \cdot d}=\frac{0.386}{\varepsilon_{t}} \cdot \frac{f_{c t}}{E_{c}}\left(1+\frac{8 \cdot G_{f} \cdot E_{c}}{f_{c t}^{2} \cdot d}\right)
$$

\subsubsection{Contribution of the longitudinal reinforcement to the shear-flexural strength}

As a consequence of the crack slip and the crack opening, the longitudinal reinforcement is subjected to a relative vertical displacement between the two surfaces of the crack. The FRP stirrups provide a constraint to the vertical movement of the longitudinal bars, enabling them to transfer a certain shear. An expression for this shear strength component, $V_{l}$, was obtained in [23] (see Eq. (13)), considering that the longitudinal bars are doubly fixed at the two stirrups adjacent to the crack initiation point, and are subjected to bending due to a relative imposed displacement between their ends.

$V_{l} \approx 0.64 \cdot \frac{E_{r}}{f_{c t}} \cdot \rho \cdot \frac{\phi^{2} \cdot d}{s_{t}^{3}} \cdot \frac{\varepsilon_{r}}{1-\xi}$

where $\phi$ is the diameter of the bars, $s_{t}$ is the longitudinal spacing between the stirrups, $\rho$ is the longitudinal reinforcement ratio, $\xi=c / d$ is the relative neutral axis depth and $\varepsilon_{r}$ is the strain at the longitudinal reinforcement. Equation (13) is not too operative, since the stirrups spacing is not known a priori in the design. In addition, the contribution of the longitudinal reinforcement is less than 5\% of the shear strength 
and, therefore, such complex expression is not justified. Then a simplified equation is proposed, obtained by assuming usual values of $\phi / s_{t}=0.1, d / s_{t}=2, \varepsilon_{\mathrm{r}}=\varepsilon_{t} \cdot \tan \theta=\varepsilon_{t} \cdot(1-\xi) / 0.85$ and $E_{c} / f_{c t}=10000$, which results in:

$v_{l}=\frac{V_{l}}{f_{c t} \cdot b \cdot d} \approx 153.3 \cdot \alpha \cdot \rho \cdot \varepsilon_{t}$

According to the database presented in section 2, the dimensionless contribution of the longitudinal reinforcement has a mean value of 0.018 , which represent only a mean value of $2.3 \%$ of the total shear strength. Therefore, to simplify the formulation of the total shear strength, the dowel action effect will be neglected in the following. This assumption is in accordance with other existing references such [3] (see section 1).

\subsubsection{Contribution of the un-cracked concrete chord to the shear-flexural strength}

The contribution of the un-cracked concrete chord to the shear-flexural strength is based on the formulation developed by Marí et al. [23] for RC beams with and without steel stirrups, which was adapted for the case of FRP RC beams without stirrups [24]. A brief summary of the model is described below.

The shear force carried by the concrete chord when the principal tensile stress reaches the concrete tensile strength, is obtained by integrating the shear stresses along the concrete chord, as follows:

$V_{c}=\int_{0}^{c} \tau(y) \cdot b \cdot d y=\frac{\tau_{t} \cdot b \cdot c}{6 \cdot \lambda_{t} \cdot\left(1-\lambda_{t}\right)}=\frac{f_{c t} \cdot b \cdot c}{6 \cdot \lambda_{t} \cdot\left(1-\lambda_{t}\right)} \cdot \sqrt{1+\frac{\sigma_{x}}{f_{c t}}}$

where $f_{c t}$ is the concrete tensile strength, $b$ is the section width, $c$ is the neutral axis depth calculated according to Eq. (16), and $\sigma_{x}$ and $\tau_{t}$ are, respectively, the concrete normal and shear stresses at the failure point, placed at a distance $y=\lambda_{t} \cdot c$ from the neutral axis.

The value of the neutral axis depth, $c$, is:

$\xi=\frac{c}{d}=\alpha \cdot \rho \cdot\left(-1+\sqrt{1+\frac{2}{\alpha \cdot \rho}}\right)$

being the reinforcing ratio $\rho=A_{r} /(b \cdot d)$ and the modular ratio $\alpha=E_{r} / E_{c}$, where $E_{r}$ is the internal reinforcement longitudinal modulus.

For the particular case of $\lambda_{t}=0.425$, Eq. (15) becomes Eq. (17):

$$
V_{c}=\frac{f_{c t} \cdot b \cdot c}{6 \cdot 0.425 \cdot(1-0.425)} \cdot \sqrt{1+\frac{\sigma_{x}}{f_{c t}}}=0.682 \cdot f_{c t} \cdot b \cdot c \cdot \sqrt{1+\frac{\sigma_{x}}{f_{c t}}}
$$


where, the normal concrete stress $\sigma_{x}$ at $y=0.425 \cdot c$ can be obtained as follows:

$\sigma_{x}=\frac{2 \cdot \lambda \cdot C}{b \cdot c}$

To obtain the resultant of the compressive stresses at the concrete chord, equilibrium between the internal forces $(V, M)$ and the stress resultants at the concrete chord $\left(C, V_{c}\right)$ along the crack $\left(V_{w}\right)$, at the stirrups $\left(V_{t}\right)$ and at the longitudinal reinforcement $(T)$ is taken in the portion indicated by Fig. 3.

Equilibrium of moments is taken with respect to the point A, where the critical crack reaches the reinforcement.

$C=T+V_{w} \cdot \tan \theta$

$V=V_{c}+V_{w}+V_{t}$

$C \cdot z=M+V_{c} \cdot \beta \cdot d+\frac{V_{w}}{\cos \theta} \cdot z_{w}+V_{t} \cdot z_{t}=M+V_{c} \cdot \beta \cdot d+V_{w} \cdot \beta_{w} \cdot d+V_{t} \cdot \beta_{t} \cdot d$

Then, the normal stress $\sigma_{x}$ at the critical point $\left(y=\lambda_{t} \cdot c\right)$ of the compression chord, can be expressed as function of the internal forces as Eq. (22):

$\sigma_{x}=\frac{2 \cdot \lambda \cdot C}{b \cdot c}=\frac{2 \cdot \lambda \cdot\left(M+V_{c} \cdot \beta \cdot d+V_{w} \cdot \beta_{w} \cdot d+V_{t} \cdot \beta_{t} \cdot d\right)}{b \cdot c \cdot\left(d-\frac{c}{3}\right)}$

where $M$ is the bending moment acting on the section.

After incorporating Eq. (22) into Eq. (17), the dimensionless shear force resisted by the concrete chord can be written as follows:

$v_{c}=\frac{V_{c}}{f_{c t} \cdot b \cdot d}=0.682 \cdot \xi \cdot \sqrt{1+\frac{2 \cdot \lambda \cdot\left(\mu+\beta_{w} \cdot v_{w}+\beta_{t} \cdot v_{t}+\beta \cdot v_{c}\right)}{\xi \cdot(1-\xi / 3)}}$

To simplify the notation, a total moment $\mu^{*}$ is defined by Eq. (24).

$\mu^{*}=\mu+\beta_{w} \cdot v_{w}+\beta_{t} \cdot v_{t}$

Thus Eq. (23) transforms into Eq. (25), which is a second order equation in $v_{c}$.

$v_{c}=0.682 \cdot \xi \cdot \sqrt{1+\frac{2 \cdot \lambda \cdot\left(\mu^{*}+\beta \cdot v_{c}\right)}{\xi \cdot(1-\xi / 3)}}$ 
The solution of Eq. (25) has been represented in Fig. 9 for different dimensionless moment, $\mu^{*}$. As observed, the concrete chord contribution to the shear strength is a linear function of the neutral axis depth, $\xi$.

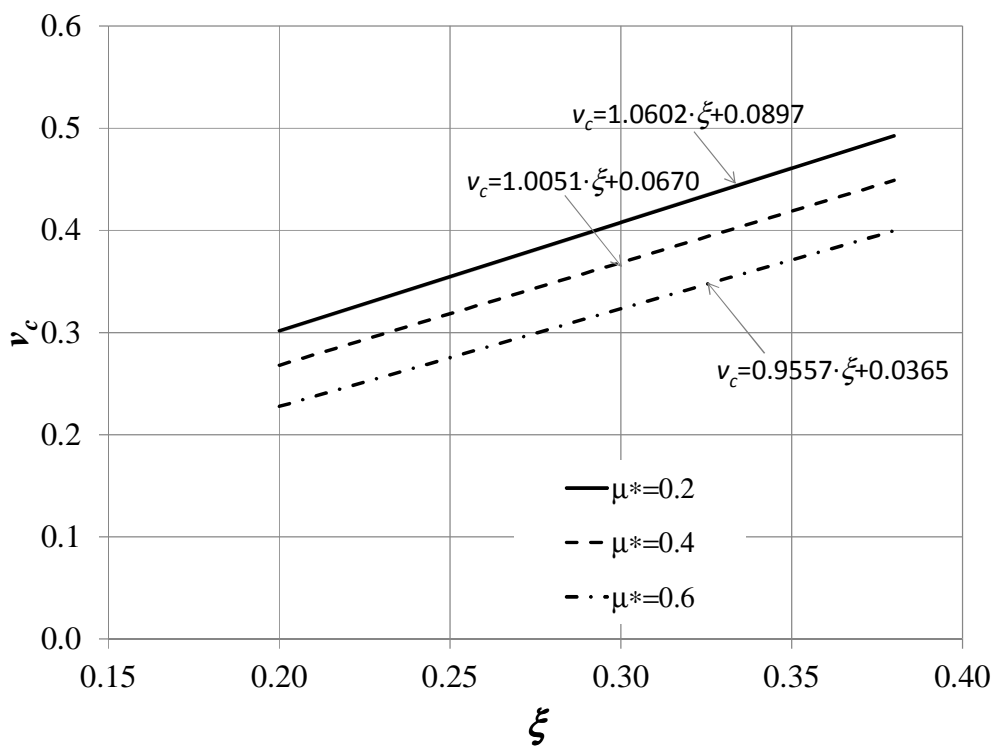

Fig. 9. Dimensionless un-cracked concrete chord contribution vs. dimensionless neutral axis depth.

Therefore, the solution of Eq. (25) can be adjusted almost exactly by the following linear expression:

$$
v_{c}=\left[0.903+0.260 \mu^{*}\right] \cdot \xi+0.012+0.1325 \mu^{*}
$$

The dimensionless moment $\mu^{*}$ is the sum of three components (see Eq. 24). In order to obtain $v_{t}$, Eq. (11) must be used, assuming a triangular distribution of forces at the stirrups along the crack. Therefore, the lever arm of the force at the stirrups is $\beta_{t}=0.85 \cdot d / 3$. With respect to the residual force along the crack, $v_{w}$, its lever arm, $\beta_{w}$, is calculate from Eq. (27)

$$
\beta_{w}=\frac{0.85-0.5 \cdot \cot \theta \cdot c_{w} / d}{\cos ^{2} \theta}
$$

For practical reasons, and since $v_{w}$ is small compared to $v_{c}$, an average value according to the database of Appendix 2, of $v_{w}=0.15$, is adopted in Eq. (24). In addition, the moment at the section where the critical crack initiates, conservatively, as the cracking moment, whose non-dimensional value for rectangular cross sections is $\mu=0.2$, approximately. Then Eq. (24) transforms into:

$\mu^{*} \simeq 0.305+0.28 \cdot v_{t}$ 
In order to obtain a more simplified practical equation, the term $0.0371 \cdot v_{t}$ is included inside the parenthesis, by assuming an average value for $\xi=0.25$, resulting the following simplified expression for $v_{c}:$

$v_{c}=\left[0.98+0.22 \cdot v_{t}\right] \cdot \xi+0.05$

In the case of beams longitudinally reinforced with FRP, due to the low stiffness of the bars, the neutral axis depth is lower and the concrete stresses higher than in steel reinforced concrete beams. Thus, the actual concrete stresses distributions in the compression zone are not linear. For this reason, in order to adequately calculate the neutral axis depth, $\xi$, the value obtained using a linear stress distribution must be corrected, as obtained by Marí et al. [24], by a factor which depends on the modular ratio, $\alpha=E_{l} / E_{c}$ where $E_{r}$ and $E_{c}$ are the elastic modulus of the longitudinal reinforcement and the concrete, respectively. Eq. (30) can be adjusted taking into account also the modular ratio of the reinforcement, $\alpha$, by the following linear expression:

$$
v_{c}=(1.072-0.01 \cdot \alpha) \cdot\left(\left(0.98+0.22 \cdot v_{t}\right) \cdot \xi+0.05\right)
$$

The dimensionless shear transferred by the un-cracked concrete chord, $v_{c}$, must be modified to account for the size effect due to the brittle character of the failure that takes place when the second branch of the critical crack develops. For this purpose, the empirical model proposed by Zararis and Papadakis [36], based on the splitting test analogy, is adopted. According to such model, the size effect on the shear failure of slender beams seems to depend on the size of the shear span $a$, that would be proportional to the diameter of the specimen of an hypothetical splitting test that occurs at the beam compression zone, between the point where the load is applied, and the tip of the first branch of the critical shear crack:

$$
\zeta=1.2-0.2 \cdot a=1.2-0.2 \cdot \frac{a}{d} \cdot d \geq 0.65
$$

with $a$ and $d$ in meters.

Then, considering the size effect, the concrete chord contribution to the shear strength is given by Eq. (33). 


$$
v_{c}=\zeta \cdot(1.072-0.01 \cdot \alpha) \cdot\left(\left(0.98+0.22 \cdot v_{t}\right) \cdot \xi+0.05\right)
$$

\subsubsection{Ultimate shear strength}

The total shear resisted will be the sum of the following three components:

$$
V=V_{c}+V_{w}+V_{t}=f_{c t} \cdot b \cdot d \cdot\left(v_{c}+v_{w}+v_{t}\right)
$$

where $v_{c}, v_{w}$ and $v_{t}$ are given by Eqs. (33), (12) and (1), respectively.

The model also provides the position where the critical shear crack starts, $x_{c r}=V_{u} / M_{c r}$, the position of the critical shear section, $x_{\mathrm{u}}=x_{c r}+0.85 \cdot d$ and the bending moment concomitant with the ultimate shear $V_{u}$, given by Eq. (34).

In addition, as explained in section 2 , it should be verified that a brittle flexural failure does not occur before reaching the shear strength given by Eq. (34). Therefore, the ultimate shear force will be the minimum value given by Eqs. (34) and (35). The bending moment that corresponds to a brittle flexural failure mode at the section under the load application $(x=a)$, can be obtained by applying equilibrium and compatibility, assuming that the most compressed concrete fibre reaches the ultimate concrete strain, $\varepsilon_{c u}$ (see Eq. (36)). In this case, $\varepsilon_{c u}$ has been assumed equal to 0.004 .

$$
V=M_{u, \text { brit flex }} / a
$$

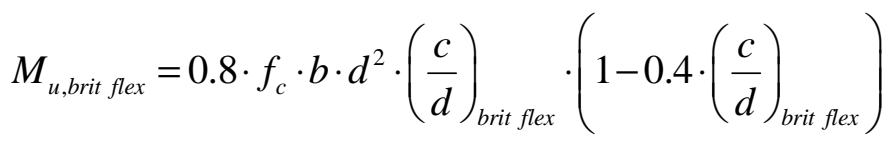

where:

$$
\begin{aligned}
& \left(\frac{c}{d}\right)_{\text {brit flex }}=0.5 \cdot K_{\lambda} \cdot\left(-1+\sqrt{1+\frac{4}{K_{\lambda}}}\right) \\
& K_{\lambda}=0.005 \cdot \frac{\rho \cdot E_{r}}{f_{c}}
\end{aligned}
$$

\section{DESIGN EQUATION FOR FRP STIRRUPS}

When designing in shear an FRP RC element with FRP stirrups, the amount of transverse reinforcement can be obtained in dimensionless form by Eq. (39), as the difference between the design shear force, $v_{S d}$, and the shear force resisted by the concrete compression chord $\left(v_{c}\right)$ and by the crack $\left(v_{w}\right)$, 
given by Eqs. (33) and (12) respectively. Eq. (39) can be obtained by incorporating the concrete contribution which depends on the contribution of the stirrups $v_{t}$.

$$
\text { If } v_{S d}>v_{c}+v_{w} ; \quad v_{t}=\frac{v_{S d}-\zeta \cdot(1.072-0.01 \cdot \alpha) \cdot\left(0.98 \cdot \frac{c}{d}+0.05\right)-v_{w}}{1+0.22 \cdot \zeta \cdot \frac{c}{d} \cdot(1.072-0.01 \cdot \alpha)}
$$

where $v_{S d}$ is the dimensionless design shear force, given by Eq. (40), which is a data of the problem. In this case, the critical shear section can be considered to be placed at a distance $d$ from the support.

$$
v_{S d}=\frac{V_{S d}}{f_{c t} \cdot b \cdot d}
$$

In relation to the minimum amount of transverse reinforcement, it is necessary to have at least two stirrups that cross the diagonal crack, in order to be able to consider aggregate interlock. Therefore, the maximum stirrups spacing should be lower than $0.425 \cdot d$.

\section{VALIDATION OF THE MODEL. COMPARISON WITH EXPERIMENTAL RESULTS}

The performance of the proposed model when predicting the ultimate shear force is evaluated in this section together with other existing models described in Appendix 1 through the database described in section 2 and compiled in Appendix 2. Table 2 summarises some statistical information related to the ratio between the experimental and the theoretical ultimate shear force, $V_{\text {test }} / V_{\text {pred. }}$.

The average of the $V_{\text {test }} / V_{\text {pred }}$ ratio is directly related to accuracy. The most accurate model is the proposal presented in this paper with the mean value closest to 1.0. $\left(V_{\text {test }} / V_{\text {pred }}=1.08\right)$. The less accurate method is the CNT-DT-203/2006 [9] guideline without applying safety factors. The standard deviation, or the coefficient of variation (COV\%), is a measure of precision. The proposed model shows the lowest COV equal to $19.5 \%$. From the models proposed in Codes or Guidelines, the CSA-S806-12 [11] presented the lowest COV, equal to $22.9 \%$, and the ACI 440.1R-06 [8] showed the highest COV, 37.1\%. If the dowel action was considered in the proposed model, the mean value would be 1.02 and the COV $19.4 \%$, very similar to the actual results.

Fig. 10 presents the correlation between the experimental ultimate shear force, $V_{\text {test }}$, and the theoretical prediction, $V_{\text {pred }}$, for the considered models. A tolerance of $15 \%$ has been represented in the graphs. It can be seen that the proposed rational method presents a very good correlation with the tests. In addition, its performance is similar to that of CSA-S806-12 [11], to the model based on genetic algorithm 
Table 2. Verification of the design procedures

\begin{tabular}{|c|c|c|c|c|c|c|c|c|c|}
\hline \multirow[b]{2}{*}{$V_{\text {test }} / V_{\text {pred }}$} & \multirow[b]{2}{*}{$\begin{array}{c}\text { ACI } \\
440.1 R-06 \\
{[8]} \\
\end{array}$} & \multicolumn{8}{|c|}{112 beams with FRP stirrups } \\
\hline & & $\begin{array}{c}\text { CSA S6-09 } \\
\text { Add. }[10]\end{array}$ & $\begin{array}{c}\text { CSA S806- } \\
\mathbf{1 2} \\
{[11]}\end{array}$ & $\begin{array}{c}\text { JSCE } \\
{[12]}\end{array}$ & $\begin{array}{c}\text { CNR-DT- } \\
\text { 203/2006 } \\
{[9]} \\
\end{array}$ & $\begin{array}{c}\text { Fico et al. } \\
{[3]}\end{array}$ & $\begin{array}{c}\text { Nehdi et al. } \\
{[19]}\end{array}$ & $\begin{array}{c}\text { Hegger et } \\
\text { al. [20] }\end{array}$ & Proposal \\
\hline Average & 1.54 & 2.03 & 1.33 & 2.73 & 0.82 & 0.95 & 1.16 & 1.51 & 1.08 \\
\hline Median & 1.58 & 1.99 & 1.29 & 2.61 & 0.80 & 0.90 & 1.13 & 1.45 & 1.05 \\
\hline Standard Deviation & 0.57 & 0.74 & 0.31 & 0.88 & 0.27 & 0.28 & 0.27 & 0.35 & 0.21 \\
\hline $\operatorname{COV}(\%)$ & 37.1 & 36.5 & 22.9 & 32.3 & 32.4 & 29.4 & 23.3 & 23.0 & 19.5 \\
\hline Minimum & 0.42 & 0.61 & 0.82 & 1.23 & 0.38 & 0.44 & 0.50 & 0.89 & 0.64 \\
\hline$\left(V_{\text {test }} / V_{\text {pred }}\right)_{5 \%}$ & 0.62 & 0.91 & 0.97 & 1.53 & 0.46 & 0.53 & 0.75 & 1.02 & 0.75 \\
\hline Maximum & 3.23 & 4.59 & 2.42 & 5.13 & 1.45 & 1.64 & 2.00 & 2.62 & 1.85 \\
\hline$\left(V_{\text {test }} / V_{\text {pred }}\right)_{95 \%}$ & 2.49 & 3.32 & 1.91 & 4.12 & 1.35 & 1.38 & 1.59 & 2.19 & 1.50 \\
\hline
\end{tabular}

Fig. 11 shows the ratio $V_{\text {test }} / V_{\text {pred }}$ in relation to the longitudinal reinforcement ratio affected by its modulus of elasticity, $E_{r} \cdot \rho$. As observed, the performance of the proposed model does not depend on this ratio. The dispersion of the different models can also be observed in Fig. 11.

In a similar manner, Fig. 12 shows the ratio $V_{\text {test }} / V_{\text {pred }}$ for the transversal reinforcement ratio by its modulus of elasticity, $E_{t} \cdot \rho_{t}$. For the proposed model, the dispersion is higher for low values of $E_{t} \cdot \rho_{t}$. In addition, the proposed model performs in a similar manner than the model of Nehdi et al. [19]. For the ACI 440.1R-06 [8] and the JSCE [12] guidelines, the ratio $V_{\text {test }} / V_{\text {pred }}$ decreases for increasing values of $E_{t} \cdot \rho_{t}$

In [24], a statistical comparison of the existing models for the prediction of the ultimate strength of beams longitudinally reinforced with FRP bars and without stirrups was performed. As observed the coefficient of variation of the existing formulations ranged between $14.8 \%$ for the proposal presented by Marí et al. [24] to $22.31 \%$ for the CNR-DT-203/2006 [9] guideline. In any case, the COV for the prediction of the ultimate shear strength with the formulations with stirrups is higher than for the case of beams without stirrups. This fact can be explained by the uncertainty in the definition of the stresses in the FRP stirrups. 

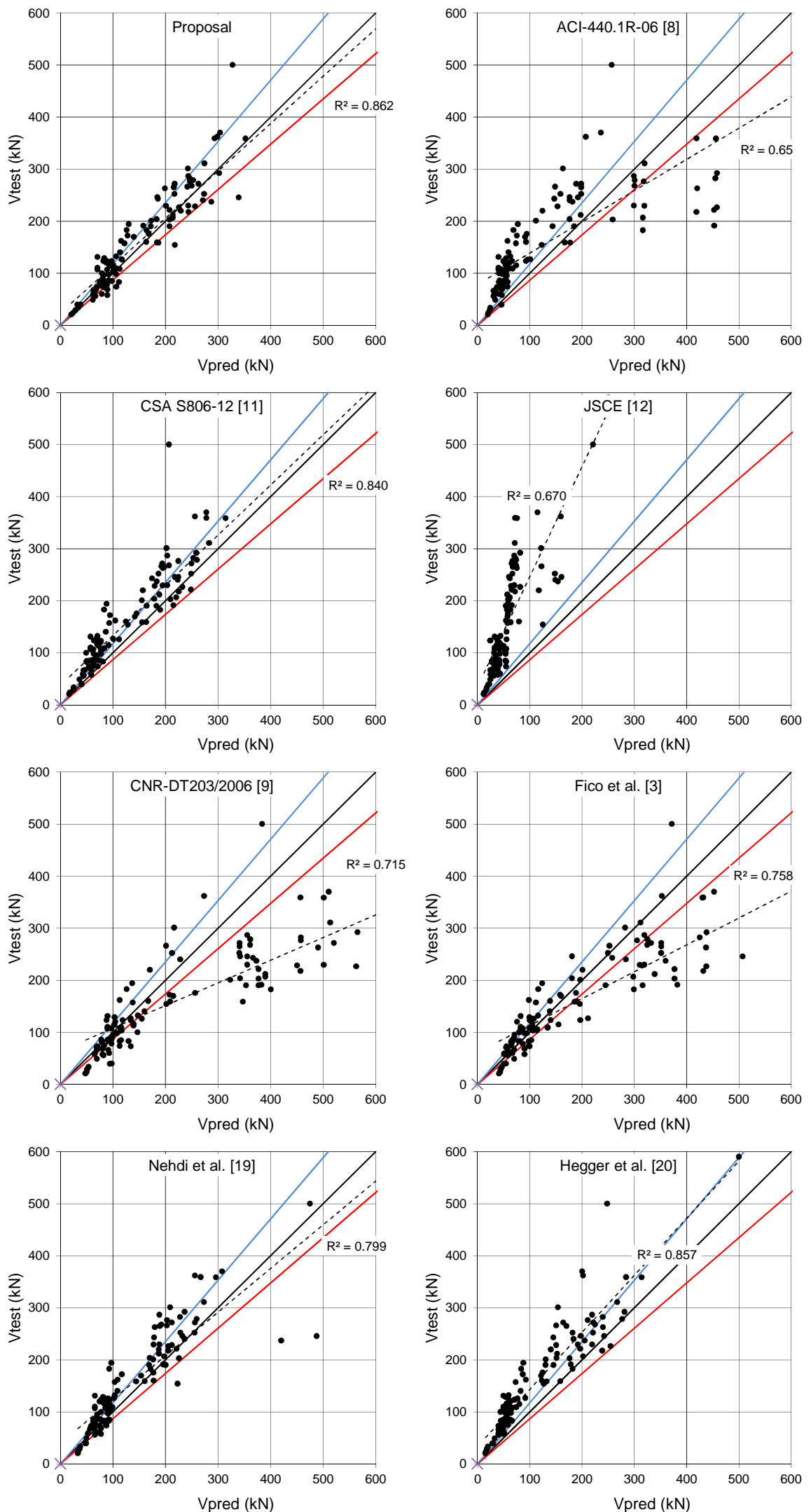

Fig. 10. Comparative analysis of the existing models to predict the shear strength of FRP RC beams with 
FRP stirrups. 

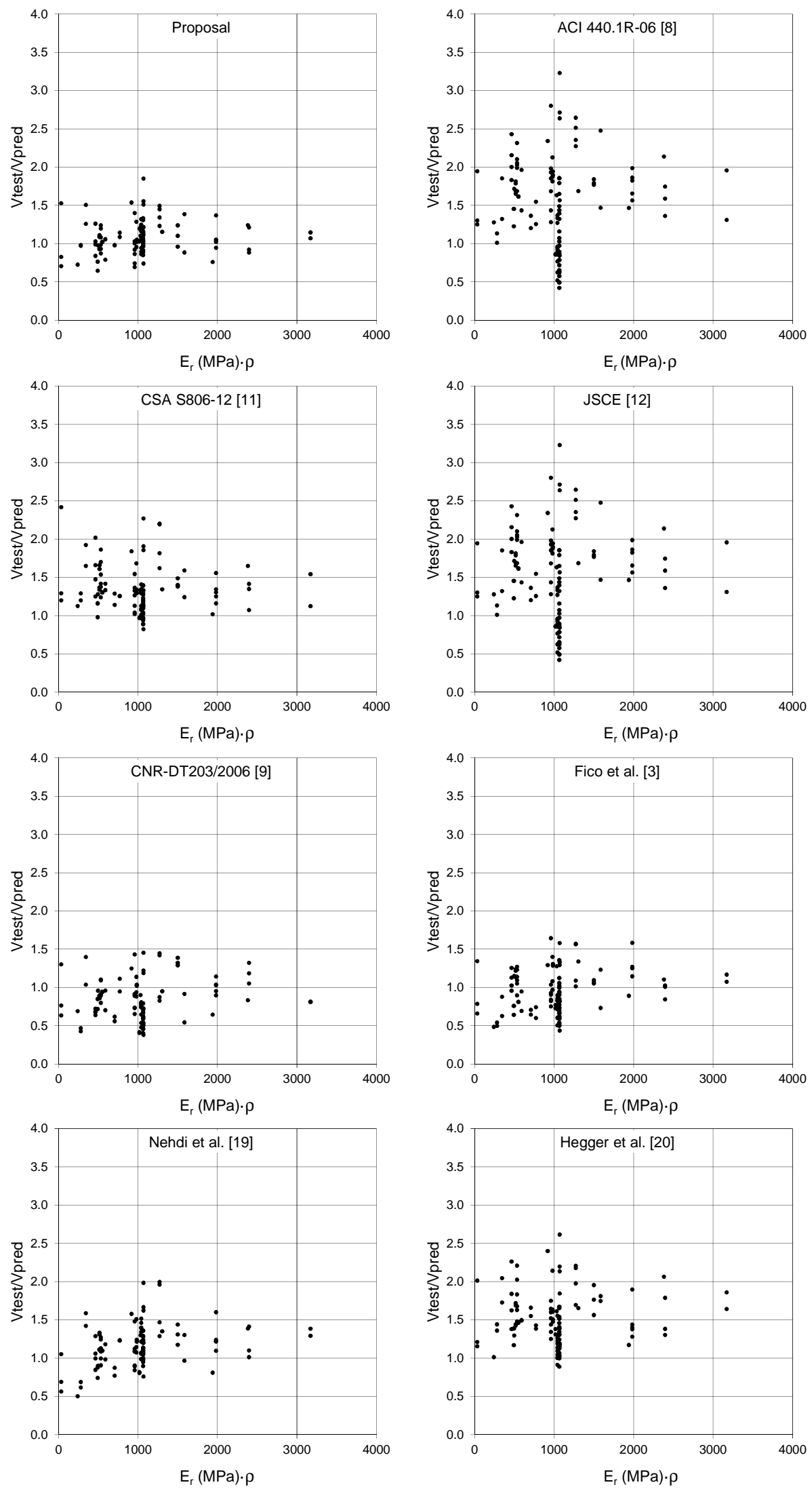

Fig. 11. Correlation of the predictions and experimental results in terms of $E_{r} \cdot \rho$. 

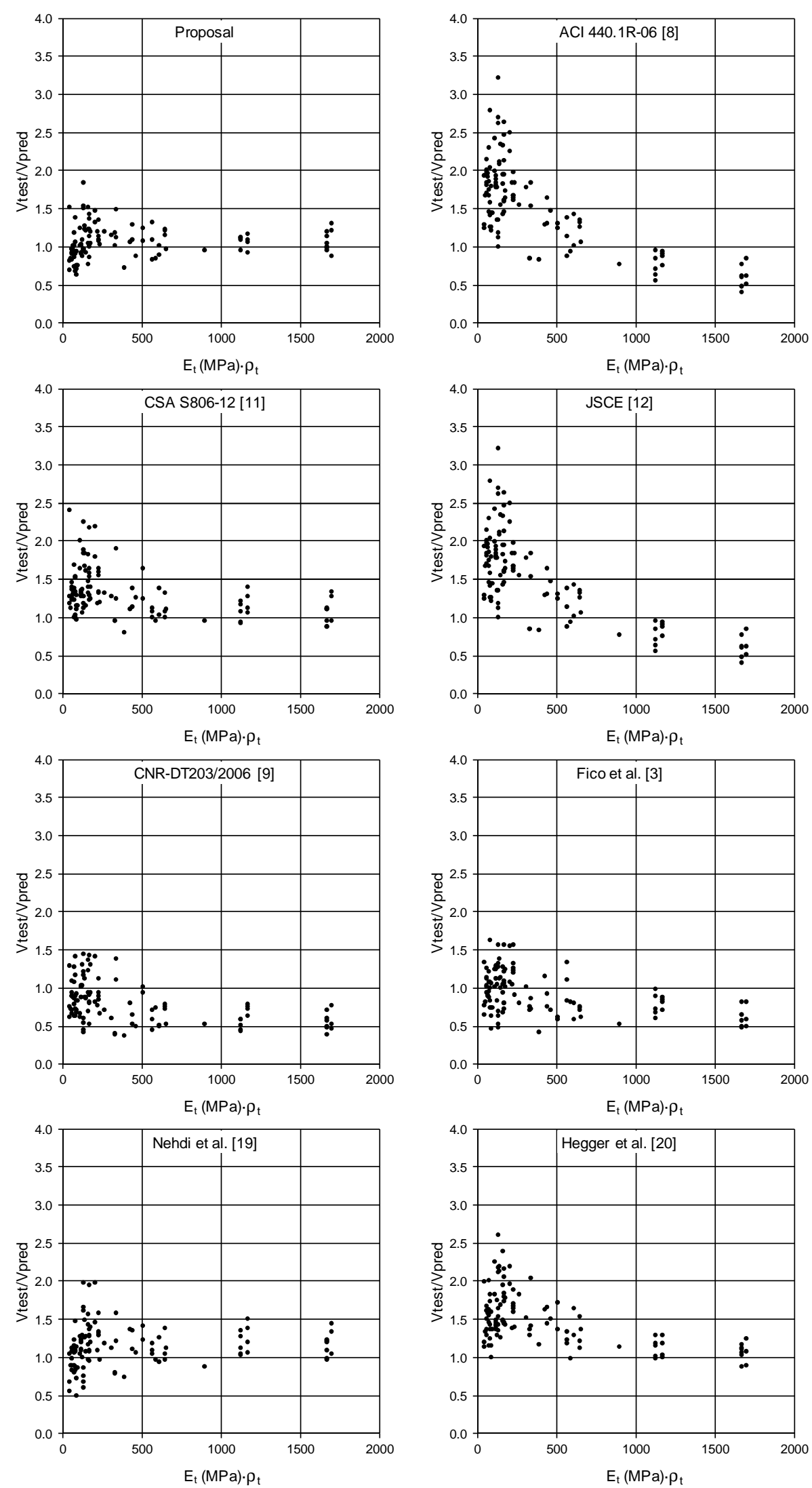

Fig. 12. Correlation of the predictions and experimental results in terms of $E_{t} \cdot \rho_{t}$. 


\section{CONCLUSIONS}

A simple and rational model for the prediction of the shear strength of simply supported FRP reinforced concrete beams with FRP transverse reinforcement has been developed. The model is fully based on the principles of structural mechanics and on the observed experimental behaviour of these structures. The contribution of each shear transfer mechanism has been quantified for the ultimate limit state. Simplified direct equations for both design and verification have been derived and checked with a large set of experimental results. The following conclusions can be drawn from the studies made:

1) In the proposed model, the shear strength is considered to be the sum of the shear transferred by the concrete compression chord, along the crack due to residual tensile stresses, and by the FRP stirrups. The shear failure of a beam is considered to take place when the principal tensile stress, at any point of the compression chord, reaches the tensile concrete strength. For simply supported beams subjected to point loads, such failure occurs at a critical section placed at the tip of the inclined critical shear crack closest to the support.

2) The shear strength of the un-cracked concrete chord, $V_{c}$, increases as the amount of the transverse reinforcement ratio increases. This is due to the fact that, as the shear capacity increases due to the direct contribution of the stirrups, also the moment acting at the critical section increases and thus, the compression at the concrete chord. Such effect is evidenced from the moment equilibrium equations (Eq. 21).

3) The modulus of elasticity of the longitudinal reinforcing bars used affects considerably the concrete shear strength, $V_{c}$. The higher is the modular ratio $\alpha$ between the FRP and the concrete modulus, the higher is the shear strength, because the neutral axis depth increases with the parameter $\alpha \cdot \rho$.

4) In conventionally RC beams with steel stirrups, usually the stirrups yield at failure. In FRP RC beams with FRP stirrups, it is assumed that the shear failure occurs when the most loaded stirrup fail in a local manner at the bent zone. Then the remaining stirrups are still in the elastic range and the distribution of stresses along the stirrups crossing the shear critical crack is assumed linear. Then, the stirrups contribution to the shear strength depends on their stress level and has an upper limit related to the reduced strength of the stirrups at the bent zone. 
5) The presence of FRP stirrups reduce the crack width, increasing the aggregate interlock effect in comparison to FRP RC beams without stirrups, where this effect can be neglected. The expression for the residual shear strength along the crack $V_{w}$ depends on the concrete properties, on the neutral axis depth and also on the stirrups strain, which is limited by their local failure.

6) In case a local rupture of the stirrups at the bent zone does not occur, and due to the high strength of the FRP rebars, a concrete crushing failure at the compression chord can develop at the load application point section. Therefore, the shear force associated to this failure mode is a lower limit value of the shear strength that should be verified.

7) The derived formulae have been applied to predict the results of 112 shear tests on FRP reinforced concrete beams with FRP stirrups. Predictions made by other existing formulations and some provisions of current guidelines have been also compared with the experimental results. The results obtained by the proposed method are very good, in terms of mean value (1.08) and coefficient of variation (19.5\%) of the ratio between the experimental and the predicted values, $V_{\text {exp }} / V_{\text {pred }}$. The coefficient of variation (COV) obtained is the lowest of all the methods studied. This fact is relevant, since the model with similar results [19] is based on genetic algorithms while the proposed method has been rationally derived, without any adjustment to the database.

8) The model, derived from the principles of structural mechanics, provides physical explanations to the influence of each parameter included in the proposed equations, thus resulting very useful for design and assessment purposes. Consequently, a natural extension of the model can be done for shear strengthened members by means of external FRP sheets or laminates, by adapting the equations to account for the effects of the strengthening system.

\section{ACKNOWLEDGEMENTS}

This paper has been developed under the framework of the Research Projects "BIA2012-36848" and "BIA2012-31432", funded by the Spanish Ministry of Economy and Competitiveness (MINECO) and co-funded by the European Regional Development Funds (ERDF). The authors would also like to acknowledge the work performed by Marta Valentí of the Universitat Politècnica de Catalunya. 


\section{REFERENCES}

[1] E. Shehata, R. Morphy, and S. Rizkalla, "Fibre reinforced polymer shear reinforcement for concrete members: behaviour and design guidelines," Can. J. Civ. Eng., vol. 27, no. 5, pp. 859$872,2000$.

[2] S. Campana, M. F. Ruiz, A. Anastasi, and A. Muttoni, "Analysis of shear-transfer actions on oneway RC members based on measured cracking pattern and failure kinematics," Mag. Concr. Res., vol. 65 , no. 6, pp. 386-404, 2013.

[3] R. Fico, A. Prota, and G. Manfredi, "Assessment of Eurocode-like design equations for the shear capacity of FRP RC members,” Compos. Part B Eng., vol. 39, no. 5, pp. 792-806, 2008.

[4] S. Tottori and H. Wakui, "Shear capacity of RC and PC beams using FRP reinforcement," in ACI SP-138, A. Nanni and C. Dolan, Eds. Detroit, Michigan: American Concrete Inst, 1993, pp. 615631.

[5] P. A. Whitehead and T. J. Ibell, "Novel shear reinforcement for fiber-reinforced polymerreinforced and prestressed concrete," ACI Struct. J., vol. 102, no. 2, pp. 286-294, 2005.

[6] A. K. El-Sayed, E. El-Salakawy, and B. Benmokrane, "Mechanical and structural characterization of new carbon FRP stirrups for concrete members," J. Compos. Constr., vol. 11, no. 4, pp. 352$362,2007$.

[7] A. K. El-Sayed and K. Soudki, "Evaluation of shear design equations of concrete beams with FRP reinforcement,” J. Compos. Constr., vol. 15, no. 1, pp. 9-20, 2011.

[8] ACI Committee 440, Guide for the Design and Construction of Structural Concrete Reinforced with FRP Bars, ACI 440.1R-06, no. May. ACI (American Concrete Institute), 2006, pp. 1-97.

[9] CNR-DT 203/2006, Guide for design and construction of concrete structures reinforced with fiber-reinforced polymer bars. Rome, Italy, 2006.

[10] E. A. Ahmed, E. El-Salakawy, and B. Benmokrane, "Shear performance of RC bridge girders reinforced with carbon FRP stirrups," J. Bridg. Eng., vol. 15, no. 1, pp. 44-54, 2010.

[11] C. S. Association, CAN/CSA S806-12 Design and construction of building components with fibre reinforced polymers. Toronto, Canada, 2012.

[12] Japan Society of Civil Engineers, Recommendations for design and construction of concrete streuctures using continuous fiber reinforcing materials., Concrete E., vol. C. Japan, 1997, p. 325.

[13] M. R. Ehsani, H. Saadatmanesh, and S. Tao, "Bond of hooked glass fiber reinforced plastic (GFRP) reinforcing bars to concrete," ACI Mater. J., vol. 92, no. 4, pp. 391-400, 1995.

[14] R. Machial, M. S. Alam, and A. Rteil, "Revisiting the shear design equations for concrete beams reinforced with FRP rebar and stirrup," Materials and Structures, vol. 45, no. 11. pp. 1593-1612, 2012.

[15] A. G. Razaqpur and S. Spadea, "Shear strength of FRP reinforced concrete members with stirrups," J. Compos. Constr., 2014. 
[16] C. S. Association, CAN/CSA S806-02 Design and construction of building components with fibre reinforced polymers. Rexdale, Ontario, Canada, 2002, p. 177.

[17] T. Nagasaka, H. Fukuyama, and M. Tanigaki, "Shear performance of concrete beams reinforced with FRP sitrups,” Detroit, Michigan, 1993.

[18] N. A. Hoult, E. G. Sherwood, E. C. Bentz, and M. P. Collins, "Does the use of FRP reinforcement change the one-way shear behaviour of reinforced concrete slabs?," J. Compos. Constr., vol. 12, no. 2, pp. 125-133, 2008.

[19] M. Nehdi, H. El Chabib, and A. Aly Saïd, "Proposed shear design equations for FRP-reinforced concrete beasm based on genetic algorithms approach," J. Mater. Civ. Eng., vol. 19, no. 12, pp. 1033-1042, 2007.

[20] J. Hegger, J. Niewels, and M. Kurth, "Shear analysis of concrete members with fiber-reinforced polymers (FRP) as internal reinforcement," in 9th International Symposium on Fiber-Reinforced Polymer Reinforcement for Concrete Structures FRPRCS-9, 2009.

[21] ACI Committee 440, Report on Fiber-Reinforced Polymer ( FRP ) Reinforcement for Concrete Structures, ACI 440R-07. ACI Committee 440, 2007, pp. 1-3.

[22] N. A. Hoult, E. G. Sherwood, E. C. Bentz, and M. P. Collins, "Does the Use of FRP Reinforcement Change the One-Way Shear Behavior of Reinforced Concrete Slabs?," Journal of Composites for Construction, vol. 12, no. 2. pp. 125-133, 2008.

[23] A. R. Mari, J. M. Bairán, A. Cladera, E. Oller, and C. Ribas, "Shear-flexural mechanical model for the design and assessment of reinforced concrete beams," Struct. Infrastruct. Eng., doi: 10.1080/15732479.2014.964735, 2014.

[24] A. Mari, A. Cladera, E. Oller, and J. M. Bairan, "Shear design of FRP reinforced concrete beams without transverse reinforcement," Compos. Part B Eng., vol. 57, pp. 228-241, 2014.

[25] T. Maruyama, M. Honama, and H. Okamura, "Experimental study on tensile strength of bent portion of FRP rods," in ACI special publications: Fiber reinforced plastic reinforcement for concrete structures, ACI SP-138, A. Nanni and C. W. Dolan, Eds. Farmington Hills, Michigan: American Concrete Institute, 1993.

[26] K. Ishihara, T. Obara, Y. Sato, T. Ueda, and Y. Kakuta, "Evaluation of ultimate strength of FRP rods at bent-up portion," in 3rd International Symposium of Non-metallic (FRP) reinforcement for concrete structures, 1997, pp. 27-34.

[27] E. F. G. Shehata, "Fiber reinforced polymer (FRP) for shear reinforcement in concrete structures," University of Manitoba, Manitoba, Canada, 1999.

[28] W. Zhao, K. Maruyama, and H. Suzuki, "Shear behaviour of concrete beams reinforced with FRP rods as longitudinal and shear reinforcement," in Proceedings of the 2nd International RILEM symposium Non-metallic (FRP) reinforcement for concrete structures (FRPRCS-2), 1995, pp. 352-359.

[29] E. C. Bentz, L. Massam, and M. P. Collins, "Shear Strength of Large Concrete Members with FRP Reinforcement,” Journal of Composites for Construction, vol. 14, no. 6. pp. 637-646, 2010.

[30] J. Niewels, "Zum tragverhalten von betonbauteilen mit faserverbundkunstoff-bewerhrung," RWTH Aachen University, 2008.

[31] S. Spadea, "Comportamento di elmenti di calcestruzzo armato con barre di materiale compositeo fibroinforzato," University of Salerno, Fisciano, Italy, 2010. 
[32] A. Cladera and A. Marí, "Shear design procedure for reinforced normal and high-strength concrete beams using artificial neural networks. part I: Beams without stirrups," Eng. Struct., vol. 26, no. 7, pp. 917-926, 2004.

[33] A. Cladera and A. Marí, "Shear design procedure for reinforced normal and high-strength concrete beams using artificial neural networks. part II: Beams with stirrups," Eng. Struct., vol. 26, no. 7, pp. 927-936, 2004.

[34] A. Cladera and A. Marí, "Experimental study on high-strength concrete beams failing in shear," Eng. Struct., vol. 27, no. 10, pp. 1519-1527, 2005.

[35] M. Guadagnini, K. Pilakoutas, and P. Waldron, "Shear Resistance of FRP RC Beams: Experimental Study," Journal of Composites for Construction, vol. 10, no. 6. pp. 464-473, 2006.

[36] P. D. Zararis and G. C. Papadakis, "Diagonal shear failure and size effect in RC beams without shear reinforcement,” J. Struct. Eng., vol. 127, no. 7, pp. 733-742, 2001.

[37] K. Maruyama and W. Zhao, "Size effect in shear behavior of FRP reinforced concrete beams," in Advanced composite materials in bridges and structures, 1996, pp. 227-234.

[38] P. Vijay, S. Jumar, and G. HVS, "Shear and ductility behavior of concrete beams reinforced with GFRP rebars," in Advanced composite materials in bridges and structures., 1996, pp. 217-227.

[39] K. Maruyama and W. J. Zhao, "Flexural and shear behaviour of concrete beams reinforced with FRP rods," in Corrosion and corrosion protection of steel in concrete, 1994, pp. 1330-1339.

[40] H. Nakamura and T. Higai, "Evaluation of shear strength of concrete beams reinforced with FRP," in Proceedings of Japanese Society of Civil Engineers, 1995, pp. 111-123.

[41] S. H. Alsayed, Y. A. Al-Salloum, and T. H. Almusallam, "Shear design for beams reinforced by GFRP bars," in Third international symposium on non-metallic (FRP) reinforcement for concrete structures, 1997, pp. 285-292.

[42] N. Duranovic, K. Pilakoutas, and P. Waldron, "Tests on concrete beams reinforced with glass fibre reinforced plastic bars," in Proceedings of the 3rd International symposium on non-metallic FRP reinforcement of concrete structures (FRPRCS-3), 1997, pp. 479-486.

[43] T. Alkhrdaji, M. Wideman, A. Belarbi, and A. Nanni, "Shear strength of GFRP RC beams and slabs," in Composites in Constructions, 2001, pp. 409-414.

[44] S. H. Alsayed, "Flexural behaviour of concrete beams reinforced with GFRP bars," Cem. Concr. Compos., vol. 20, no. 1, pp. 1-11, 1998.

[45] F. Matta, A. Nanni, T. M. Hernandez, and B. Benmokrane, "Scaling of strength of FRP reinforced concrete beams without shear reinforcement," in Fourth International Conference on FRP Composites in Civil Engineering (CICE 2008), 2008.

[46] L. Ascione, G. Mancusi, and S. Spadea, "Flexural behaviour of concrete beams reinforced with GFRP bars," Strain, vol. 46, no. 5, pp. 460-469, 2010.

[47] T. Okamoto, T. Nagasaka, and M. Tanigaki, "Shear capacity of concrete beams using FRP reinforcement,” J. Struct. Constr. Eng., vol. 455, pp. 127-136, 1994. 


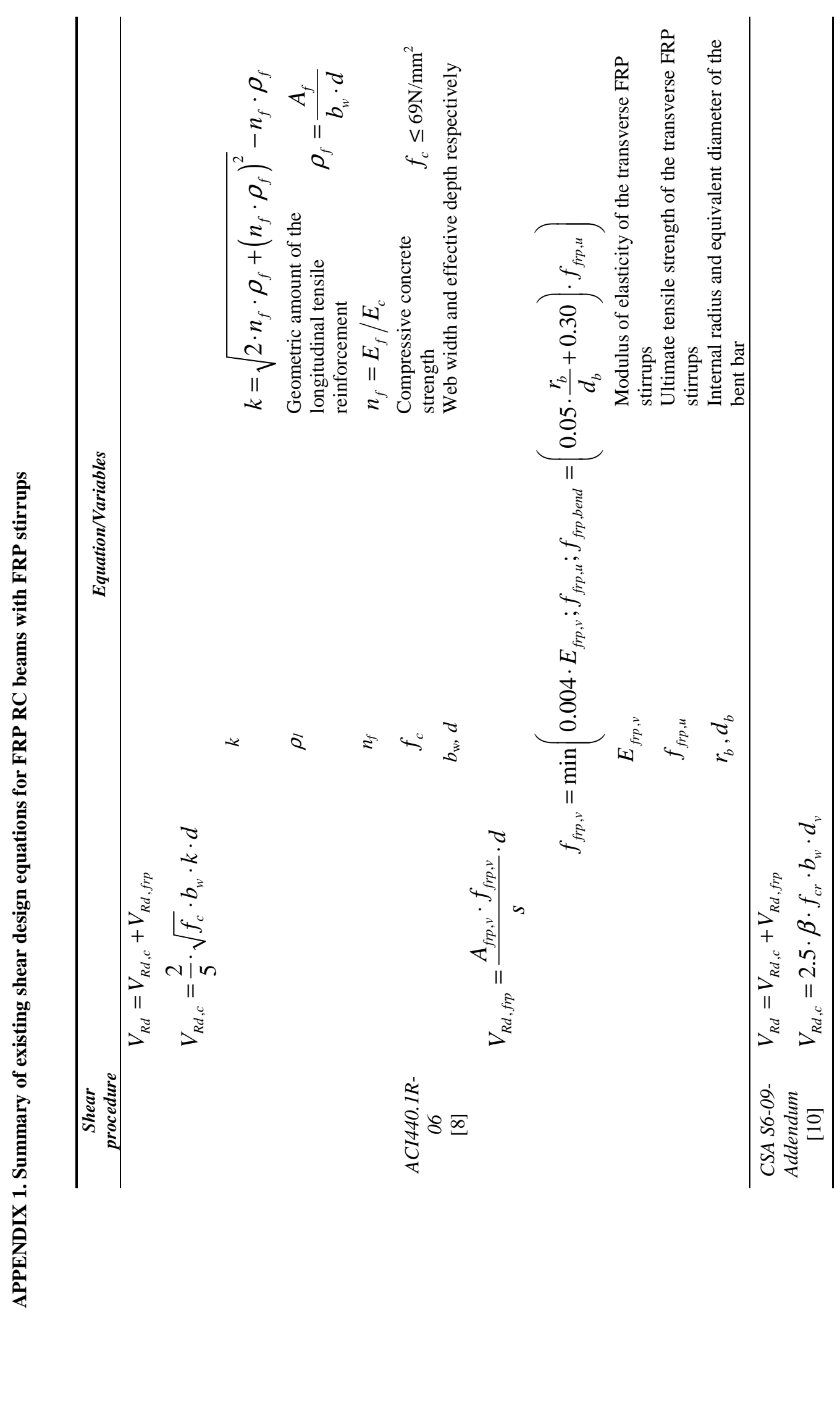




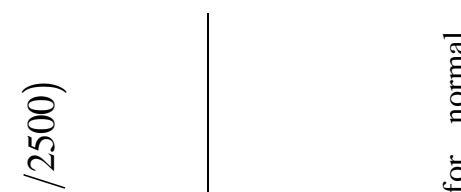

뭉

$\stackrel{\circ}{-}$

它

䆑

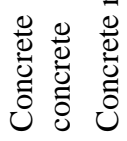

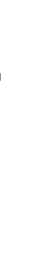

$u^{i} \tau^{2} \theta \quad \omega^{x} \quad n^{\pi} \quad n^{N}$
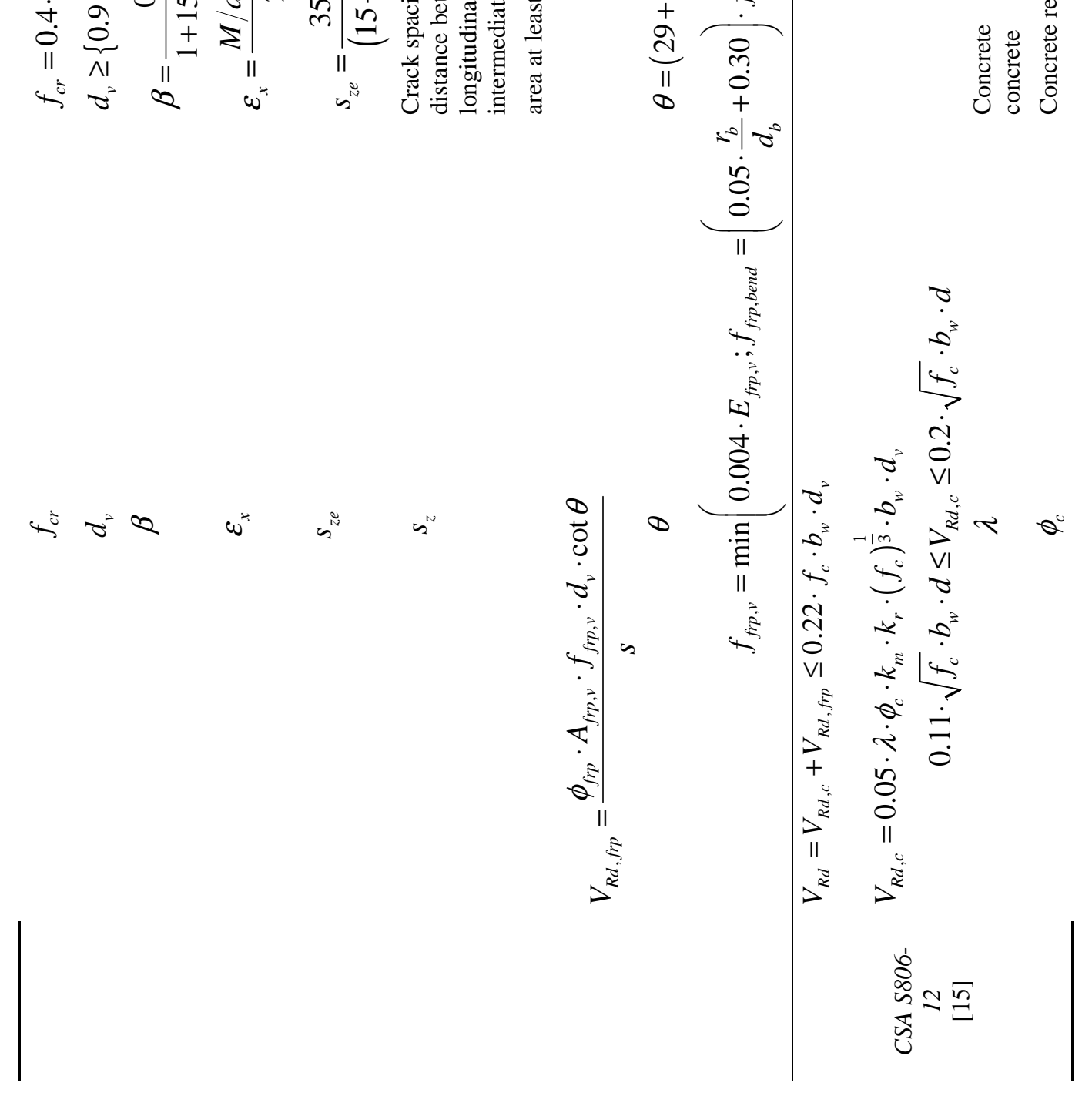


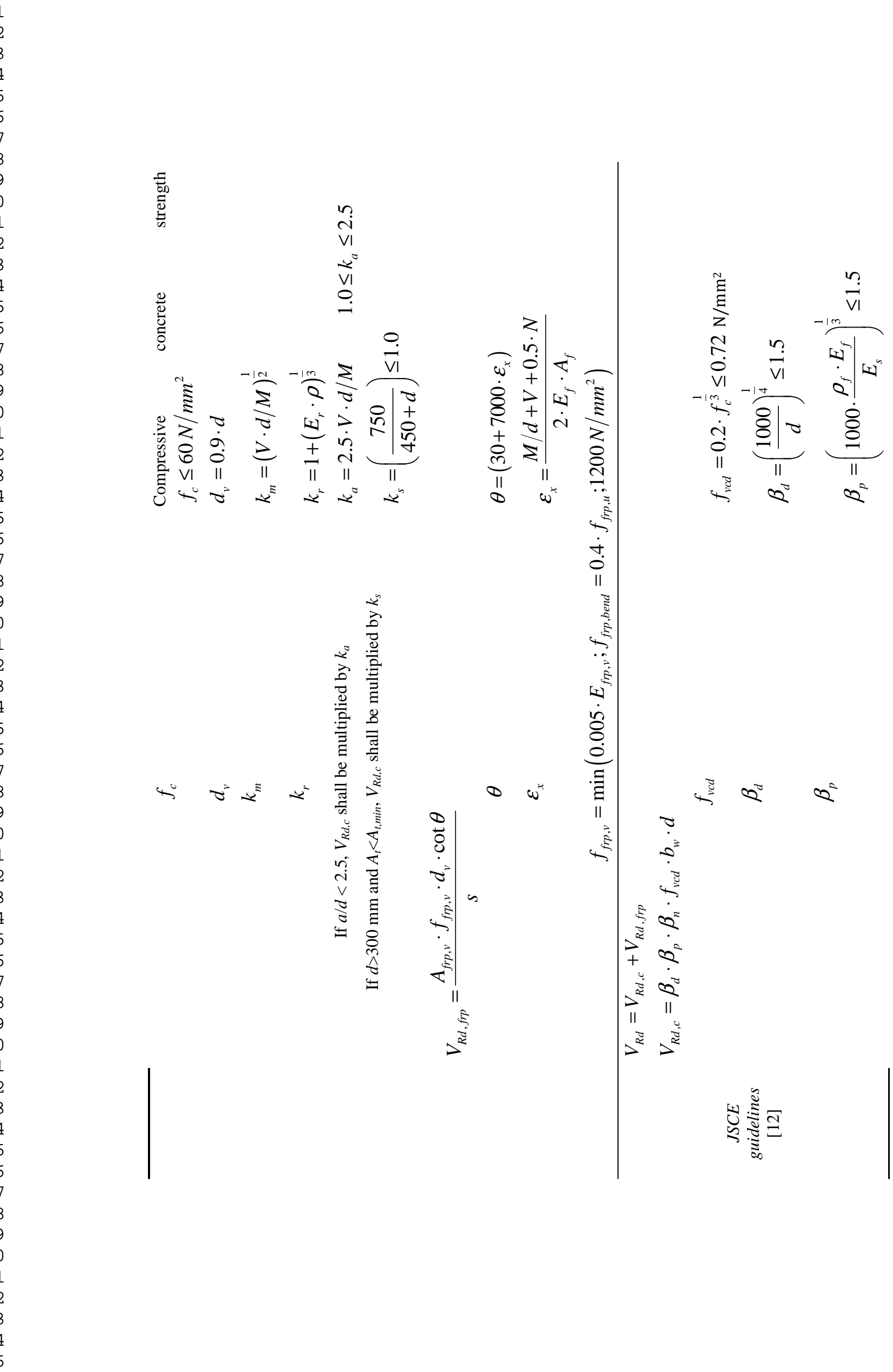




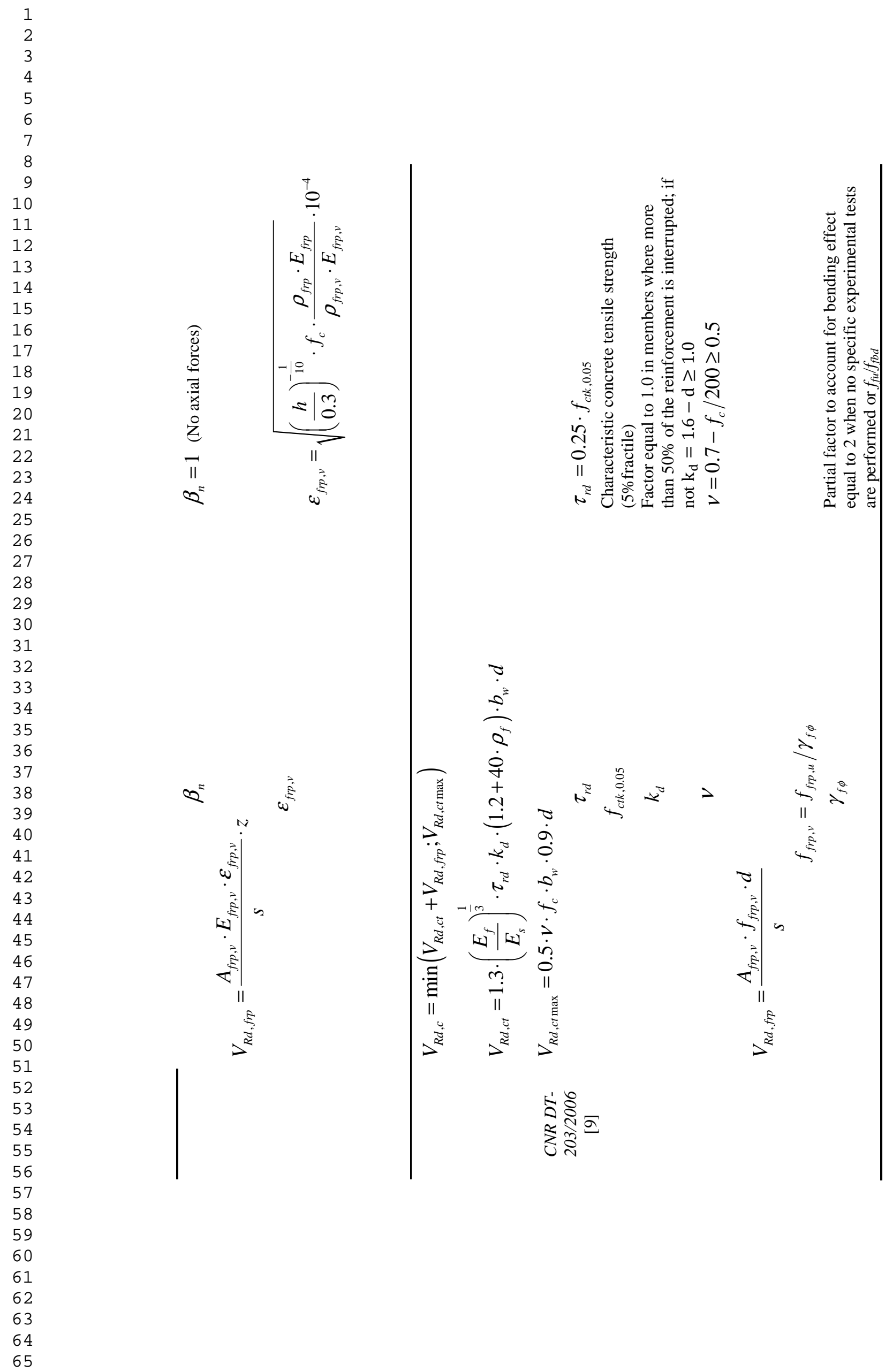




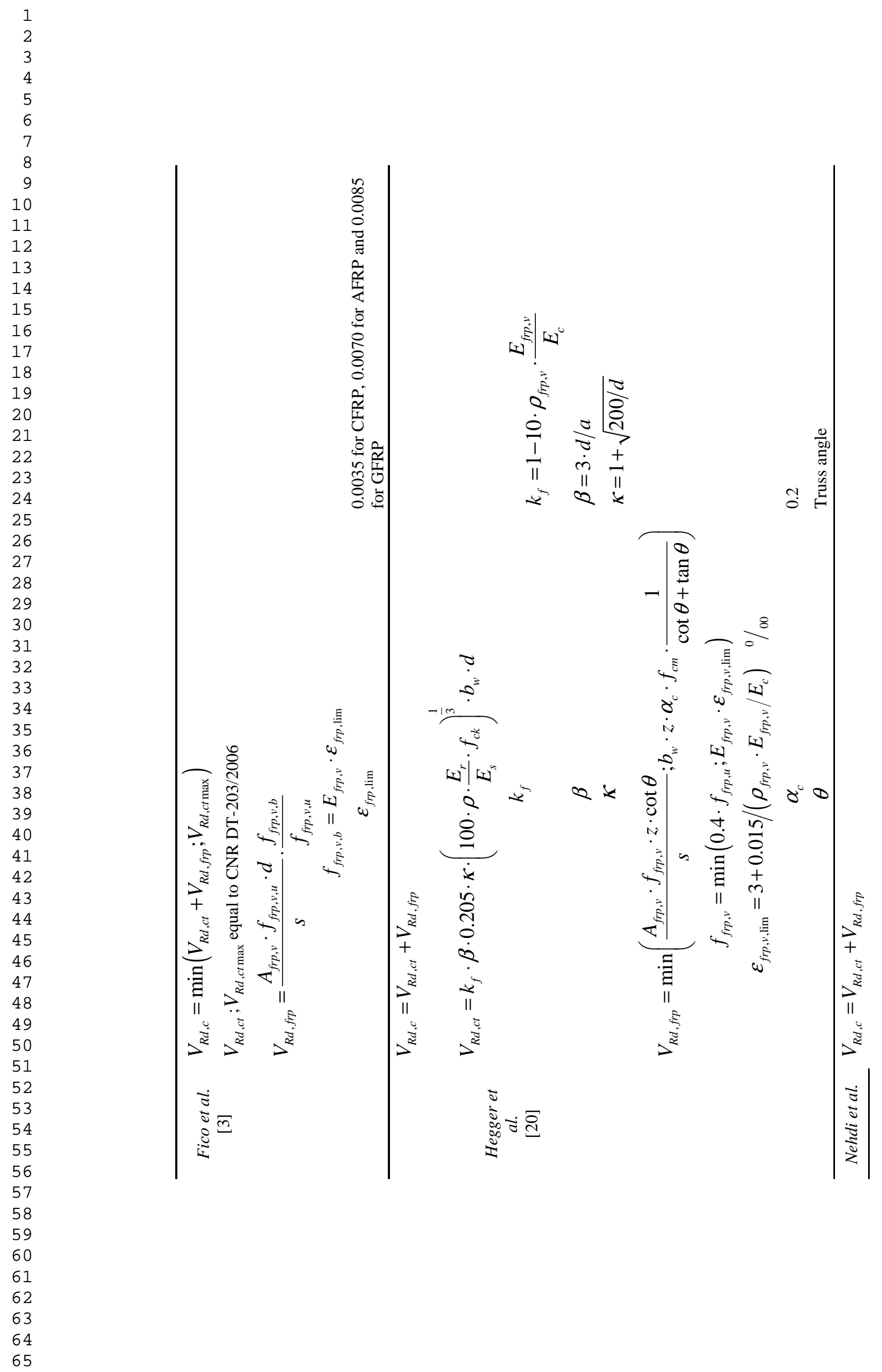




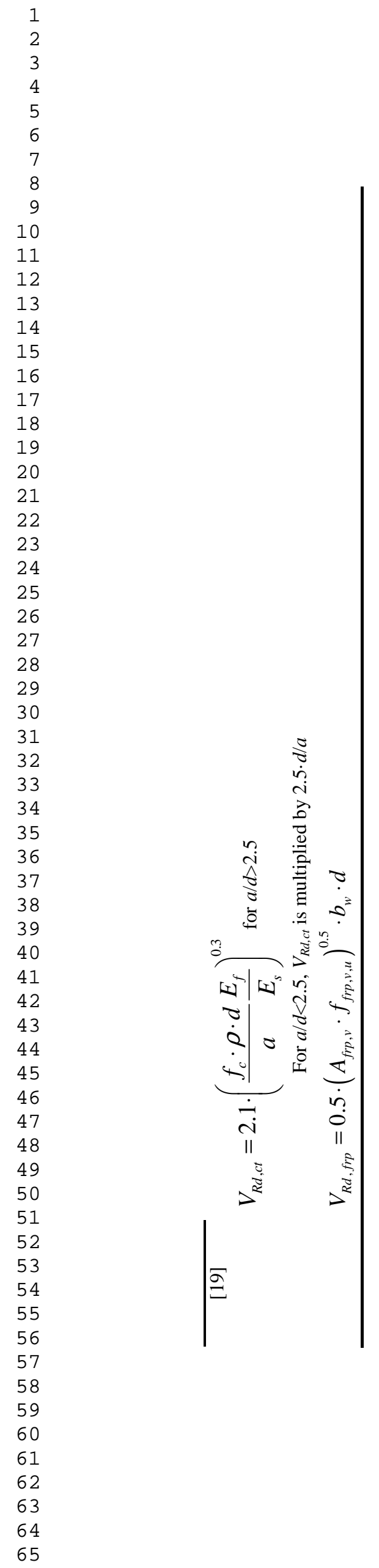


Appendix 2. Database of 112 FRP reinforced concrete beams with FRP stirrups.

\begin{tabular}{|c|c|c|c|c|c|c|c|c|c|c|c|c|c|}
\hline $\begin{array}{c}\text { Beam } \\
\#\end{array}$ & Ref. & $\begin{array}{c}b \\
(\mathbf{m m})\end{array}$ & $\begin{array}{c}d \\
(\mathbf{m m})\end{array}$ & $\begin{array}{c}f_{c} \\
\text { (MPa) }\end{array}$ & $\underset{(\%)}{\rho}$ & $\begin{array}{c}E_{r} \\
(\mathbf{G P a})\end{array}$ & $\begin{array}{c}\rho_{t} \\
(\%)\end{array}$ & $\begin{array}{c}E_{t} \\
(\mathbf{G P a})\end{array}$ & $\begin{array}{c}f_{u . t} \\
(\mathbf{M P a})\end{array}$ & $a / d$ & $\begin{array}{c}V_{\text {test }} \\
(\mathbf{k N})\end{array}$ & $\begin{array}{c}V_{\text {pred }} \\
(\mathbf{k N}) \\
\text { Eqs. } \\
(\mathbf{3 1})- \\
(\mathbf{3 2})\end{array}$ & $V_{\text {test }} / V_{\text {pred }}$ \\
\hline 1 & [4] & 200 & 325 & 44.4 & 0.70 & 137 & 0.15 & 40 & 716 & 3.2 & 103.0 & 107.0 & 0.96 \\
\hline 2 & [4] & 200 & 325 & 44.7 & 0.70 & 137 & 0.15 & 40 & 716 & 3.2 & 106.0 & 107.3 & 0.99 \\
\hline 3 & [4] & 200 & 325 & 44.9 & 0.70 & 137 & 0.07 & 69 & 1511 & 3.2 & 85.0 & 102.0 & 0.83 \\
\hline 4 & [4] & 200 & 325 & 44.6 & 0.70 & 137 & 0.07 & 110 & 1413 & 2.2 & 162.0 & 121.8 & 1.33 \\
\hline 5 & [4] & 200 & 325 & 44.8 & 0.70 & 137 & 0.07 & 110 & 1413 & 3.2 & 83.0 & 117.8 & 0.70 \\
\hline 6 & [4] & 200 & 325 & 44.6 & 0.70 & 137 & 0.07 & 110 & 1413 & 4.3 & 74.0 & 112.9 & 0.66 \\
\hline 7 & [4] & 200 & 325 & 45.0 & 0.70 & 137 & 0.04 & 144 & 2040 & 3.2 & 98.0 & 111.9 & 0.88 \\
\hline 8 & [4] & 200 & 325 & 44.7 & 0.70 & 140 & 0.06 & 137 & 1746 & 3.2 & 108.0 & 119.2 & 0.91 \\
\hline 9 & [4] & 200 & 325 & 44.7 & 0.70 & 140 & 0.10 & 137 & 1746 & 3.2 & 157.0 & 128.3 & 1.22 \\
\hline 10 & [4] & 200 & 325 & 39.4 & 0.70 & 140 & 0.12 & 58 & 1089 & 3.2 & 103.0 & 103.9 & 0.99 \\
\hline 11 & [4] & 200 & 325 & 39.4 & 0.92 & 58 & 0.09 & 58 & 1236 & 3.2 & 83.0 & 87.7 & 0.95 \\
\hline 12 & [4] & 200 & 325 & 39.4 & 0.92 & 58 & 0.13 & 58 & 1236 & 3.2 & 98.0 & 94.0 & 1.04 \\
\hline 13 & [4] & 200 & 325 & 39.4 & 0.92 & 58 & 0.23 & 58 & 1236 & 3.2 & 132.0 & 110.0 & 1.20 \\
\hline 14 & [4] & 200 & 325 & 39.4 & 0.92 & 58 & 0.12 & 58 & 1089 & 3.2 & 107.0 & 93.3 & 1.15 \\
\hline 15 & [4] & 200 & 325 & 39.4 & 0.92 & 58 & 0.12 & 58 & 1089 & 3.2 & 78.0 & 93.3 & 0.84 \\
\hline 16 & [4] & 200 & 325 & 39.4 & 0.92 & 58 & 0.04 & 137 & 1746 & 3.2 & 86.0 & 98.1 & 0.88 \\
\hline 17 & [4] & 150 & 250 & 35.5 & 0.55 & 94 & 0.12 & 94 & 1283 & 2.5 & 58.0 & 66.3 & 0.88 \\
\hline 18 & [4] & 150 & 250 & 37.6 & 0.55 & 94 & 0.24 & 94 & 1283 & 2.5 & 82.0 & 79.1 & 1.04 \\
\hline 19 & [4] & 150 & 250 & 34.3 & 1.05 & 94 & 0.12 & 94 & 1283 & 2.5 & 71.0 & 72.8 & 0.97 \\
\hline 20 & [4] & 150 & 250 & 34.2 & 2.11 & 94 & 0.12 & 94 & 1283 & 2.5 & 81.0 & 82.9 & 0.98 \\
\hline 21 & [4] & 300 & 500 & 31.9 & 0.53 & 94 & 0.06 & 94 & 1283 & 2.5 & 160.0 & 172.0 & 0.93 \\
\hline 22 & [4] & 150 & 260 & 42.2 & 3.08 & 63 & 0.13 & 53 & 1766 & 3.1 & 60.0 & 80.8 & 0.74 \\
\hline 23 & [4] & 200 & 250 & 82.5 & 0.93 & 137 & 0.38 & 53 & 1278 & 3.0 & 172.2 & 131.5 & 1.31 \\
\hline 24 & [4] & 200 & 250 & 84.2 & 0.93 & 137 & 0.15 & 137 & 1278 & 3.0 & 194.2 & 138.6 & 1.40 \\
\hline 25 & [4] & 200 & 250 & 84.2 & 0.93 & 137 & 0.27 & 53 & 1278 & 3.0 & 140.3 & 117.3 & 1.20 \\
\hline 26 & [4] & 200 & 250 & 82.5 & 0.93 & 137 & 0.12 & 137 & 1278 & 3.0 & 182.9 & 134.7 & 1.36 \\
\hline 27 & {$[17]$} & 250 & 253 & 28.9 & 1.89 & 56 & 0.50 & 112 & 1284 & 1.2 & 246.0 & 191.6 & 1.28 \\
\hline 28 & [17] & 250 & 253 & 34.0 & 1.89 & 56 & 1.00 & 112 & 1284 & 1.2 & 310.7 & 281.7 & 1.10 \\
\hline 29 & {$[17]$} & 250 & 253 & 32.8 & 1.89 & 56 & 1.48 & 112 & 1284 & 1.2 & 358.7 & 359.4 & 1.00 \\
\hline 30 & {$[17]$} & 250 & 253 & 28.9 & 1.89 & 56 & 0.50 & 112 & 1284 & 1.8 & 203.8 & 189.9 & 1.07 \\
\hline 31 & {$[17]$} & 250 & 253 & 28.9 & 1.89 & 56 & 1.00 & 112 & 1284 & 1.8 & 276.4 & 246.4 & 1.12 \\
\hline 32 & [17] & 250 & 253 & 28.9 & 1.89 & 56 & 1.48 & 112 & 1284 & 1.8 & 282.2 & 246.4 & 1.15 \\
\hline 33 & {$[17]$} & 250 & 253 & 32.8 & 1.89 & 56 & 0.50 & 112 & 1284 & 2.4 & 158.8 & 193.9 & 0.82 \\
\hline 34 & [17] & 250 & 253 & 32.8 & 1.89 & 56 & 1.00 & 112 & 1284 & 2.4 & 229.3 & 201.1 & 1.14 \\
\hline 35 & {$[17]$} & 250 & 253 & 33.4 & 1.89 & 56 & 0.50 & 60 & 1372 & 1.8 & 200.9 & 176.9 & 1.14 \\
\hline 36 & {$[17]$} & 250 & 253 & 34.7 & 1.89 & 56 & 1.00 & 60 & 1372 & 1.8 & 271.5 & 266.4 & 1.02 \\
\hline 37 & {$[17]$} & 250 & 253 & 33.4 & 1.89 & 56 & 0.50 & 44 & 715 & 1.8 & 169.5 & 145.0 & 1.17 \\
\hline 38 & {$[17]$} & 250 & 253 & 33.4 & 1.89 & 56 & 1.00 & 44 & 715 & 1.8 & 243.0 & 190.9 & 1.27 \\
\hline 39 & {$[17]$} & 250 & 253 & 34.7 & 1.89 & 56 & 0.50 & 46 & 1352 & 1.8 & 175.4 & 171.4 & 1.02 \\
\hline 40 & {$[17]$} & 250 & 253 & 36.0 & 1.89 & 56 & 1.00 & 46 & 1352 & 1.8 & 228.3 & 259.5 & 0.88 \\
\hline 41 & {$[17]$} & 250 & 253 & 23.5 & 1.89 & 56 & 1.00 & 112 & 1284 & 1.8 & 206.8 & 214.3 & 0.96 \\
\hline 42 & [17] & 250 & 253 & 22.5 & 1.89 & 56 & 1.48 & 112 & 1284 & 1.8 & 221.5 & 208.2 & 1.06 \\
\hline 43 & {$[17]$} & 250 & 253 & 24.3 & 1.89 & 56 & 1.00 & 112 & 1284 & 2.4 & 182.3 & 164.4 & 1.11 \\
\hline 44 & [17] & 250 & 253 & 22.9 & 1.89 & 56 & 1.48 & 112 & 1284 & 2.4 & 191.1 & 158.0 & 1.21 \\
\hline 45 & {$[17]$} & 250 & 253 & 22.5 & 1.89 & 56 & 1.00 & 60 & 1372 & 1.8 & 190.1 & 208.2 & 0.91 \\
\hline 46 & [17] & 250 & 253 & 22.5 & 1.89 & 56 & 1.48 & 60 & 1372 & 1.8 & 202.9 & 208.2 & 0.97 \\
\hline 47 & {$[17]$} & 250 & 253 & 23.5 & 1.89 & 56 & 1.00 & 44 & 715 & 1.8 & 190.1 & 176.8 & 1.08 \\
\hline 48 & {$[17]$} & 250 & 253 & 23.5 & 1.89 & 56 & 1.48 & 44 & 715 & 1.8 & 211.7 & 214.3 & 0.99 \\
\hline 49 & {$[17]$} & 250 & 253 & 39.5 & 1.89 & 56 & 1.48 & 112 & 1284 & 1.8 & 292.0 & 302.5 & 0.97 \\
\hline 50 & [17] & 250 & 253 & 39.2 & 1.89 & 56 & 1.48 & 112 & 1284 & 2.4 & 226.4 & 225.8 & 1.00 \\
\hline 51 & {$[28]$} & 150 & 250 & 34.3 & 3.02 & 105 & 0.42 & 39 & 1100 & 3.0 & 113.0 & 100.4 & 1.13 \\
\hline 52 & [28] & 150 & 250 & 34.3 & 3.02 & 105 & 0.42 & 100 & 1300 & 3.0 & 126.0 & 121.6 & 1.04 \\
\hline 53 & {$[28]$} & 150 & 250 & 34.3 & 2.27 & 105 & 0.42 & 39 & 1100 & 3.0 & 116.0 & 95.2 & 1.22 \\
\hline 54 & {$[28]$} & 150 & 250 & 34.3 & 1.51 & 105 & 0.42 & 39 & 1100 & 2.0 & 123.0 & 90.6 & 1.36 \\
\hline 55 & {$[28]$} & 150 & 250 & 34.3 & 1.51 & 105 & 0.42 & 39 & 1100 & 4.0 & 73.0 & 82.7 & 0.88 \\
\hline 56 & [29] & 450 & 937 & 46.0 & 0.51 & 37 & 0.09 & 41 & 760 & 3.3 & 237.0 & 302.7 & 0.78 \\
\hline 57 & [29] & 450 & 857 & 36.0 & 2.23 & 37 & 0.09 & 41 & 760 & 3.6 & 500.0 & 339.9 & 1.47 \\
\hline 58 & [29] & 450 & 405 & 35.0 & 2.36 & 37 & 0.09 & 41 & 760 & 3.8 & 154.0 & 227.1 & 0.68 \\
\hline 59 & {$[30]$} & 300 & 441 & 48.3 & 3.65 & 66 & 0.25 & 32 & 322 & 3.0 & 252.0 & 287.1 & 0.88 \\
\hline 60 & {$[30]$} & 300 & 441 & 48.3 & 3.65 & 66 & 0.54 & 32 & 322 & 3.0 & 362.0 & 312.0 & 1.16 \\
\hline 61 & [30] & 300 & 441 & 43.3 & 3.65 & 66 & 0.38 & 32 & 322 & 3.0 & 240.0 & 284.2 & 0.84 \\
\hline
\end{tabular}




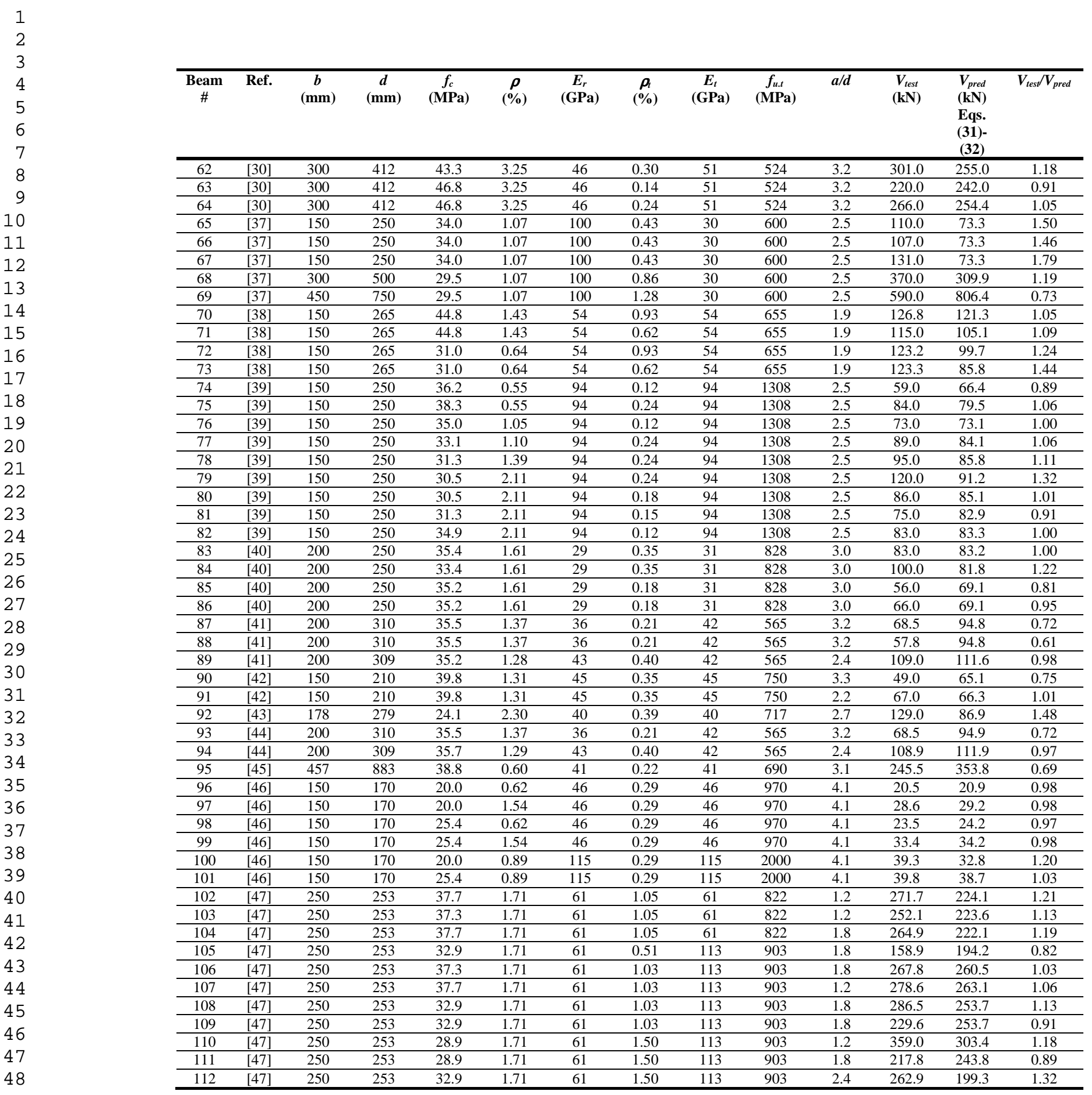


Table 1

Table 1. Range of variables in the compiled database of 112 tests of FRP RC beams with FRP stirrups.

\begin{tabular}{lcc}
\hline & Min & Max \\
\hline$b(\mathrm{~mm})$ & 150 & 457 \\
\hline$d(\mathrm{~mm})$ & 170 & 937 \\
\hline$a / d$ & 1.2 & 4.3 \\
\hline$f_{c}(\mathrm{MPa})$ & 20.0 & 84.2 \\
\hline$\rho(\%)$ & 0.51 & 3.65 \\
\hline$E_{r}(\mathrm{GPa})$ & 29 & 140 \\
\hline$\rho E_{r}(\mathrm{MPa})$ & 34 & 3171 \\
\hline$\rho_{t}(\%)$ & 0.04 & 1.50 \\
\hline$E_{t}(\mathrm{GPa})$ & 30 & 144 \\
\hline$\rho_{t} E_{t}(\mathrm{MPa})$ & 38 & 1695 \\
\hline$V_{u}(\mathrm{kN})$ & 49 & 590 \\
\hline
\end{tabular}


Table 2. Verification of the design procedures

\begin{tabular}{lccccccccc}
\hline \multicolumn{1}{c}{} & \multicolumn{10}{c}{ 112 beams with FRP stirrups } \\
\hline \multicolumn{1}{c}{$\boldsymbol{V}_{\text {tes }} / \boldsymbol{V}_{\text {pred }}$} & $\begin{array}{c}\text { ACI } \\
\mathbf{4 4 0 . 1 R - 0 6} \\
{[8]}\end{array}$ & $\begin{array}{c}\text { CSA S6-09 } \\
\text { Add. }[10]\end{array}$ & $\begin{array}{c}\text { CSA S806- } \\
\mathbf{1 2}\end{array}$ & $\begin{array}{c}\text { JSCE } \\
{[12]}\end{array}$ & $\begin{array}{c}\text { CNR-DT- } \\
\mathbf{2 0 3 / 2 0 0 6} \\
{[9]}\end{array}$ & $\begin{array}{c}\text { Fico et al. } \\
{[3]}\end{array}$ & $\begin{array}{c}\text { Nehdi et al. } \\
{[19]}\end{array}$ & $\begin{array}{c}\text { Hegger et } \\
\text { al. [20] }\end{array}$ & Proposal \\
\hline Average & 1.54 & 2.03 & 1.33 & 2.73 & 0.82 & 0.95 & 1.16 & 1.51 & 1.08 \\
\hline Median & 1.58 & 1.99 & 1.29 & 2.61 & 0.80 & 0.90 & 1.13 & 1.45 & 1.05 \\
\hline Standard Deviation & 0.57 & 0.74 & 0.31 & 0.88 & 0.27 & 0.28 & 0.27 & 0.35 & 0.21 \\
\hline COV $(\boldsymbol{\%})$ & 37.1 & 36.5 & 22.9 & 32.3 & 32.4 & 29.4 & 23.3 & 23.0 & 19.5 \\
\hline Minimum & 0.42 & 0.61 & 0.82 & 1.23 & 0.38 & 0.44 & 0.50 & 0.89 & 0.64 \\
\hline$\left(\boldsymbol{V}_{\text {tes }} / \boldsymbol{V}_{\text {pred }}\right)_{\mathbf{5} \%}$ & 0.62 & 0.91 & 0.97 & 1.53 & 0.46 & 0.53 & 0.75 & 1.02 & 0.75 \\
\hline Maximum & 3.23 & 4.59 & 2.42 & 5.13 & 1.45 & 1.64 & 2.00 & 2.62 & 1.85 \\
\hline$\left(\boldsymbol{V}_{\text {tes }} / \boldsymbol{V}_{\text {pred }}\right)_{\mathbf{9 5} \%}$ & 2.49 & 3.32 & 1.91 & 4.12 & 1.35 & 1.38 & 1.59 & 2.19 & 1.50 \\
\hline
\end{tabular}




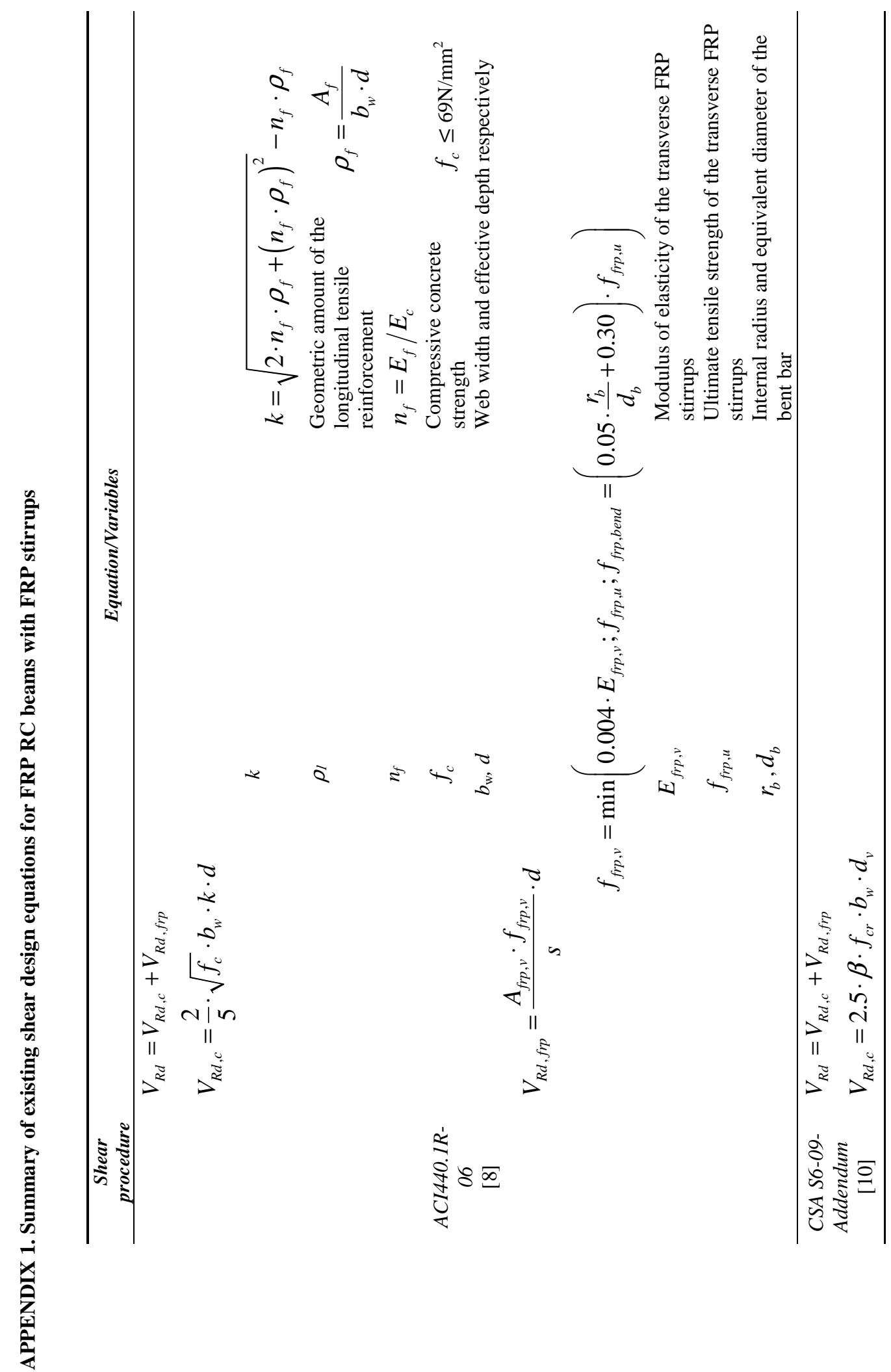




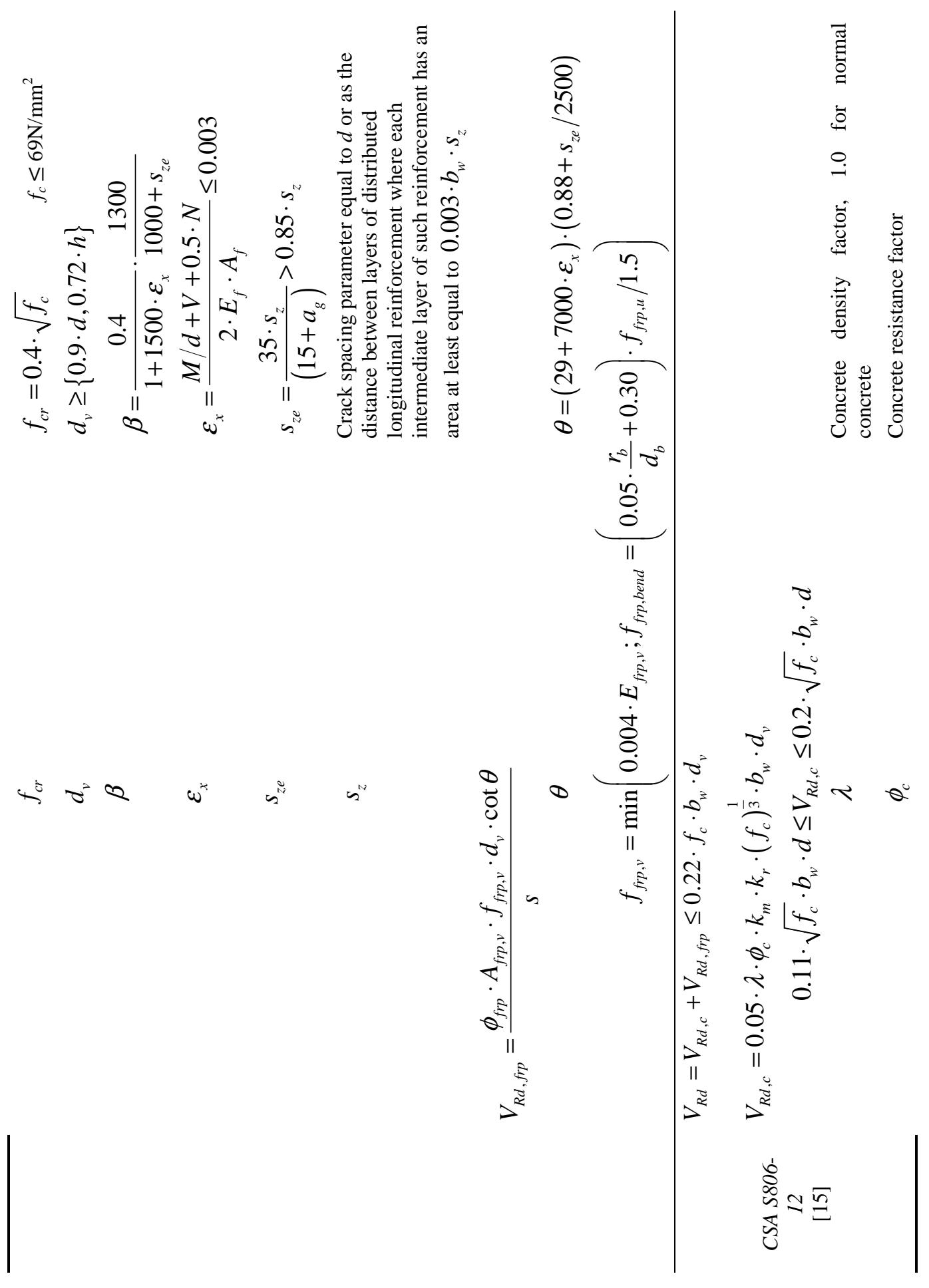




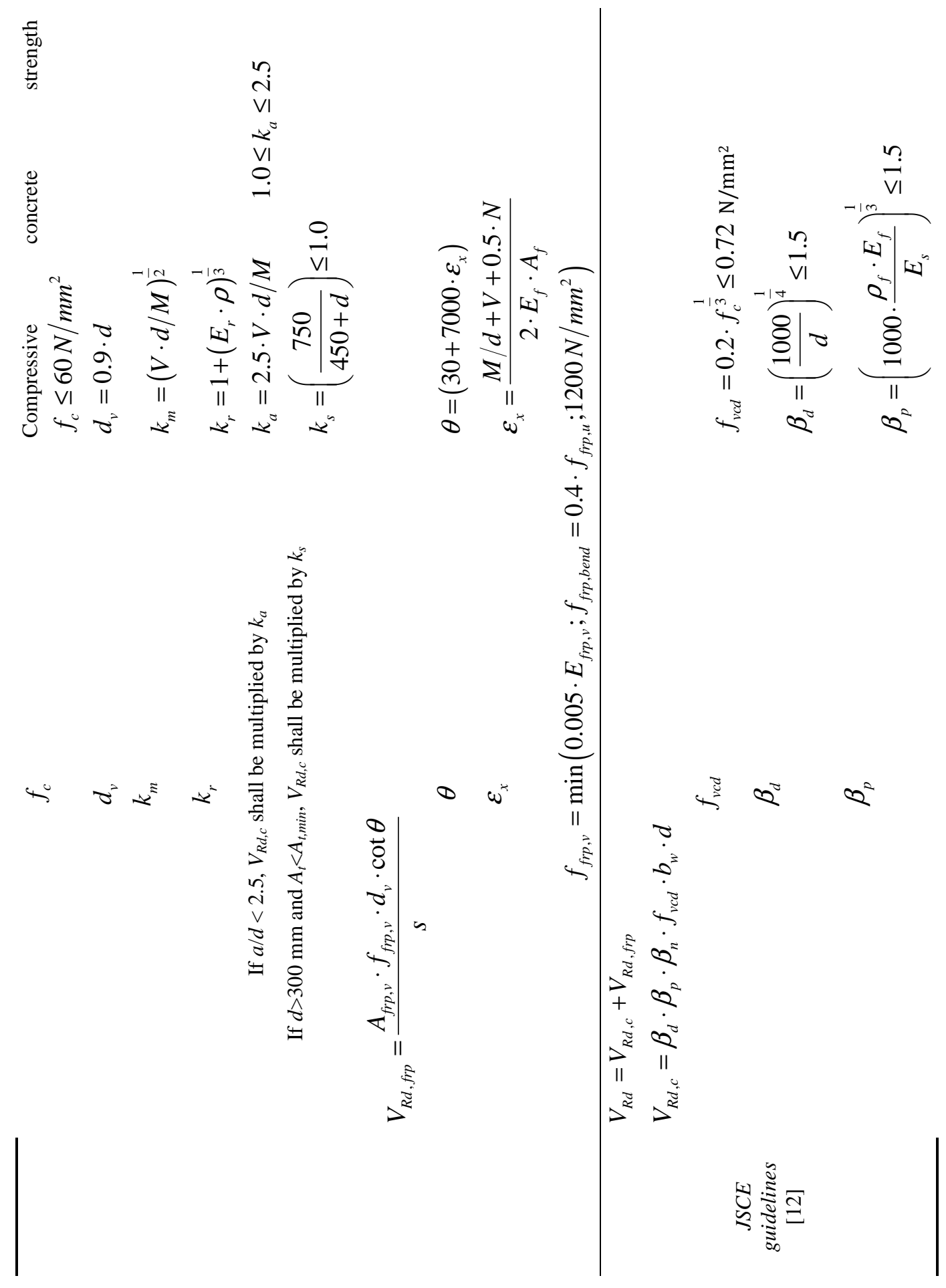




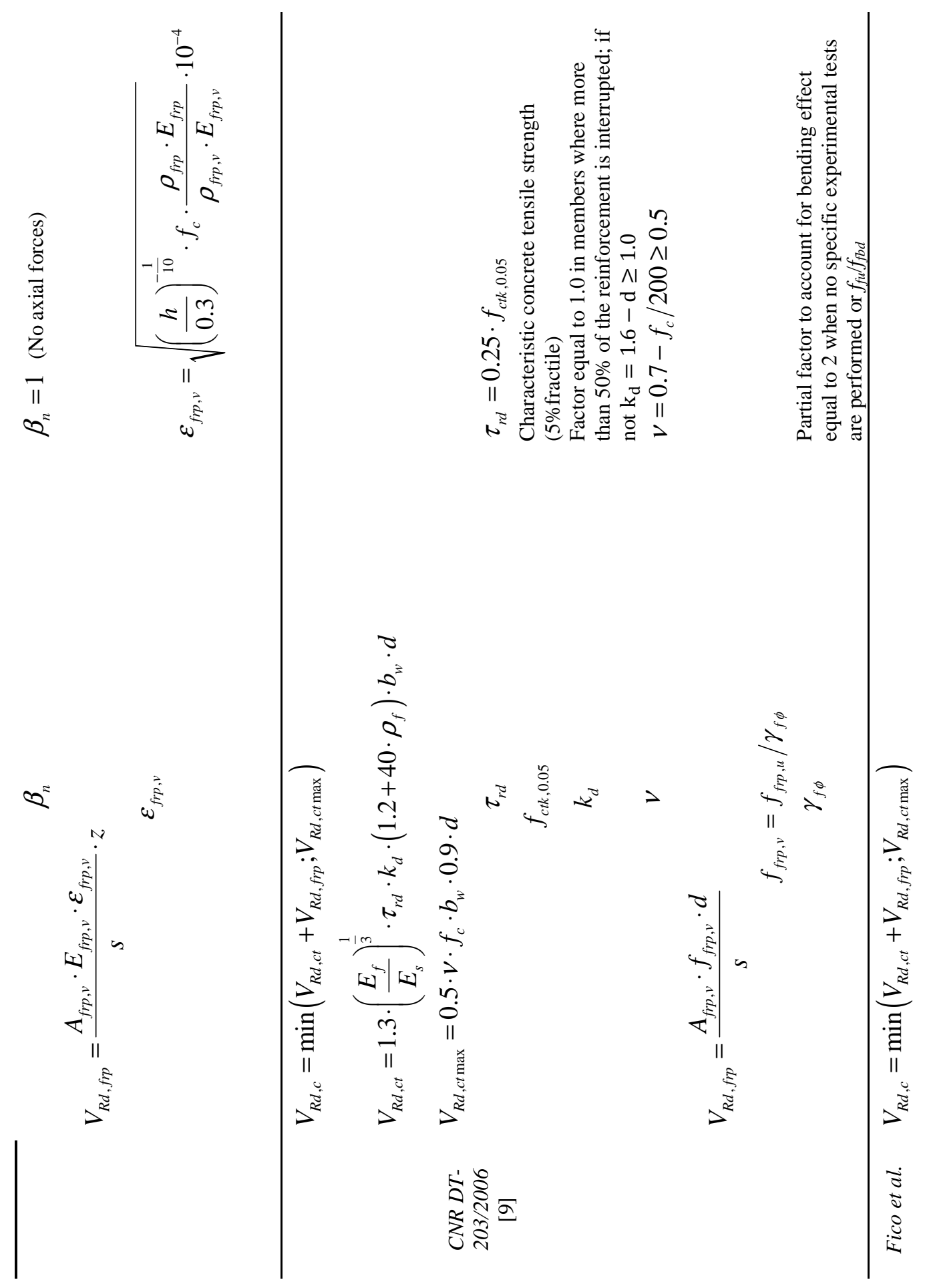




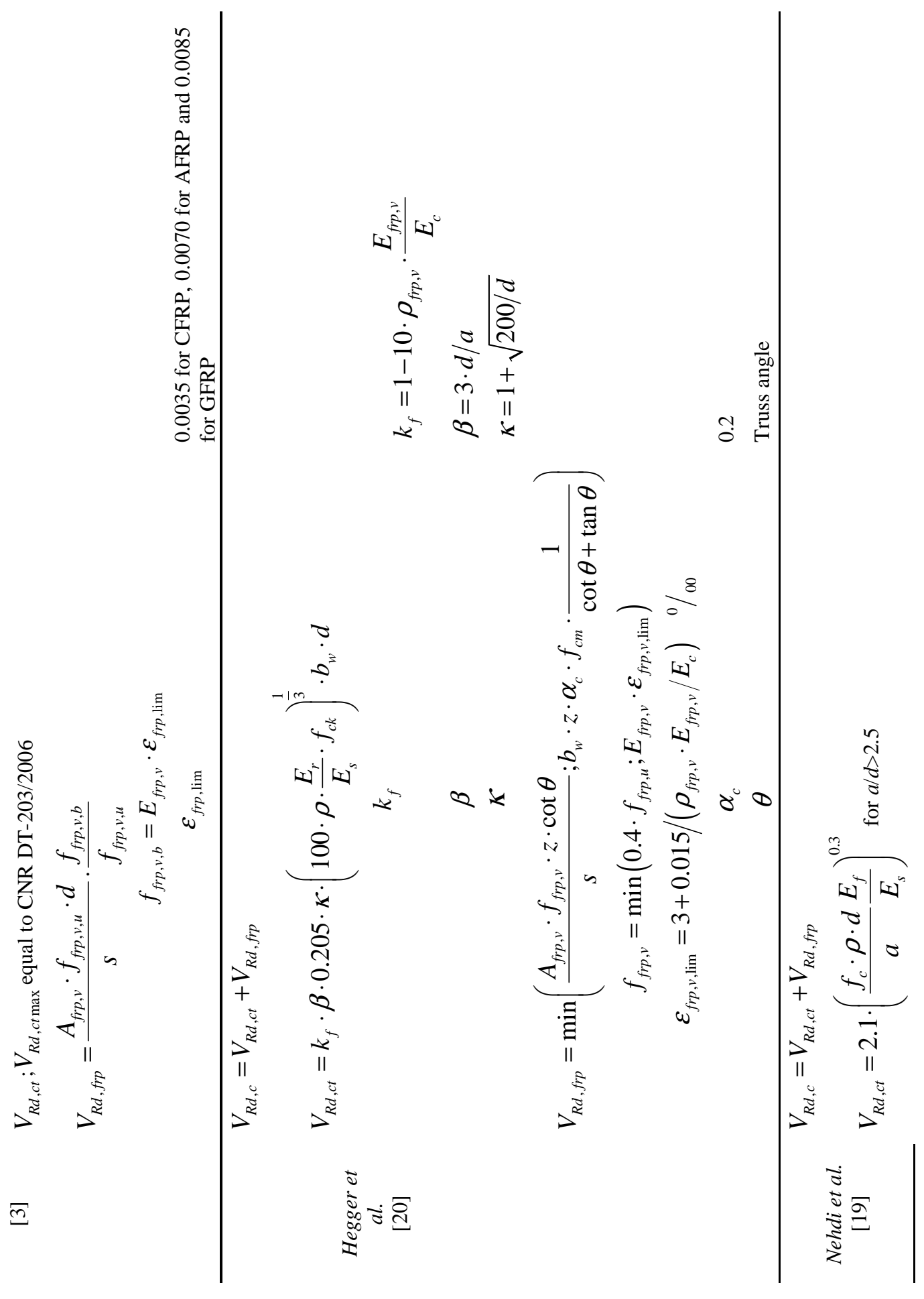




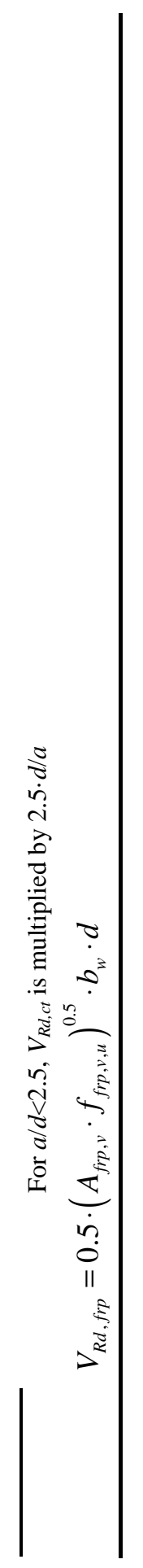


Appendix 2. Database of 112 FRP reinforced concrete beams with FRP stirrups.

\begin{tabular}{|c|c|c|c|c|c|c|c|c|c|c|c|c|c|}
\hline $\begin{array}{c}\text { Beam } \\
\#\end{array}$ & Ref. & $\begin{array}{c}b \\
(\mathbf{m m})\end{array}$ & $\begin{array}{c}d \\
(\mathbf{m m})\end{array}$ & $\begin{array}{c}f_{c} \\
(\mathbf{M P a})\end{array}$ & $\begin{array}{c}\rho \\
(\%)\end{array}$ & $\begin{array}{c}E_{r} \\
(\mathbf{G P a})\end{array}$ & $\begin{array}{c}\rho_{t} \\
(\%)\end{array}$ & $\begin{array}{c}E_{t} \\
(\mathbf{G P a})\end{array}$ & $\begin{array}{c}f_{u . t} \\
(\mathbf{M P a})\end{array}$ & $a / d$ & $\begin{array}{c}V_{\text {test }} \\
(\mathbf{k N})\end{array}$ & $\begin{array}{l}V_{\text {pred }} \\
(\mathbf{k N}) \\
\text { Eqs. } \\
(\mathbf{3 1})- \\
(\mathbf{3 2})\end{array}$ & $V_{\text {test }} / V_{\text {pred }}$ \\
\hline 1 & [4] & 200 & 325 & 44.4 & 0.70 & 137 & 0.15 & 40 & 716 & 3.2 & 103.0 & 107.0 & 0.96 \\
\hline 2 & {$[4]$} & 200 & 325 & 44.7 & 0.70 & 137 & 0.15 & 40 & 716 & 3.2 & 106.0 & 107.3 & 0.99 \\
\hline 3 & [4] & 200 & 325 & 44.9 & 0.70 & 137 & 0.07 & 69 & 1511 & 3.2 & 85.0 & 102.0 & 0.83 \\
\hline 4 & [4] & 200 & 325 & 44.6 & 0.70 & 137 & 0.07 & 110 & 1413 & 2.2 & 162.0 & 121.8 & 1.33 \\
\hline 5 & [4] & 200 & 325 & 44.8 & 0.70 & 137 & 0.07 & 110 & 1413 & 3.2 & 83.0 & 117.8 & 0.70 \\
\hline 6 & {$[4]$} & 200 & 325 & 44.6 & 0.70 & 137 & 0.07 & 110 & 1413 & 4.3 & 74.0 & 112.9 & 0.66 \\
\hline 7 & {$[4]$} & 200 & 325 & 45.0 & 0.70 & 137 & 0.04 & 144 & 2040 & 3.2 & $\begin{array}{l}98.0 \\
\end{array}$ & 111.9 & 0.88 \\
\hline 8 & {$[4]$} & 200 & 325 & 44.7 & 0.70 & 140 & 0.06 & 137 & 1746 & 3.2 & 108.0 & 119.2 & 0.91 \\
\hline 9 & {$[4]$} & 200 & 325 & 44.7 & 0.70 & 140 & 0.10 & 137 & 1746 & 3.2 & 157.0 & 128.3 & 1.22 \\
\hline 10 & {$[4]$} & 200 & 325 & 39.4 & 0.70 & 140 & 0.12 & 58 & 1089 & 3.2 & 103.0 & 103.9 & 0.99 \\
\hline 11 & [4] & 200 & 325 & 39.4 & 0.92 & 58 & $\begin{array}{l}0.09 \\
\end{array}$ & 58 & 1236 & 3.2 & $\begin{array}{l}83.0 \\
\end{array}$ & 87.7 & 0.95 \\
\hline 12 & {$[4]$} & 200 & 325 & 39.4 & 0.92 & 58 & 0.13 & 58 & 1236 & 3.2 & 98.0 & $\begin{array}{l}94.0 \\
\end{array}$ & 1.04 \\
\hline 13 & {$[4]$} & 200 & 325 & 39.4 & 0.92 & 58 & 0.23 & 58 & 1236 & 3.2 & 132.0 & 110.0 & 1.20 \\
\hline 14 & {$[4]$} & 200 & 325 & 39.4 & 0.92 & 58 & 0.12 & 58 & 1089 & 3.2 & 107.0 & $\begin{array}{l}93.3 \\
\end{array}$ & 1.15 \\
\hline 15 & [4] & 200 & 325 & 39.4 & 0.92 & 58 & 0.12 & 58 & 1089 & 3.2 & 78.0 & 93.3 & 0.84 \\
\hline 16 & [4] & 200 & 325 & 39.4 & 0.92 & 58 & 0.04 & 137 & 1746 & 3.2 & 86.0 & $\begin{array}{l}98.1 \\
\end{array}$ & 0.88 \\
\hline 17 & {$[4]$} & 150 & 250 & 35.5 & 0.55 & 94 & 0.12 & 94 & 1283 & 2.5 & 58.0 & 66.3 & 0.88 \\
\hline 18 & [4] & 150 & 250 & 37.6 & 0.55 & 94 & 0.24 & 94 & 1283 & 2.5 & 82.0 & 79.1 & 1.04 \\
\hline 19 & [4] & 150 & 250 & 34.3 & 1.05 & 94 & 0.12 & 94 & 1283 & 2.5 & 71.0 & 72.8 & 0.97 \\
\hline 20 & {$[4]$} & 150 & 250 & 34.2 & 2.11 & 94 & 0.12 & 94 & 1283 & 2.5 & 81.0 & 82.9 & 0.98 \\
\hline 21 & [4] & 300 & 500 & 31.9 & 0.53 & 94 & 0.06 & 94 & 1283 & 2.5 & 160.0 & 172.0 & 0.93 \\
\hline 22 & {$[4]$} & 150 & 260 & 42.2 & 3.08 & 63 & 0.13 & 53 & 1766 & 3.1 & 60.0 & 80.8 & 0.74 \\
\hline 23 & [4] & 200 & 250 & 82.5 & 0.93 & 137 & 0.38 & 53 & 1278 & 3.0 & 172.2 & 131.5 & 1.31 \\
\hline 24 & {$[4]$} & 200 & 250 & 84.2 & 0.93 & 137 & 0.15 & 137 & 1278 & 3.0 & 194.2 & 138.6 & 1.40 \\
\hline 25 & [4] & 200 & 250 & 84.2 & 0.93 & 137 & 0.27 & 53 & 1278 & 3.0 & 140.3 & 117.3 & 1.20 \\
\hline 26 & [4] & 200 & 250 & 82.5 & 0.93 & 137 & 0.12 & 137 & 1278 & 3.0 & 182.9 & 134.7 & 1.36 \\
\hline 27 & {$[17]$} & 250 & 253 & 28.9 & 1.89 & 56 & 0.50 & 112 & 1284 & 1.2 & 246.0 & 191.6 & 1.28 \\
\hline 28 & {$[17]$} & 250 & 253 & 34.0 & 1.89 & 56 & 1.00 & 112 & 1284 & 1.2 & 310.7 & 281.7 & 1.10 \\
\hline 29 & {$[17]$} & 250 & 253 & 32.8 & 1.89 & 56 & 1.48 & 112 & 1284 & 1.2 & 358.7 & 359.4 & 1.00 \\
\hline 30 & {$[17]$} & 250 & 253 & 28.9 & 1.89 & 56 & 0.50 & 112 & 1284 & 1.8 & 203.8 & 189.9 & 1.07 \\
\hline 31 & {$[17]$} & 250 & 253 & 28.9 & 1.89 & 56 & 1.00 & 112 & 1284 & 1.8 & 276.4 & 246.4 & 1.12 \\
\hline 32 & [17] & 250 & 253 & 28.9 & 1.89 & 56 & 1.48 & 112 & 1284 & 1.8 & 282.2 & 246.4 & 1.15 \\
\hline 33 & {$[17]$} & 250 & 253 & 32.8 & 1.89 & 56 & 0.50 & 112 & 1284 & 2.4 & 158.8 & 193.9 & 0.82 \\
\hline 34 & {$[17]$} & 250 & 253 & 32.8 & 1.89 & 56 & 1.00 & 112 & 1284 & 2.4 & 229.3 & 201.1 & 1.14 \\
\hline 35 & {$[17]$} & 250 & 253 & 33.4 & 1.89 & 56 & 0.50 & 60 & 1372 & 1.8 & 200.9 & 176.9 & 1.14 \\
\hline 36 & {$[17]$} & 250 & 253 & 34.7 & 1.89 & 56 & 1.00 & 60 & 1372 & 1.8 & 271.5 & 266.4 & 1.02 \\
\hline 37 & {$[17]$} & 250 & 253 & 33.4 & 1.89 & 56 & 0.50 & 44 & 715 & 1.8 & 169.5 & 145.0 & 1.17 \\
\hline 38 & {$[17]$} & 250 & 253 & 33.4 & 1.89 & 56 & 1.00 & 44 & 715 & 1.8 & 243.0 & 190.9 & 1.27 \\
\hline 39 & [17] & 250 & 253 & 34.7 & 1.89 & 56 & 0.50 & 46 & 1352 & 1.8 & 175.4 & 171.4 & 1.02 \\
\hline 40 & [17] & 250 & 253 & 36.0 & 1.89 & 56 & 1.00 & 46 & 1352 & 1.8 & 228.3 & 259.5 & 0.88 \\
\hline 41 & {$[17]$} & 250 & 253 & 23.5 & 1.89 & 56 & 1.00 & 112 & 1284 & 1.8 & 206.8 & 214.3 & 0.96 \\
\hline 42 & [17] & 250 & 253 & 22.5 & 1.89 & 56 & 1.48 & 112 & 1284 & 1.8 & 221.5 & 208.2 & 1.06 \\
\hline 43 & {$[17]$} & 250 & 253 & 24.3 & 1.89 & 56 & 1.00 & 112 & 1284 & 2.4 & 182.3 & 164.4 & 1.11 \\
\hline 44 & $\begin{array}{l}{[17]} \\
\end{array}$ & 250 & 253 & 22.9 & 1.89 & 56 & 1.48 & 112 & 1284 & 2.4 & 191.1 & 158.0 & 1.21 \\
\hline 45 & [17] & 250 & 253 & 22.5 & 1.89 & 56 & 1.00 & 60 & 1372 & 1.8 & 190.1 & 208.2 & 0.91 \\
\hline 46 & [17] & 250 & 253 & 22.5 & 1.89 & 56 & 1.48 & 60 & 1372 & $\begin{array}{l}1.8 \\
\end{array}$ & 202.9 & 208.2 & 0.97 \\
\hline 47 & [17] & 250 & 253 & 23.5 & 1.89 & 56 & 1.00 & 44 & 715 & 1.8 & 190.1 & 176.8 & 1.08 \\
\hline 48 & {$[17]$} & 250 & 253 & 23.5 & 1.89 & 56 & 1.48 & 44 & 715 & 1.8 & 211.7 & 214.3 & 0.99 \\
\hline 49 & [17] & 250 & 253 & 39.5 & 1.89 & 56 & 1.48 & 112 & 1284 & 1.8 & 292.0 & 302.5 & 0.97 \\
\hline 50 & [17] & 250 & 253 & 39.2 & 1.89 & 56 & 1.48 & 112 & 1284 & 2.4 & 226.4 & 225.8 & 1.00 \\
\hline 51 & {$[28]$} & 150 & 250 & 34.3 & 3.02 & 105 & 0.42 & 39 & 1100 & 3.0 & 113.0 & 100.4 & 1.13 \\
\hline 52 & {$[28]$} & 150 & 250 & 34.3 & 3.02 & 105 & 0.42 & 100 & 1300 & 3.0 & 126.0 & 121.6 & 1.04 \\
\hline 53 & [28] & 150 & 250 & 34.3 & 2.27 & 105 & 0.42 & 39 & 1100 & 3.0 & 116.0 & 95.2 & 1.22 \\
\hline 54 & {$[28]$} & 150 & 250 & 34.3 & 1.51 & 105 & 0.42 & 39 & 1100 & 2.0 & 123.0 & 90.6 & 1.36 \\
\hline 55 & {$[28]$} & 150 & 250 & 34.3 & 1.51 & 105 & 0.42 & 39 & 1100 & 4.0 & 73.0 & 82.7 & 0.88 \\
\hline 56 & [29] & 450 & 937 & 46.0 & 0.51 & 37 & 0.09 & 41 & 760 & 3.3 & 237.0 & 302.7 & 0.78 \\
\hline 57 & {$[29]$} & 450 & 857 & 36.0 & 2.23 & 37 & $\begin{array}{l}0.09 \\
\end{array}$ & 41 & 760 & 3.6 & 500.0 & 339.9 & 1.47 \\
\hline 58 & [29] & 450 & 405 & 35.0 & 2.36 & 37 & 0.09 & 41 & 760 & 3.8 & 154.0 & 227.1 & 0.68 \\
\hline 59 & {$[30]$} & 300 & 441 & 48.3 & 3.65 & 66 & 0.25 & 32 & 322 & 3.0 & 252.0 & 287.1 & 0.88 \\
\hline 60 & [30] & 300 & 441 & 48.3 & 3.65 & 66 & 0.54 & 32 & 322 & 3.0 & 362.0 & 312.0 & 1.16 \\
\hline 61 & {$[30]$} & 300 & 441 & 43.3 & 3.65 & 66 & 0.38 & 32 & 322 & 3.0 & 240.0 & 284.2 & 0.84 \\
\hline
\end{tabular}




\begin{tabular}{|c|c|c|c|c|c|c|c|c|c|c|c|c|c|}
\hline $\begin{array}{c}\text { Beam } \\
\#\end{array}$ & Ref. & $\begin{array}{c}b \\
(\mathbf{m m})\end{array}$ & $\begin{array}{c}d \\
(\mathbf{m m})\end{array}$ & $\begin{array}{c}f_{c} \\
(\mathbf{M P a})\end{array}$ & $\begin{array}{c}\rho \\
(\%)\end{array}$ & $\begin{array}{c}E_{r} \\
(\mathbf{G P a})\end{array}$ & $\begin{array}{c}\rho_{t} \\
(\%)\end{array}$ & $\begin{array}{c}E_{t} \\
(\mathbf{G P a})\end{array}$ & $\begin{array}{c}f_{u . t} \\
(\mathbf{M P a})\end{array}$ & $a / d$ & $\begin{array}{c}V_{\text {test }} \\
(\mathbf{k N})\end{array}$ & $\begin{array}{c}V_{\text {pred }} \\
(\mathbf{k N}) \\
\text { Eqs. } \\
(\mathbf{3 1})- \\
(32)\end{array}$ & $V_{\text {test }} / V_{\text {pred }}$ \\
\hline 62 & {$[30]$} & 300 & 412 & 43.3 & 3.25 & 46 & 0.30 & 51 & 524 & 3.2 & 301.0 & 255.0 & 1.18 \\
\hline 63 & [30] & 300 & 412 & 46.8 & 3.25 & 46 & 0.14 & 51 & 524 & 3.2 & 220.0 & 242.0 & 0.91 \\
\hline 64 & [30] & 300 & 412 & 46.8 & 3.25 & 46 & 0.24 & 51 & 524 & 3.2 & 266.0 & 254.4 & 1.05 \\
\hline 65 & {$[37]$} & 150 & 250 & 34.0 & 1.07 & 100 & 0.43 & 30 & 600 & 2.5 & 110.0 & 73.3 & 1.50 \\
\hline 66 & [37] & 150 & 250 & 34.0 & 1.07 & 100 & 0.43 & 30 & 600 & 2.5 & 107.0 & 73.3 & 1.46 \\
\hline 67 & [37] & 150 & 250 & 34.0 & 1.07 & 100 & 0.43 & 30 & 600 & 2.5 & 131.0 & 73.3 & 1.79 \\
\hline 68 & [37] & 300 & 500 & 29.5 & 1.07 & 100 & 0.86 & 30 & 600 & 2.5 & 370.0 & 309.9 & 1.19 \\
\hline 69 & [37] & 450 & 750 & 29.5 & 1.07 & 100 & 1.28 & 30 & 600 & 2.5 & 590.0 & 806.4 & 0.73 \\
\hline 70 & [38] & 150 & 265 & 44.8 & 1.43 & 54 & 0.93 & 54 & 655 & 1.9 & 126.8 & 121.3 & 1.05 \\
\hline 71 & {$[38]$} & 150 & 265 & 44.8 & 1.43 & 54 & 0.62 & 54 & 655 & 1.9 & 115.0 & 105.1 & 1.09 \\
\hline 72 & [38] & 150 & 265 & 31.0 & 0.64 & 54 & 0.93 & 54 & 655 & 1.9 & 123.2 & 99.7 & 1.24 \\
\hline 73 & {$[38]$} & 150 & 265 & 31.0 & 0.64 & 54 & 0.62 & 54 & 655 & 1.9 & 123.3 & 85.8 & 1.44 \\
\hline 74 & [39] & 150 & 250 & 36.2 & 0.55 & 94 & 0.12 & 94 & 1308 & 2.5 & 59.0 & 66.4 & 0.89 \\
\hline 75 & [39] & 150 & 250 & 38.3 & 0.55 & 94 & 0.24 & 94 & 1308 & 2.5 & 84.0 & 79.5 & 1.06 \\
\hline 76 & [39] & 150 & 250 & 35.0 & 1.05 & 94 & 0.12 & 94 & 1308 & 2.5 & 73.0 & 73.1 & 1.00 \\
\hline 77 & [39] & 150 & 250 & 33.1 & 1.10 & 94 & 0.24 & 94 & 1308 & 2.5 & 89.0 & 84.1 & 1.06 \\
\hline 78 & [39] & 150 & 250 & 31.3 & 1.39 & 94 & 0.24 & 94 & 1308 & 2.5 & 95.0 & 85.8 & 1.11 \\
\hline 79 & {$[39]$} & 150 & 250 & 30.5 & 2.11 & 94 & 0.24 & 94 & 1308 & 2.5 & 120.0 & 91.2 & 1.32 \\
\hline 80 & [39] & 150 & 250 & 30.5 & 2.11 & 94 & 0.18 & 94 & 1308 & 2.5 & 86.0 & 85.1 & 1.01 \\
\hline 81 & [39] & 150 & 250 & 31.3 & 2.11 & 94 & 0.15 & 94 & 1308 & 2.5 & 75.0 & 82.9 & 0.91 \\
\hline 82 & [39] & 150 & 250 & 34.9 & 2.11 & 94 & 0.12 & 94 & 1308 & 2.5 & 83.0 & 83.3 & 1.00 \\
\hline 83 & [40] & 200 & 250 & 35.4 & 1.61 & 29 & 0.35 & 31 & 828 & 3.0 & 83.0 & 83.2 & 1.00 \\
\hline 84 & {$[40]$} & 200 & 250 & 33.4 & 1.61 & 29 & 0.35 & 31 & 828 & 3.0 & 100.0 & 81.8 & 1.22 \\
\hline 85 & {$[40]$} & 200 & 250 & 35.2 & 1.61 & 29 & 0.18 & 31 & 828 & 3.0 & 56.0 & 69.1 & 0.81 \\
\hline 86 & [40] & 200 & 250 & 35.2 & 1.61 & 29 & 0.18 & 31 & 828 & 3.0 & 66.0 & 69.1 & 0.95 \\
\hline 87 & {$[41]$} & 200 & 310 & 35.5 & 1.37 & 36 & 0.21 & 42 & 565 & 3.2 & 68.5 & 94.8 & 0.72 \\
\hline 88 & [41] & 200 & 310 & 35.5 & 1.37 & 36 & 0.21 & 42 & 565 & 3.2 & 57.8 & 94.8 & 0.61 \\
\hline 89 & {$[41]$} & 200 & 309 & 35.2 & 1.28 & 43 & 0.40 & 42 & 565 & 2.4 & 109.0 & 111.6 & 0.98 \\
\hline 90 & [42] & 150 & 210 & 39.8 & 1.31 & 45 & 0.35 & 45 & 750 & 3.3 & 49.0 & 65.1 & 0.75 \\
\hline 91 & {$[42]$} & 150 & 210 & 39.8 & 1.31 & 45 & 0.35 & 45 & 750 & 2.2 & 67.0 & 66.3 & 1.01 \\
\hline 92 & [43] & 178 & 279 & 24.1 & 2.30 & 40 & 0.39 & 40 & 717 & 2.7 & 129.0 & 86.9 & 1.48 \\
\hline 93 & [44] & 200 & 310 & 35.5 & 1.37 & 36 & 0.21 & 42 & 565 & 3.2 & 68.5 & 94.9 & 0.72 \\
\hline 94 & [44] & 200 & 309 & 35.7 & 1.29 & 43 & 0.40 & 42 & 565 & 2.4 & 108.9 & 111.9 & 0.97 \\
\hline 95 & [45] & 457 & 883 & 38.8 & 0.60 & 41 & 0.22 & 41 & 690 & 3.1 & 245.5 & 353.8 & 0.69 \\
\hline 96 & [46] & 150 & 170 & 20.0 & 0.62 & 46 & 0.29 & 46 & 970 & 4.1 & 20.5 & 20.9 & 0.98 \\
\hline 97 & {$[46]$} & 150 & 170 & 20.0 & 1.54 & 46 & 0.29 & 46 & 970 & 4.1 & 28.6 & 29.2 & 0.98 \\
\hline 98 & [46] & 150 & 170 & 25.4 & 0.62 & 46 & 0.29 & 46 & 970 & 4.1 & 23.5 & 24.2 & 0.97 \\
\hline 99 & [46] & 150 & 170 & 25.4 & 1.54 & 46 & 0.29 & 46 & 970 & 4.1 & 33.4 & 34.2 & 0.98 \\
\hline 100 & [46] & 150 & 170 & 20.0 & 0.89 & 115 & 0.29 & 115 & 2000 & 4.1 & 39.3 & 32.8 & 1.20 \\
\hline 101 & [46] & 150 & 170 & 25.4 & 0.89 & 115 & 0.29 & 115 & 2000 & 4.1 & 39.8 & 38.7 & 1.03 \\
\hline 102 & {$[47]$} & 250 & 253 & 37.7 & 1.71 & 61 & 1.05 & 61 & 822 & 1.2 & 271.7 & 224.1 & 1.21 \\
\hline 103 & {$[47]$} & 250 & 253 & 37.3 & 1.71 & 61 & 1.05 & 61 & 822 & 1.2 & 252.1 & 223.6 & 1.13 \\
\hline 104 & {$[47]$} & 250 & 253 & 37.7 & 1.71 & 61 & 1.05 & 61 & 822 & 1.8 & 264.9 & 222.1 & 1.19 \\
\hline 105 & [47] & 250 & 253 & 32.9 & 1.71 & 61 & 0.51 & 113 & 903 & 1.8 & 158.9 & 194.2 & 0.82 \\
\hline 106 & [47] & 250 & 253 & 37.3 & 1.71 & 61 & 1.03 & 113 & 903 & 1.8 & 267.8 & 260.5 & 1.03 \\
\hline 107 & [47] & 250 & 253 & 37.7 & 1.71 & 61 & 1.03 & 113 & 903 & 1.2 & 278.6 & 263.1 & 1.06 \\
\hline 108 & {$[47]$} & 250 & 253 & 32.9 & 1.71 & 61 & 1.03 & 113 & 903 & 1.8 & 286.5 & 253.7 & 1.13 \\
\hline 109 & {$[47]$} & 250 & 253 & 32.9 & 1.71 & 61 & 1.03 & 113 & 903 & 1.8 & 229.6 & 253.7 & 0.91 \\
\hline 110 & {$[47]$} & 250 & 253 & 28.9 & 1.71 & 61 & 1.50 & 113 & 903 & 1.2 & 359.0 & 303.4 & 1.18 \\
\hline 111 & {$[47]$} & 250 & 253 & 28.9 & 1.71 & 61 & 1.50 & 113 & 903 & 1.8 & 217.8 & 243.8 & 0.89 \\
\hline 112 & [47] & 250 & 253 & 32.9 & 1.71 & 61 & 1.50 & 113 & 903 & 2.4 & 262.9 & 199.3 & 1.32 \\
\hline
\end{tabular}




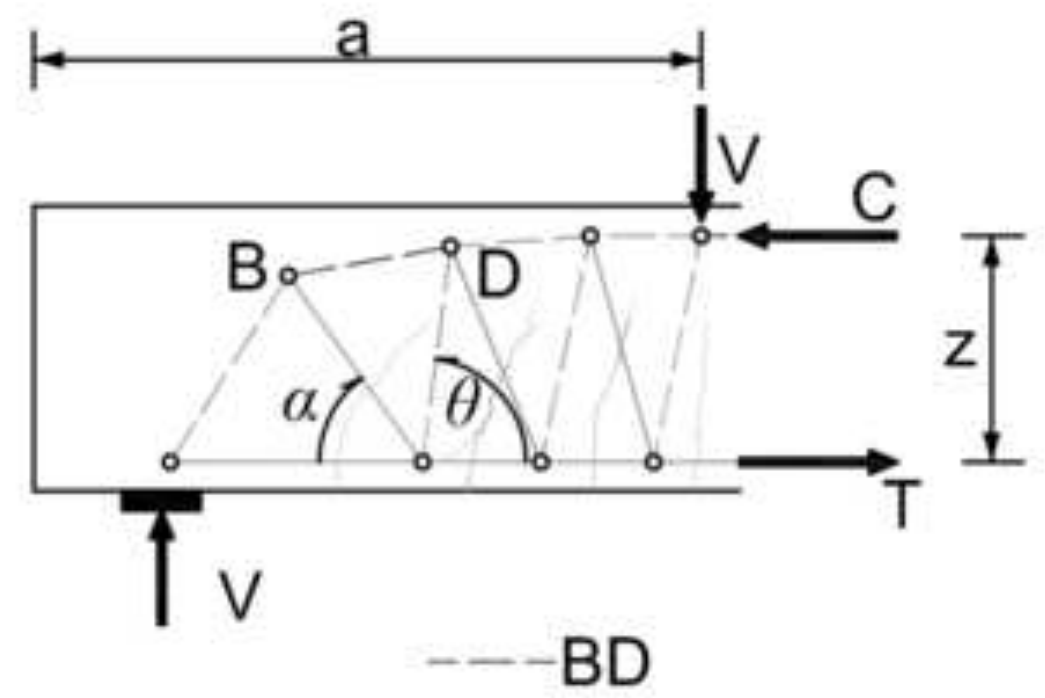

a) Slightly cracked

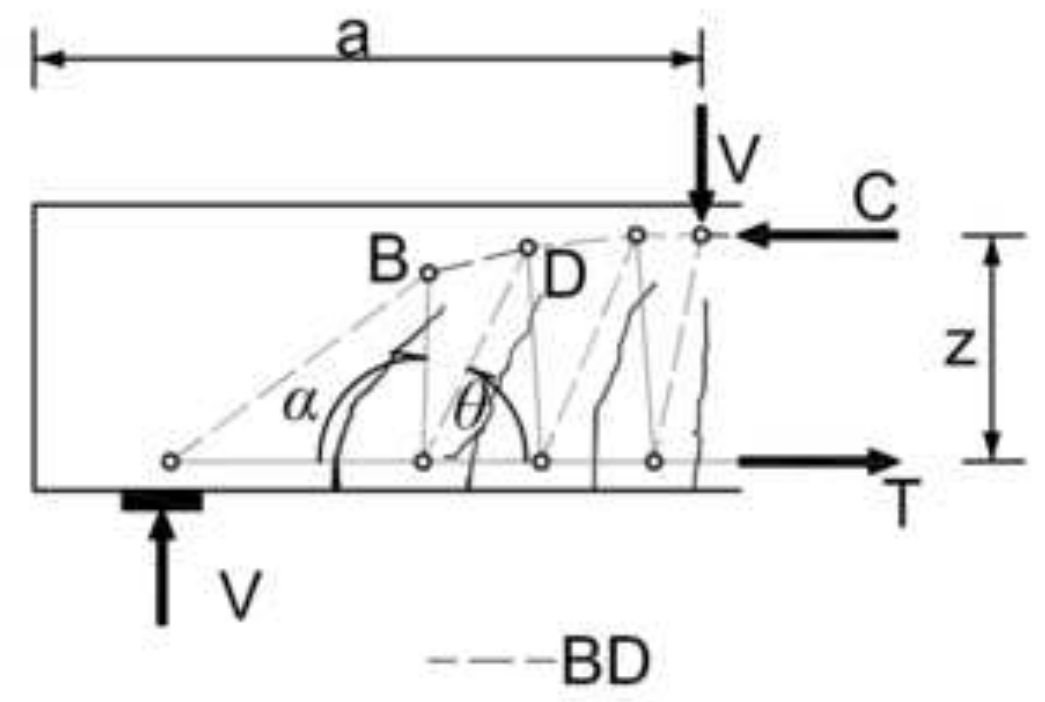

b) Heavily cracked 

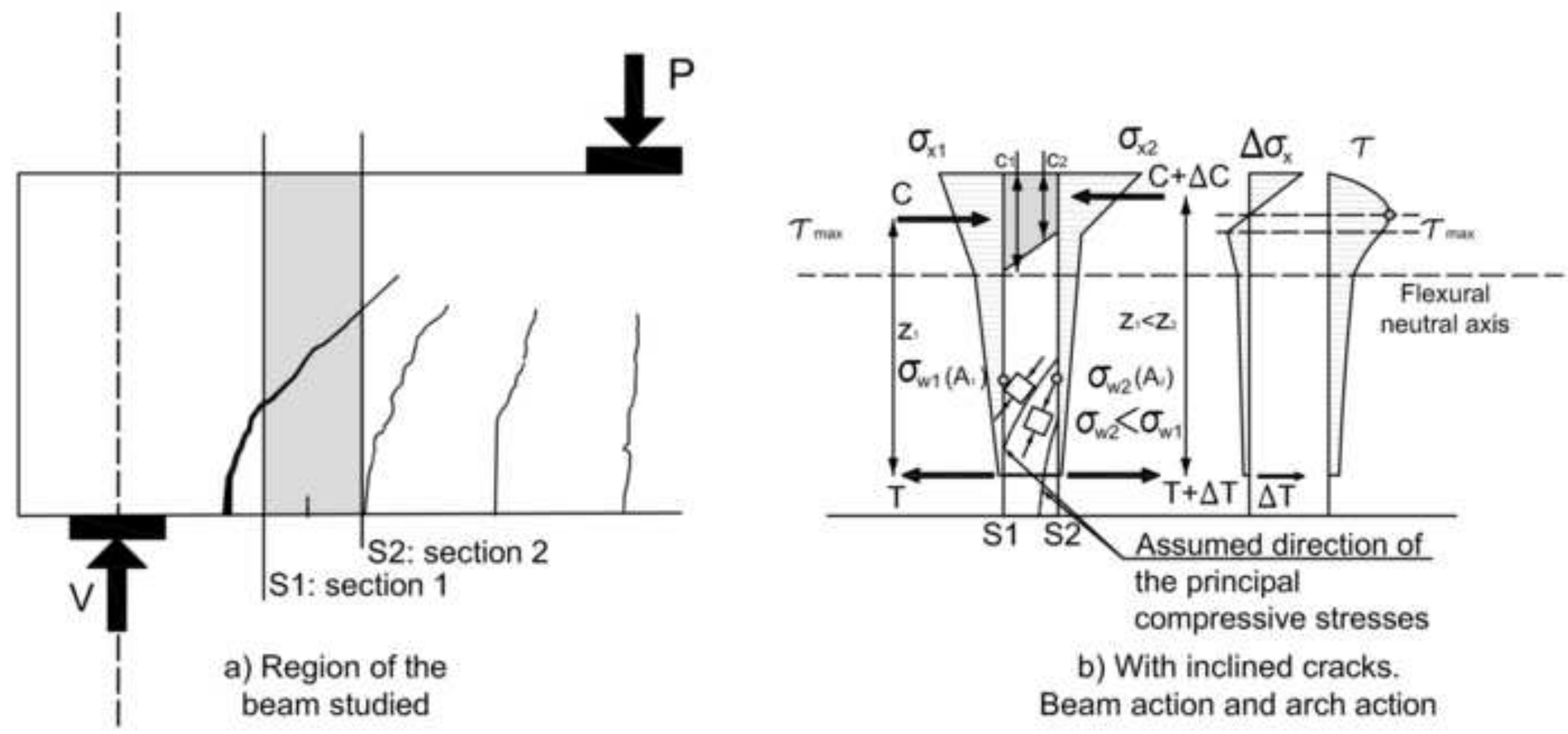

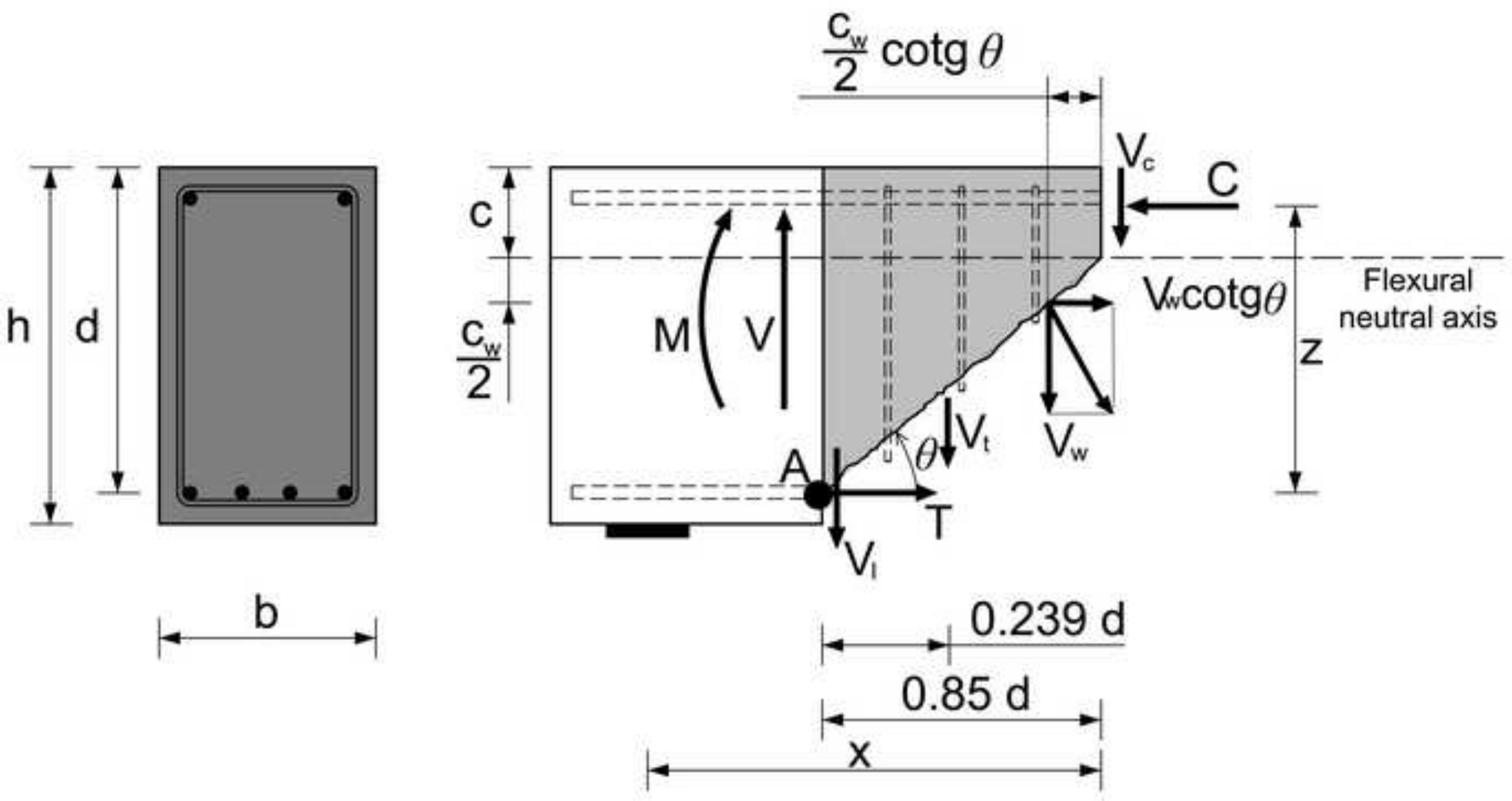


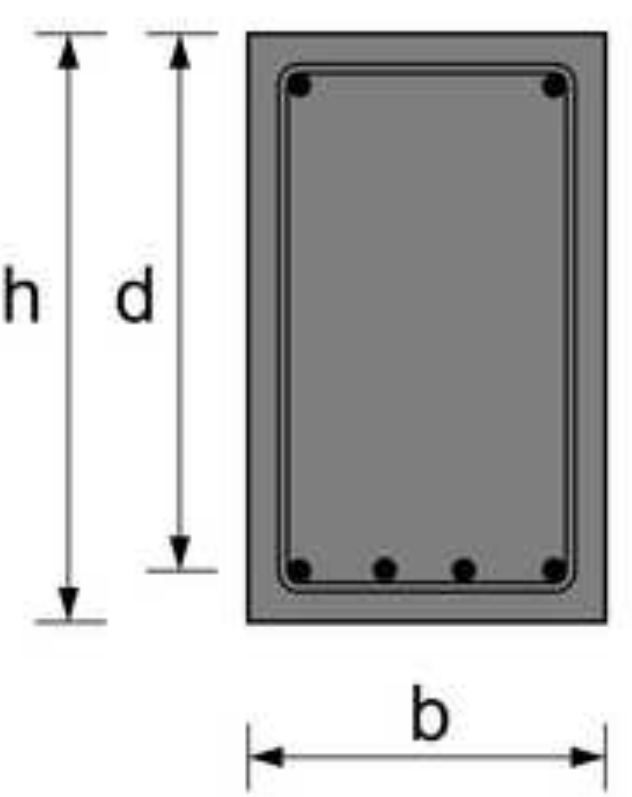

$$
\sigma_{\mathrm{x}} \rightarrow \square+
$$$$
\tau|\underline{\square}|
$$

Assumed
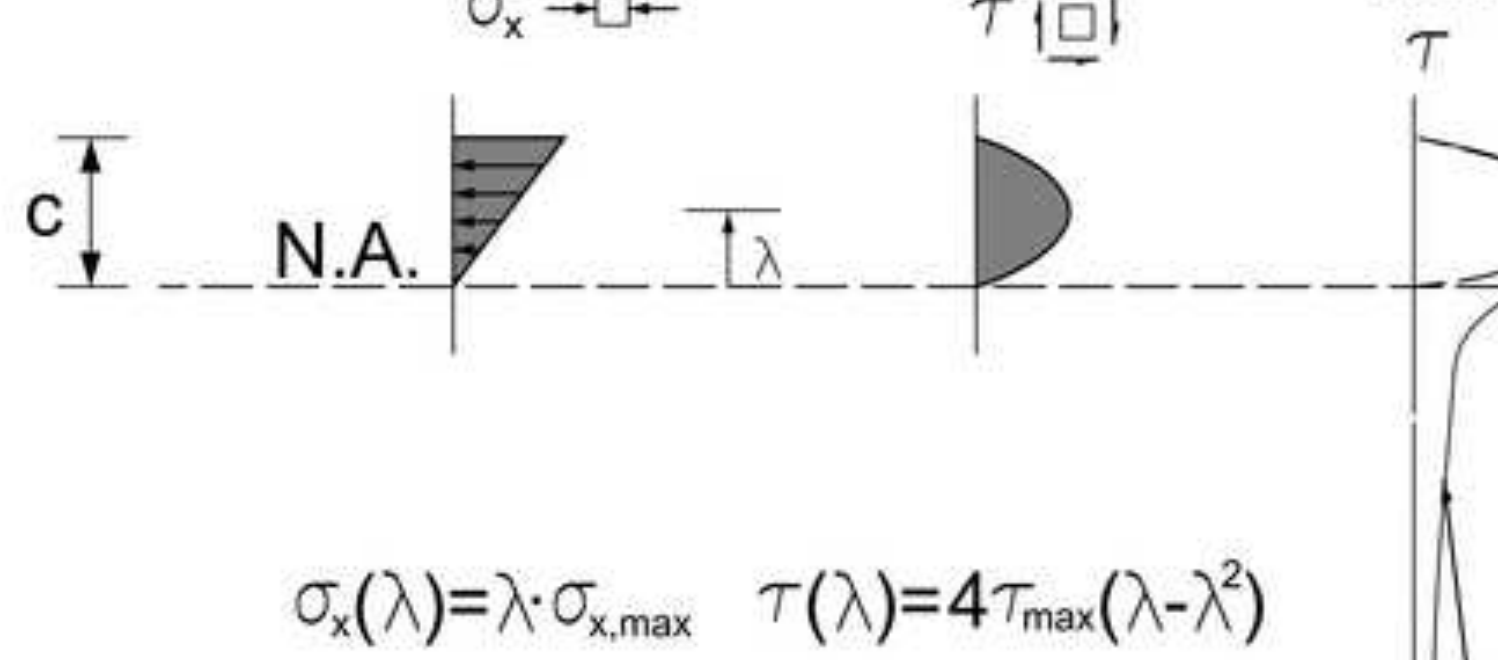

Theoretical 


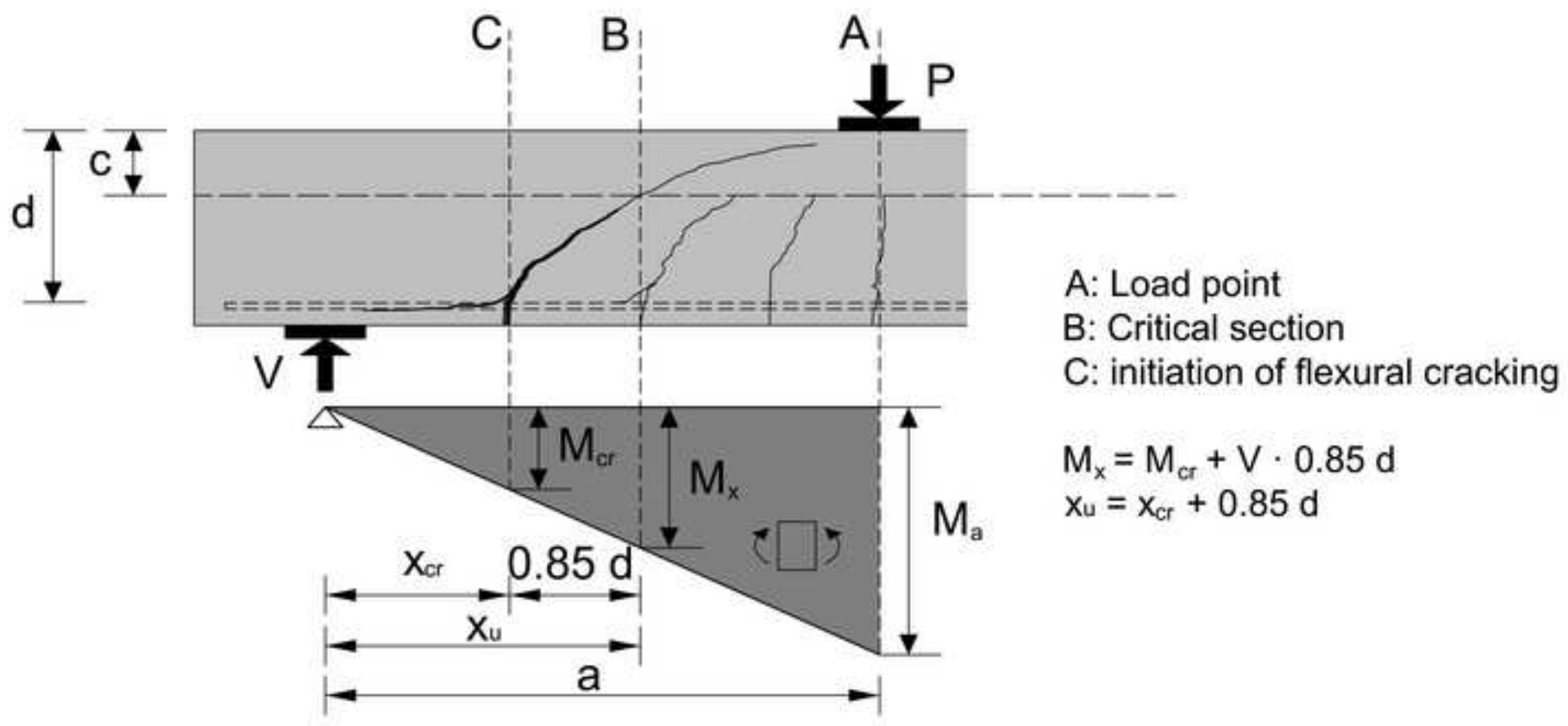

A: Load point

B: Critical section

$\mathrm{C}$ : initiation of flexural cracking

$\mathrm{M}_{\mathrm{x}}=\mathrm{M}_{\mathrm{cr}}+\mathrm{V} \cdot 0.85 \mathrm{~d}$

$\mathrm{x}_{\mathrm{u}}=\mathrm{x}_{\mathrm{cr}}+0.85 \mathrm{~d}$ 


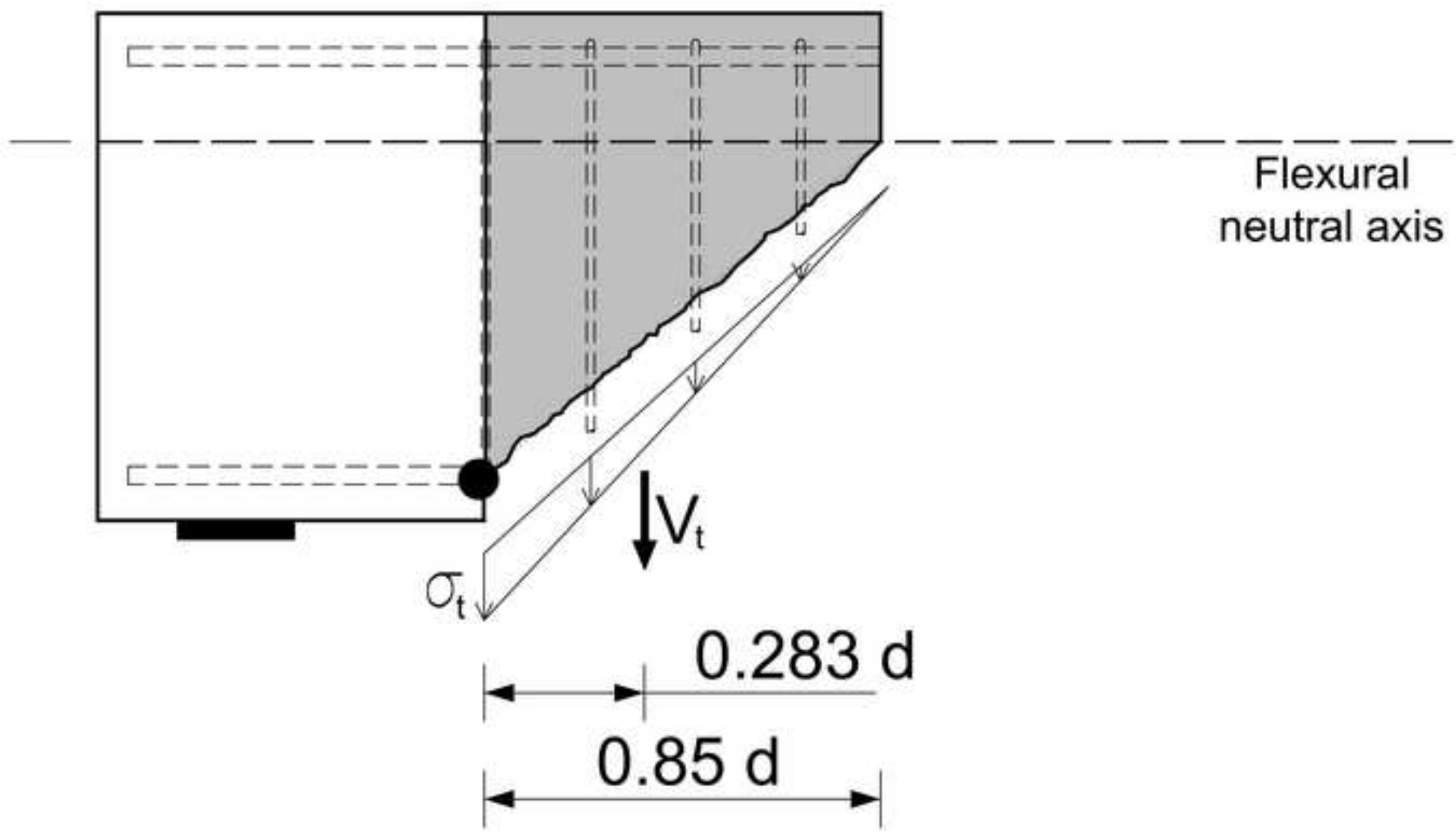



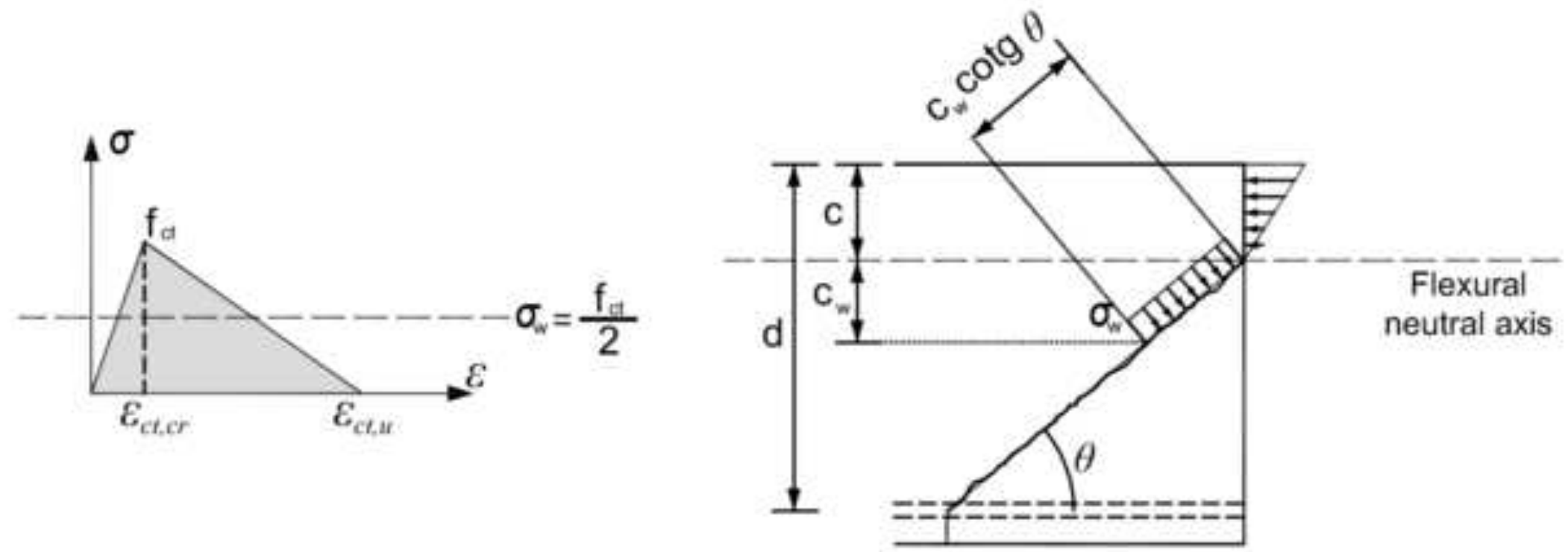

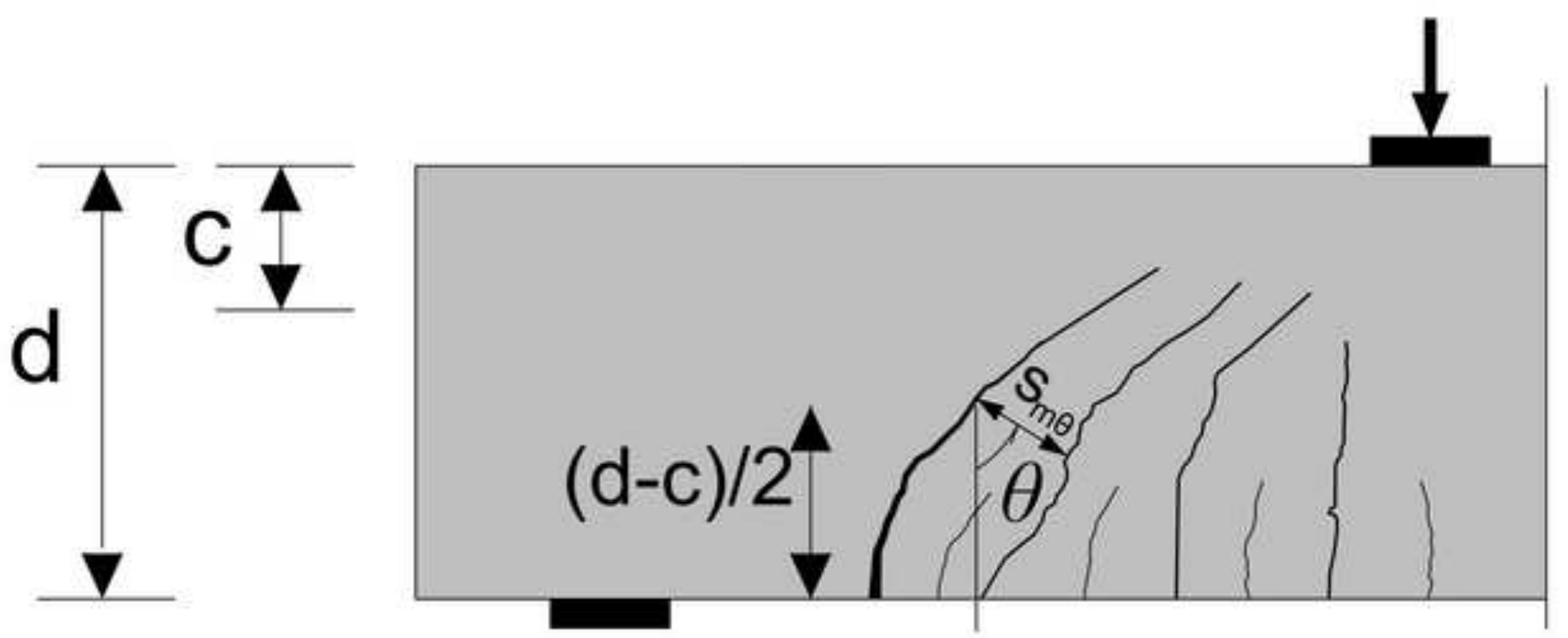


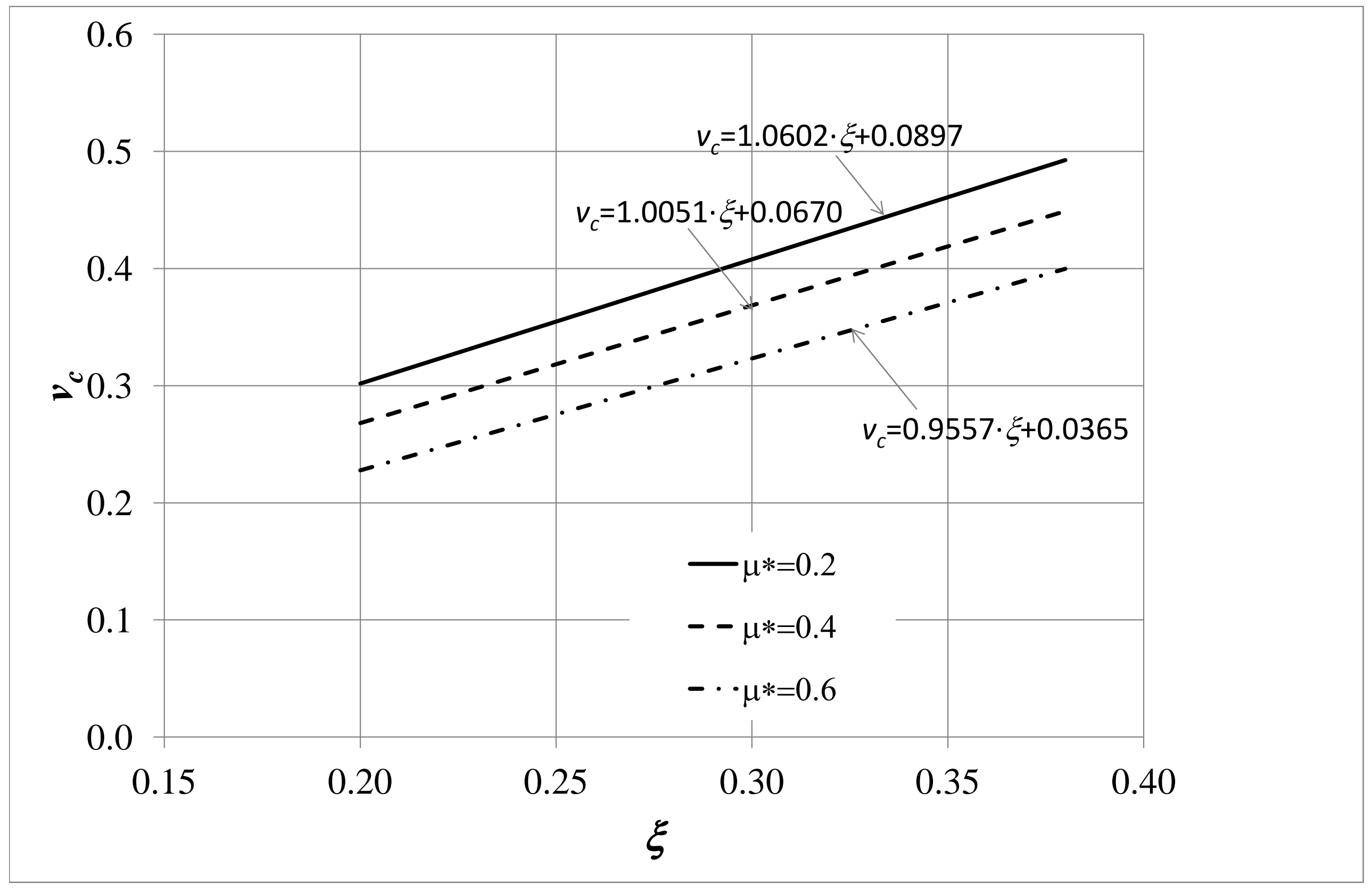



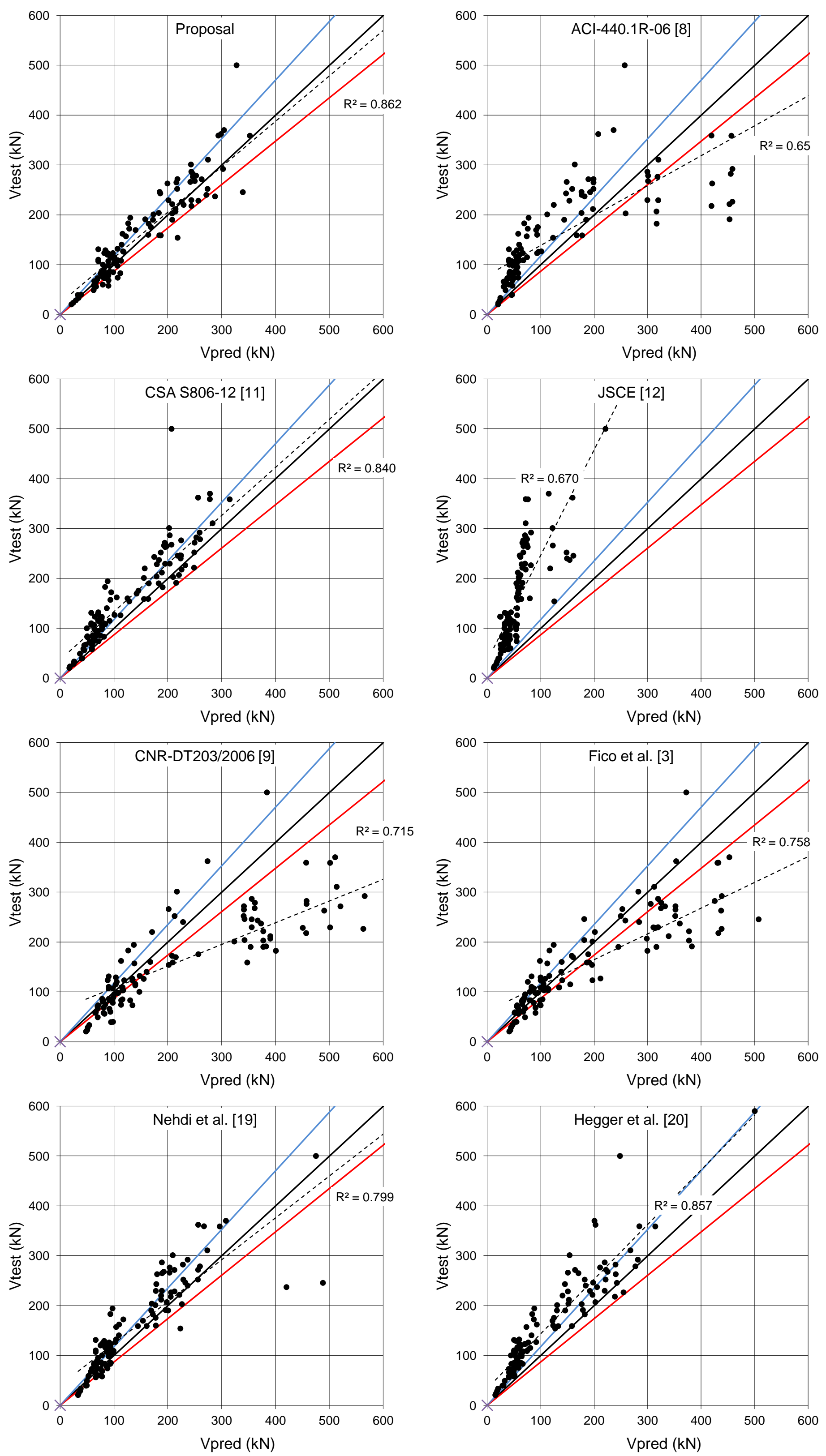

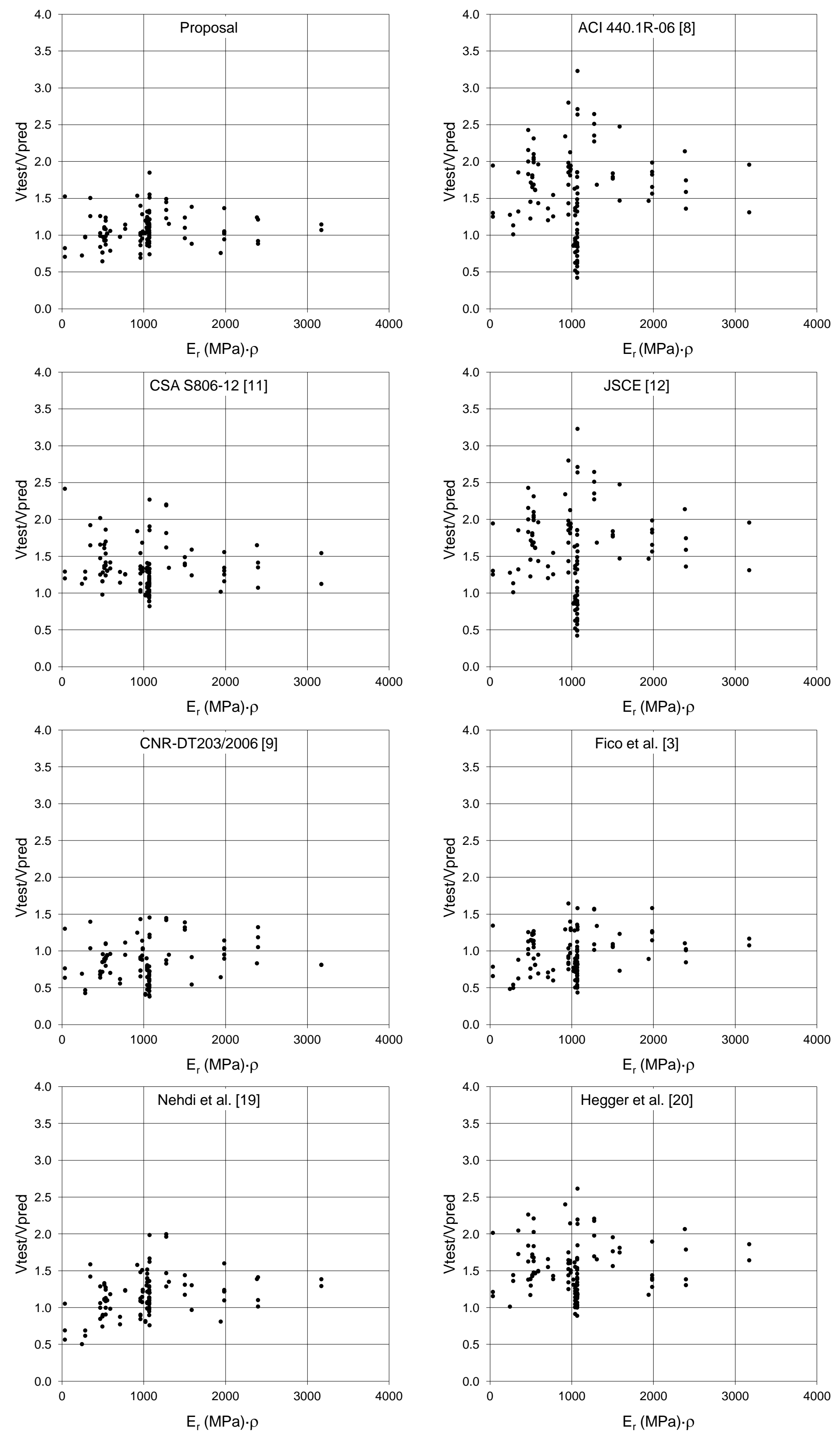

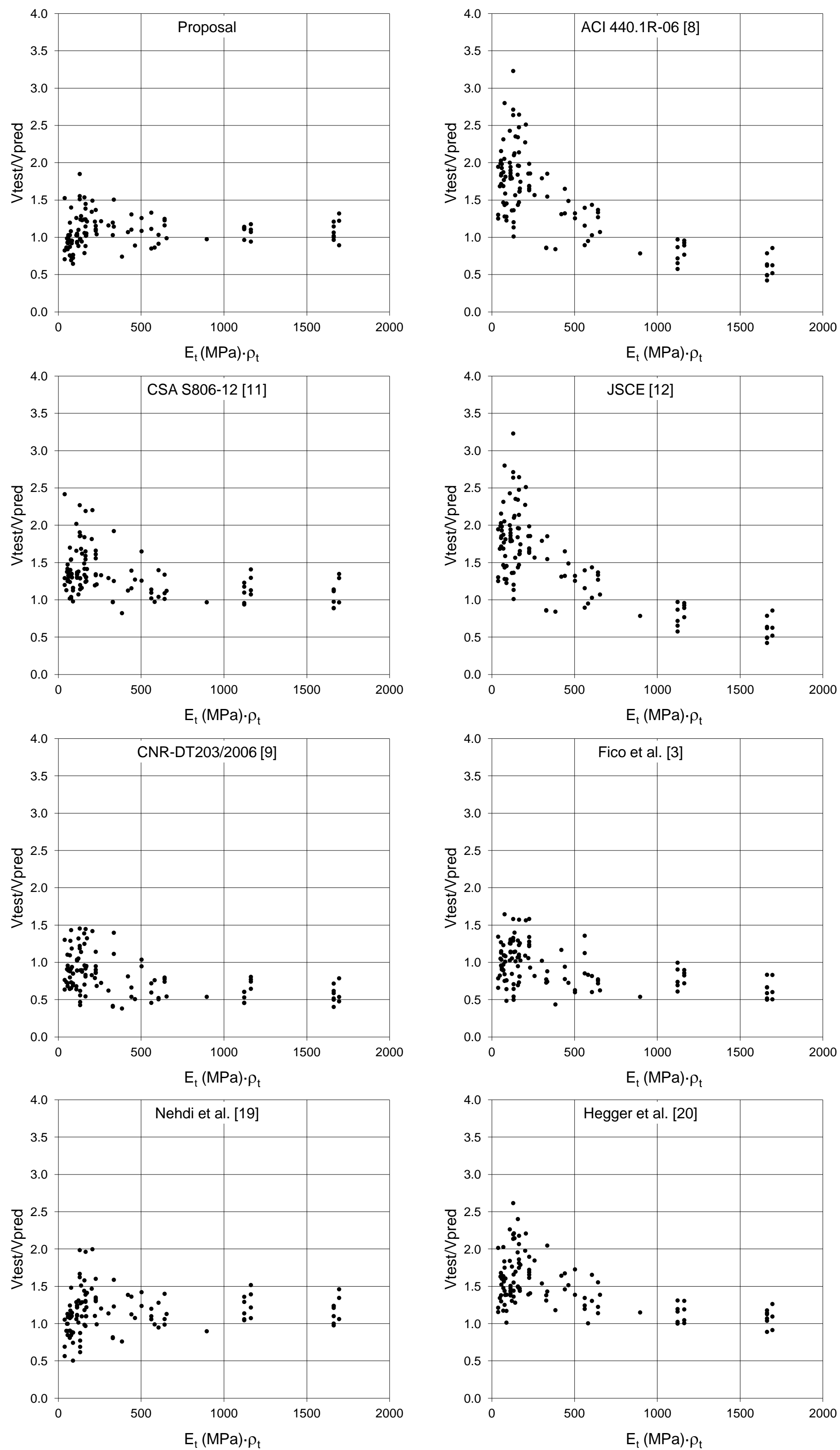